Florida International University FIU Digital Commons

$7-1-2014$

\title{
Spatial Articulations of Race, Desire, and Belonging in Western North Carolina
}

\author{
LaToya Eaves
}

leave001@fiu.edu

DOI: $10.25148 /$ etd.FI14110718

Follow this and additional works at: https://digitalcommons.fiu.edu/etd

Part of the Human Geography Commons, and the Lesbian, Gay, Bisexual, and Transgender Studies Commons

\section{Recommended Citation}

Eaves, LaToya, "Spatial Articulations of Race, Desire, and Belonging in Western North Carolina" (2014). FIU Electronic Theses and Dissertations. 1640.

https://digitalcommons.fiu.edu/etd/1640

This work is brought to you for free and open access by the University Graduate School at FIU Digital Commons. It has been accepted for inclusion in FIU Electronic Theses and Dissertations by an authorized administrator of FIU Digital Commons. For more information, please contact dcc@fiu.edu. 


\section{FLORIDA INTERNATIONAL UNIVERSITY}

Miami, Florida

\section{SPATIAL ARTICULATIONS OF RACE, DESIRE, AND BELONGING IN WESTERN NORTH CAROLINA}

A dissertation submitted in partial fulfillment of the requirements for the degree of DOCTOR OF PHILOSOPHY

in

GLOBAL AND SOCIOCULTURAL STUDIES

by

LaToya E. Eaves

2014 
To: Interim Dean Michael R. Heithaus

College of Arts and Sciences

This dissertation, written by LaToya E. Eaves, and entitled Spatial Articulations of Race, Desire, and Belonging in Western North Carolina, having been approved in respect to style and intellectual content, is referred to you for judgment.

We have read this dissertation and recommend that it be approved.

Vrushali Patil

Percy Hintzen

Caroline Faria

Dionne Stephens

Gail M. Hollander, Major Professor

Date of Defense: July 1, 2014

The dissertation of LaToya E. Eaves is approved.

Interim Dean Michael R. Heithaus

College of Arts and Sciences

Dean Lakshmi N. Reddi

University Graduate School

Florida International University, 2014 
(C) Copyright 2014 by LaToya E. Eaves

All rights reserved. 


\section{DEDICATION}

I dedicate this dissertation to the First Nations People of the North Carolina Mountains. May the ancestors be remembered and honored.

In memory of my mother, Brenda Kaye Eaves, and my father, Belvin Gene Eaves. 


\section{ACKNOWLEDGMENTS}

I wish to thank Vrushali Patil, Caroline Faria, Dionne Stephens and Percy Hintzen, my committee members, for their willingness to support me through the doctoral process. I would like to thank Gail Hollander for agreeing to be my major professor. I am grateful for your time, patience, and advocacy. I wish to thank my department chair Rod Neumann and graduate program director Guillermo Grenier for the invaluable training and support and the creation of opportunities for me over the past 5 years. Thank you to the other faculty (in addition to all those mentioned above) who have had a hand in my doctoral training - Rick Tardanico, Maria Aysa-Lastra, Ben Smith, Patricia Price, Sarah Mahler, Jason Ritchie, and Aurora Morcillo. I would like to thank my cohort, a group of amazing people who have been crucial to my success in the doctoral journey from day one, and my fellow students in Global and Sociocultural Studies for cultivating an intellectual environment that challenged me in so many ways. I would also like to Laurie Shrage and Yesim Darici for creating space for me to engage with and teach for the Center for Women's and Gender Studies. A special note of thanks is extended to Chaundra Whitehead, my closest ally and fellow doctoral student, for helping me through the ups and downs of my journey. I look forward to supporting you over the next year as your chapter comes to a close. I would especially like to thank fellow FIU students Linda Smith, Sheila Sutton, Christina Bazzaroni, Elisa Medina-Rivera, Julio Capo, and Ebony Russ for keeping me sane, focused, and laughing. To Shannan Reaze, thank you for the immeasurable support and necessary challenges that have made me a more critical scholar and better person. To my friends and colleagues at the University of Connecticut - Kenneth Foote, Nancy Naples, Caryl Nuñez, Heather Turcotte, Priscilla McCutcheon, 
Cathy Schlund-Vials, Marysol Asencio, Laura Mauldin, Fleurette King, and the students of WGSS 3998 - thank you for creating space for me in your lives and supporting me and my work during the 2013-2014 academic year. I would like to extend a special note of gratitude to the other visiting predoctoral fellows at UConn - Melissa Huerta, Amanda Almond, and Quan Tran - for the writing group time, coffee breaks, and laughs. I extend an additional note of gratitude to Rashad Shabazz and Derek Alderman for inviting me to give lectures on your campuses, providing an opportunity to work through theoretical and empirical musings that appear in the dissertation.

To Stephanie, Nicole, Vern, Rebeca, Karen, and Tausha, thank you for allowing me into your lives and agreeing to appear in the dissertation project. It would not exist without your testimonies.

To Shaeeda Mensah, thank you for the support, encouragement, and nourishment. You came along right on time, and I am forever grateful.

To my siblings Meriam, Tajsha, Beverly, Geno, and Pamela, and the children Michael, Kaylie, Lena, Sasha, A.J., and Nicholas. I hope I have made you proud. Thank you for believing in me. I love you extra much. 


\begin{abstract}
OF THE DISSERTATION
SPATIAL ARTICULATIONS OF RACE, DESIRE AND BELONGING IN WESTERN

NORTH CAROLINA

by

LaToya E. Eaves
\end{abstract}

Florida International University, 2014

Miami, Florida

Professor Gail M. Hollander, Major Professor

The sociocultural mythology of the South homogenizes it as a site of abjection. To counter the regionalist discourse, the dissertation intersects queer sexualities with gender and race and focuses on exploring identity and spatial formation among Black lesbian and queer women. The dissertation seeks to challenge the monolith of the South and place the region into multiple contexts and to map Black geographies through an intentional intersectional account of Black queer women. The dissertation utilizes qualitative research methods to ascertain understandings of lived experiences in the production of space. The dissertation argues that an idea of Progress has been indoctrinated as a synonym for the lgbtq civil rights movement and subsequently provides an analysis of progress discourses and queer sexualities and political campaigns of equality in the South. Analyses revealed different ways to situate progress utilizing the public contributions of three Black women interviewed for the dissertation. Moreover, the dissertation utilizes six Black queer and lesbian women to explain the multifarious nature of identities and their construction in place. Black queer and lesbian women produce spaces that deconstruct the normativity of stasis and physicality, and the 
dissertation explores the consequential realities of being a body in space. These consequences are particularly highlighted in the dissertation by discussions of the processes of racialization in the bounded and unbounded senses of space and place and the impacts of religious institutions, specifically Christianity.

The dissertation concluded that no space is without complication. Other considerations should be made in the advancement of alleviating oppression deeply embedded in United States landscapes. Black women’s geographies offer epistemological and ontological renderings that enrich analyses of space, place, and landscape. The dissertation also concludes that Black women's bodies represent sites for the production of geographic knowledge through narrating their spaces of material trajectories of interlocking, multiscalar lives. 


\section{TABLE OF CONTENTS}

CHAPTER

PAGE

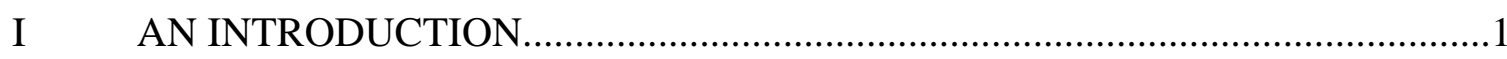

Research objectives .....................................................................................

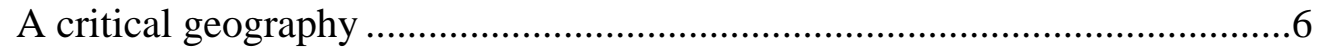

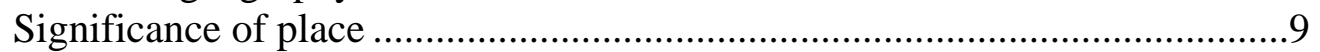

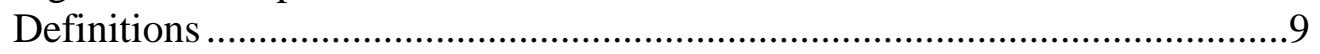

Organization of the dissertation ................................................................11

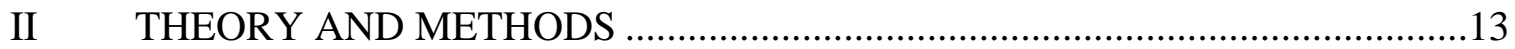

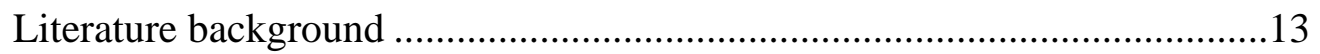

Geography, regions, and the Appalachian South........................................15

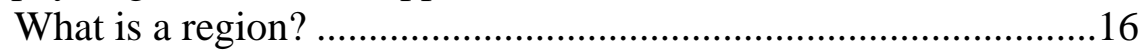

Region and the creation of place...................................................17

Orientalism and regional discursive formation...............................18

The region known as Appalachia...............................................19

Regionalism and local color..........................................................20

In(visible) constructions of place..................................................23

What about the South? .................................................................26

Space, place, and identities ...................................................................28

Feminist debates in sociospatial contexts ......................................29

Towards a queer geography .........................................................32

Black geographies ................................................................................34

What is Black geographies...........................................................35

Antiracist geography ……………………………….....................38

Theorizing geographies of difference ...........................................................4

Intersections of feminist, queer, and race scholarship .....................43

Engaging intersectionality .............................................................46

Intersectionality in critical race studies.........................................46

Key elements of intersectionality....................................................47

Critiquing a theoretical model .........................................................48

Intersectionality as a scholarly intervention ...................................50

Engaging geographic intersectionality.........................................52

Intense intimacies.....................................................................56

Methods and reflections...............................................................................56

The research experience.............................................................................57

Reflections in research .......................................................................64

III CALL-AND-RESPONSE: THINKING PROGRESS …………………..............70

Public sexuality: The marker of progress .......................................................73

CSE framing the South ..........................................................................8

CSE framing equality ............................................................................8

CSE framing equality in the South ............................................................

Redemption: Multiple lives, multiple Souths ....................................................91 
IV THE IDENTITY SPACE DEMANDS .....................................................104

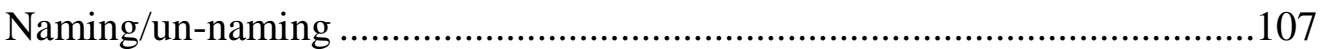

Belonging/un-belonging ...........................................................................114

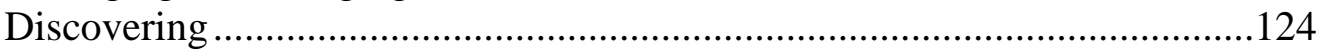

V. BLACK WOMEN, SEXUALITY AND RELIGION ........................................129

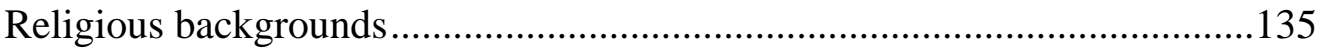

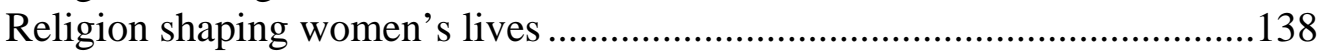

Moving forward with/out religion ..............................................................145

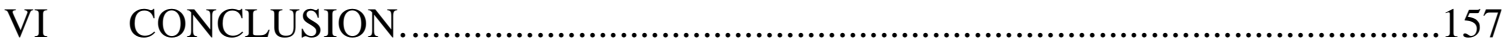

Dissertation summary ...........................................................................159

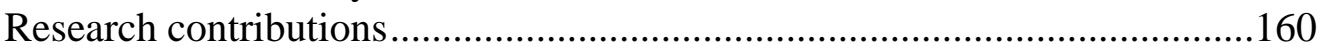

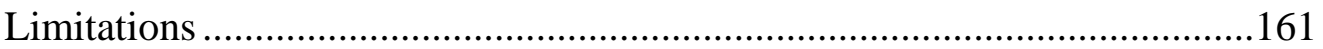

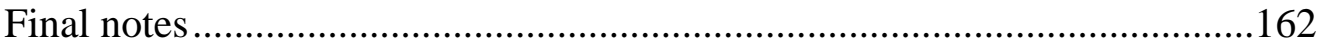

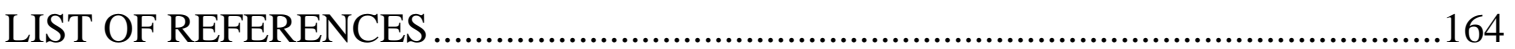

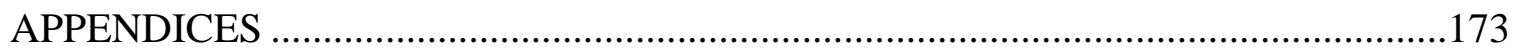

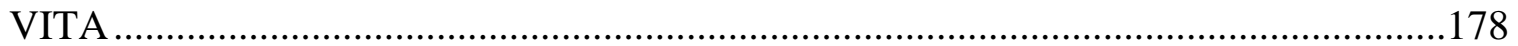




\section{LIST OF FIGURES}

FIGURE

PAGE

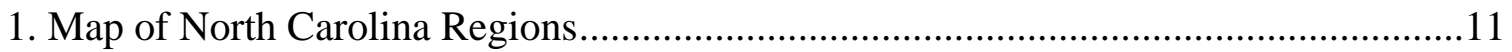

2. The Women’s Wellness and Education Center, Asheville, Retrieved 2014..................76

3. Banner Graphic, Campaign for Southern Equality Website........................................78

4. Campaign for Southern Equality We DO Campaign March .......................................84

5. Screenshot of Facebook event for CSE’s July 30, 2011 Family Dinner ......................87

6. Screenshot of Email from Prospective Participant, May 8, 2013 ...............................108

7. Exterior of Blue Ridge Books, Waynesville, North Carolina....................................109

8. Table in Café Area of Blue Ridge Books, Waynesville, North Carolina ....................110

9. Religious Protesters at Blue Ridge Pride, October 2012 .........................................132

10. First Baptist Church, Located Next to Blue Ridge Books, Waynesville, NC ...........137

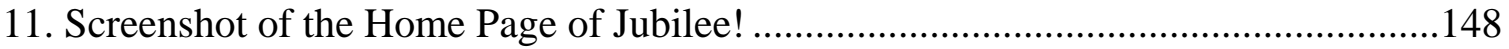




\section{CHAPTER I}

\section{AN INTRODUCTION}

"One muffled strain in the Silent South, a jarring chord and a vague and uncomprehended cadenza has been and still is the Negro. And of that muffled chord, the one mute and voiceless note has been the sadly expectant Black Woman.”

Anna Julia Cooper (1892/1988)

"I have a belief that the body holds memory, and there is something ontological about being black and female that is divine, that is healing, that is so necessary and vital for our community.”

Michael Angelo Robinson (2014)

"We Decide Who We Are. We Decide Who We Love. We Decide How We Survive and Thrive."

Southerners on New Ground (2014)

$* * * *$

Anna Julia Cooper, one of North Carolina's renowned daughters, wrote A Voice

from the South. In the book, as well as throughout her life, Anna Julia Cooper argued that recognizing and uplifting Black women's positions in society would improve the conditions of Black communities, seeing Black women as essential to pursuing a more just society. Some fifty years after the death of Anna Julia Cooper, Michael Angelo Robinson, a theology student, participated in the documentary Journey to Liberation: The Legacy of Womanist Theology and Ethics at Union Theological Seminary. In it, he 
argued for the vital nature of recognizing and understanding Black women’s lives and experiences, aligning with the trajectory of Anna Julia Cooper. In understanding the interlocking social structures of race, class, gender, and sexuality, Southerners on New Ground build upon Black feminist and womanist legacies and connect the material survival of people into the justice required to moving towards liberation for all people. It is within that lineage that the dissertation enters.

The dissertation focuses on the lived experiences of black women who experience same-gender desire, love, and intimacy and who live in Western North Carolina. I chose the site because I was frustrated by reading literature on queer empirics that relied on the conveniences of urban spaces. Alternatively, if the literature provided discussions about queer life outside of the urban core, it did one of two things: 1) it pathologized the experiences of nonurban sexualities or 2) it explicitly failed to include the experiences of people of color, stating they were not there, did not exist in those spaces, or were otherwise peripheral to their respective projects.

The dissertation also exposes the ways race is articulated through Black women's sociospatial interactions with a particular interest in relationships of power as mediated by symbolic structures of the South. The sociocultural mythology of the South often homogenizes its regional discourse as a site of abjection. A strict definitiveness of the South is problematic because it insinuates a strict regionalism that does not acknowledge the opportunities for more nuanced contexts, realities, and experiences of the South that can be differentiated from other communities and regions. As such, it is important for empirical work to disrupt the cultural narrative of the South into one that centralizes the everyday geographies. The dissertation intersects queer sexualities with gender and race 
by focusing on the particular marginalities of queer Black women who occupy the U.S. South geographies, specifically in the state of North Carolina. An examination of relevant literature within geography reveals limited scholarly projects that engage Black geographies of sexuality and a nearly complete lack of engagement with Black queer women in geography. By studying the experiences of women whose lives are shaped by gender, race, sexuality and non-urban, Appalachian South geographies, I expect to add to literatures exploring identity and spatial formation and negotiation among queer Black women. Moreover, the research provides an analysis of the nation-wide based discourse of equality and queer sexualities and national political campaigns of equality with particular interest in completing a comparative analysis to a "queer" region of the United States - that being the Appalachian South. The project is not to denigrate any individual or program. Rather, the project is aimed at understanding the geographical and political relationship of black same-gender love, desire and intimacy in Appalachia to a national discourse and making visible new knowledges about the spectrum of same-sex sexualities. The current dissertation project is first of its kind, as there is no social science scholarship that centralizes the lives and experiences of lgbtq people of color in the Appalachian region

The complicated formation of region must absolutely be considered in terms of the connections of other layers of identity and power, most poignantly being race, ethnicity, gender, class, and sexuality. The regionalist discourse of Appalachia must recognize the significance of social location and the array and diversity of impacts, agency, subjugations, and points of resistance that are real and present occupations of a particular social location (Bryant and Pini 2011). Renegotiating and constructing 
alternative discourses of Appalachia is simultaneously intriguing and difficult to conceptualize. Poststructural, queer and feminist frameworks would encourage understanding how individuals subvert binarisms and modernist categories that restrict the fluidities of identities, particularly as they are mediated in time and space. In talking about research on women, Engelhardt argues for a framework "that does not let stereotypes dictate the terms of analysis—but that instead thinks in complicated ways about social hierarchies that intersect and shape individual lives ... we must examine and investigate the diversity of women living in Appalachia and their range of experiences, foregrounding gender while insisting on its intersections with other categories of identity and power, such as race, class, age, and sexual orientation” (Engelhardt 2005, 3).

The complexities stemming from the absence of racial consciousness in the discursiveness of sexuality and space are myriad. My aim, therefore, is intended to bring specific attention to the importance of race discussion in geographies of sexuality and of the Appalachian South, specifically Blackness and Black women. In their essay "No One Knows the Mysteries at the Bottom of the Ocean”, geographers Katherine McKittrick and Clyde Woods (2007) offer three trajectories that lend themselves to the understanding of Black human geographies in the production of space. They are: 1) the ways that essentialism positions Black subjects and geopolitics as not situated, 2) that Black subjects are normalized through "geographies of exclusion" in considerations of modernity and citizenship, and 3) that Black geographies (both real and imagined) are political in their ways and means. It is through these trajectories that I examine the spatialties of queer Black women in the context of contemporary U.S. South locales and discuss the implications of external (urban/global) politics on the intersections of 
Appalachia, South, race, sexuality, and gender. Building on works of Black feminists and scholars of sexuality, I can situate the complexities and privileges that queer Black women experience into larger discussions of anti-essentialist thought in the public sphere.

\section{Research Objectives}

For the dissertation, I have chosen to embark on the endeavor through the use of research objectives, rather than through research questions. Through the dissertation, I have made a broad attempt at challenging the strict parameters of what qualifies as "good” or “appropriate” research. While I remain mindful that I have certain obligations that are the standards for success in the discipline, I am also interested in encountering new ways to think about how I might be a successful social scientist who can also conduct research that aligns with my values. As a feminist scholar, I am interested in deconstructing the hierarchical dichotomy of researcher/subject. A research question imposes the aspects that a researcher might inappropriately and unjustly subjugate people, places, and things. While a research question can be proven or disproven, like a scientific hypothesis, it does not account for how I approached the dissertation. Rather, I approached the dissertation by utilizing a set of objectives that serve as standpoints from which to disseminate information. They are as follows:

Objective 1: The study challenges the monolithic, imagined geography of the Appalachian South by placing its manifestations into varying contexts. These contexts include the national discourses related to gay and lesbian equality movements, religion, sexuality, gender, and race. The study asserts the lived 
experience as an important site for the production of knowledge. Regions operate as symbolic systems, rather than as fixed truths, and therefore necessitate a dismantling of power relationships that serve to delegitimize scales of the body and locality.

Objective 2: The study locates Black geographies through an intentional intersectional account of Black queer women in Western North Carolina. Katherine McKittrick (2011) argues, "Black diasporic histories and geographies are difficult to track and cartographically map” (948). Moreover, Black queer women's perspectives are understudied in empirical research and particularly within geography. In that understanding, the study explores useful possibilities for uncovering individual accounts of place and body.

\section{A critical geography}

In the past decade, reactions critiquing the epistemologies of queer have increased. Queer of color analyses have become integral in the critique of the scope of queer. A queer of color analysis troubles the assumptions made and knowledge produced about communities of color:

[Q]ueer of color analysis attempts to explain how gender and sexuality variegate racial formations and how that variety indexes material process. We must engage racial knowledge about African American culture as it was produced by sociology if we are to understand the gender and sexual variation within African American culture as the outcome of material and discursive processes. (Ferguson 2004, 19) 
Jose Esteban Muñoz uses the idea of disidentification, which he describes as “a performative mode of tactical recognition that various minoritarian subjects employ in an effort to resist the oppressive and normalizing discourse of dominant ideology” (Muñoz 1999, 97). Muñoz invokes bloc formation, built on Gramscian contexts, that "emphasizes the centrality of class relations in any critical analysis, while not diminishing the importance of other cultural struggles” (Muñoz 1999, 102). A critique of queer also involves the politics of visibility, which are oft celebrated in dominant queer discourse. Muñoz, instead, talks of gay shame, troubling the visibility and power that gay pride seems to implicate for some gay and lesbian people. Muñoz argues that disidentification is constructed and contradictory as a result of tensions surrounding the elite gay lifestyle produced as queer identity. The regulations of queer are dislodged when examinations of race are centralized. For Ferguson, the critique of queer requires disassembling the epistemologies of race produced by sociological knowledges. A queer of color critique disrupts regulations of nationalism that fails to recognize the heterogeneity of African American culture especially in relationship to liberal capitalism. For Ferguson, it requires a certain kind of consciousness:

If the intersections of race, gender, sexuality, and class constitute social formations within liberal capitalism, then queer of color analysis obtains its genealogy within a variety of locations. We may say that women of color feminism names a crucial component of that genealogy as women of color theorists have historically theorized intersections as the basis of social formations. Queer of color analysis extends women of color feminism by investigating how intersecting racial, gender, and sexual practices antagonize and/or conspire with the normative investments of nation-states and capital. (Ferguson 2004, 4) 
In fact, it is as David Graeber notes, "The logic of identity is, always and everywhere, entangled in the logic of hierarchy” (Graeber 2011, 111). The focus on a monolithic set of sexual possibilities in terms of race without greater comprehension and reverence for time, place, history, cause, and effect have caused them to make peripheral people who are not white and continuous to perpetuate white privilege and white supremacy.

While completing my project, I have been mindful that singling out Black, samegender loving women could be a bit controversial because it could serve to (re)create difference, in some ways. However, I keep an ear to Kimberle Crenshaw, who writes "delineating difference need not be the power of domination; it can instead be the source of social empowerment and reconstruction” (Crenshaw 1991, 1242). My work will contribute to the creating of an alternative notion of Appalachia by centering the experiences of queer, black North Carolinian women. The specificity of place offers an opportunity to decenter stereotypes and format a discussion that localizes lived experiences. I anticipate that the women's narratives will help produce alternative knowledges of gender, sexuality, and blackness and dismantle ideas about who calls Appalachia home. My goal is to allow voices of these women come through as regional citizens, not necessarily as a comparative project to hegemonic discourse, but as an additional discourse of place. Ultimately, I hope to document their resistances to their individual oppressions that can significantly contribute to knowledge production rather than providing a comparative to hegemonic discursive formations. It is exciting to be conducting the project because I get to deconstruct interstices of geography with institutional power structures and create a new feminist, queer, Black geography of Western North Carolina. Race, gender, and sexuality shape individual and communal 
identity through rebirth and recreation in space, and I hope to legitimize and affirm women’s experiences through my project.

\section{The significance of place}

Western North Carolina (WNC) is not necessarily imagined as Appalachian space in popular discourse. The vision of Appalachia as a disparate object is most often relegated to the hills of West Virginia and/or Kentucky. The focus on WNC has typically included its packaging of tourist destinations, notably the Blue Ridge Parkway (a division of the U.S. National Park Service), the Biltmore Estate, as well as the frequent visits of major cultural figures, diplomats, and politicians (Barack Obama has visited the Asheville’s Grove Park Inn during both campaigns for President). However, small town charm, idyllic views of nature, and the interest in preserving mountain culture incorporate its geography into Appalachian discourse. Moreover, WNC has a reputation of being inclusive and open for many ways of life. It is characterized as inviting to a diverse population to both reside and visit. The city of Asheville is regarded as one of most gayfriendly places to live, work, vacation in the United States (Kompes 2005). As such, there is space to analyze these discourses and examine the ways they live up to their expectations the regional discourse suggests.

\section{Definitions}

As a basis for the pursuit of my project, I will employ the following definitions: 
- Appalachia - the region of the Untied States and Canada situated within the Appalachian Mountain Range of eastern seaboard North America.

- Community - a collectivity in which individual entities organize and maintain identification along a similar demarcation.

- lgbtq - the acronym for lesbian, gay, bisexual, transgender, and queer; may also be seen as lgbt or lgbq in the dissertation; typically capitalized but will be used the lowercase form in the dissertation in order to diffuse the rigidity of a Westernized LGBTQ identity and work in favor of more fluid, self-defining categories (Epprecht 2008).

- Queer - the umbrella identity that encompasses a collective of nonheteronormative sexual desire(s).

- South - a geographic region encompassing the southeastern United States, consisting of Virginia, West Virginia, North Carolina, South Carolina, Georgia, Florida, Kentucky, Tennessee, Alabama, Mississippi, Arkansas, and Texas.

- Western North Carolina (WNC) - the region of the state of North Carolina that is typified by the Blue Ridge Mountain Range of the Appalachian Mountains. North Carolina is generally divided into three regions - Western, Piedmont, and Eastern. The counties generally included in Western North Carolina are: Alexander, Alleghany, Ashe, Avery, Buncombe, Burke, Caldwell, Catawba, Cherokee, Clay, Cleveland, Graham, Haywood, Henderson, Jackson, Macon, Madison, McDowell, Mitchell, Polk, Rutherford, Swain, Transylvania, Watauga, Wilkes, and Yancey. The map below shows the defined regions of North Carolina. 


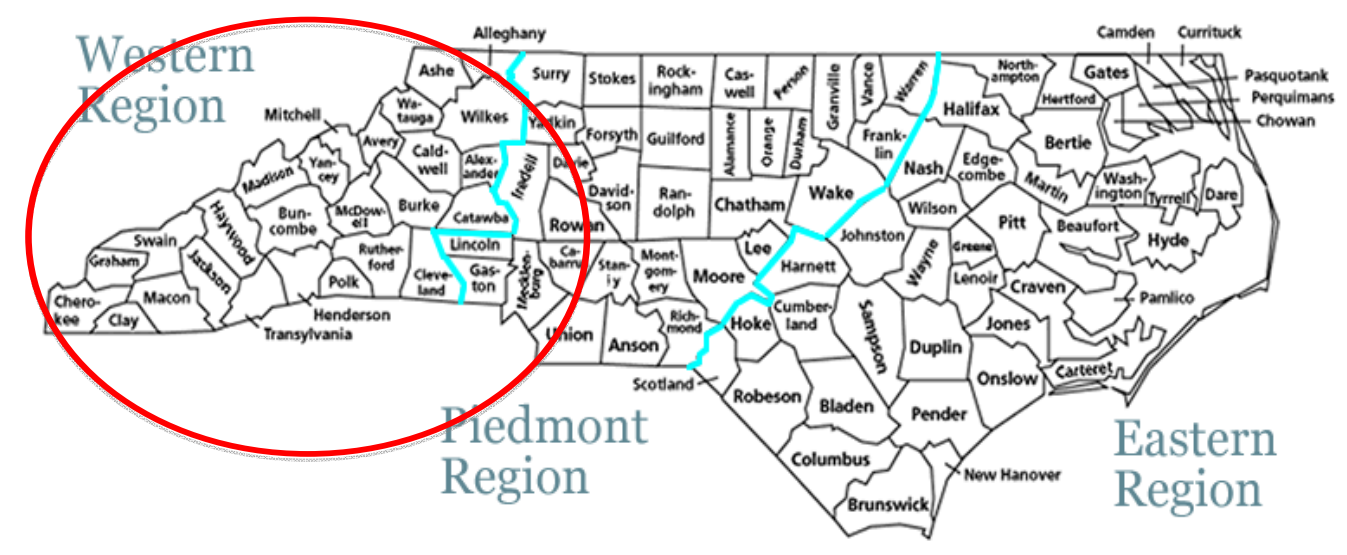

Figure 1: Map of North Carolina Regions

\section{Organization of the dissertation}

The dissertation is organized into four chapters in addition to an introduction and a conclusion. Chapter II provides an explanation of the major theoretical frameworks, and thus spaces of contribution, for the dissertation. I outline three sets of literature - the Creation of Region, Feminist and Queer Geographies, and Black Geographies - and situate the research endeavor within those contexts. Chapter II is also comprised of the methods I utilized in the completion of the project. I also offer reflections on the research process and the accompanying questions around whether the current project is sufficient enough for the discipline. Chapter III initiates a broad conceptualization of the South by analyzing the narrative of Progress in contemporary United States discourse. I argue that Progress has become an indoctrinated object that is representative of the gay and lesbian equality movement. In the chapter, I introduce the ways that the South does wrestle with Progress by providing an analysis of emails from the listserv of the Campaign for Southern Equality, a nonprofit headquartered in Asheville, North Carolina, that seeks to establish rights and protections for gay, lesbian, bisexual, transgender, and queer people 
across the South. Then I counter the ideal of Progress by asserting the production of spaces as envisioned by the women I interviewed. To do so, I analyze three organizations located in Western North Carolina - the Color ME Brown Project, Community Alliance for Equality, and Different Strokes Performing Arts Collective. Each of these organizations was founded by three of the women I interviewed. I argue that the coalitional endeavors presented through the work of these organizations demonstrate for the possibilities of progress enacted at varying contextualized sites. In Chapter IV, I open the space for testimony from the women who I interviewed for the project, by allowing renarrating portions of the stories and entering them into a discussion of the production of space. I thematically divide the dialogue into three considerations of the power in naming, belonging to, and discovering space. In Chapter V, I examine the inextricability of religion and queer sexualities by considering the confluence of individual relationships to Christianity. In doing so, I narrate the ways the research participants are moving forward with/out religion in their lives. In Chapter VI, the Conclusion, I summarize the journey of the dissertation and its contributions to scholarship. I also discuss the implications of conducting the current and related research projects. 


\section{CHAPTER II \\ THEORY AND METHODS}

The purpose of the chapter is to articulate a framework for analyzing the spatialities of Black queer women. As established in Chapter I, the legitimacy and contributions of Black queer women to geographic understanding has been minimal. In the chapter, I discuss the main literatures I used to inform the dissertation project as well as the methods I undertook for its completion.

As outlined in Chapter I, my research objectives are: 1) To challenge the monolith of the South and place the region into multiple contexts; and 2) To “map” Black geographies through an intentional intersectional account of Black queer women. As such, I utilized my thoughts about the research questions as well as my personal convictions about my disciplinary interventions to proceed in theory and method. Many of the tensions and questions posed throughout the section subsequently guide my analysis in the dissertation.

\section{Literature background}

When I initially began the project, I studied the literature areas that I deemed the “right” fit for the research I wanted to pursue, surveying the literature areas that provided the greatest possibilities for critique, with much of the literature background centered on queer theory, queer geographies and, more broadly, sexuality studies. Upon review of the literatures, it was and remains evident that the representation of people of color is severely lacking in these bodies of literature. As such, scholars of color began to venture 
into creating intellectual spaces for their research and ruminations. Texts such as Black Queer Studies (Johnson and Henderson 2000) and Aberrations in Black: Toward a Queer of Color Critique (Ferguson 2004) asserted the necessity for queer engagements along intersectional axes and discourses of power that had not been sufficiently addressed in other literatures. For my interests, the lack of representation and engagement was especially true in geography. I engaged extensively with tracking the roots and routes of queer geographies and queer studies in order to effectively argue for the absences and marginalized perspectives in the literatures and approaches, engaging with the works listed above among many others, such as Cohen (1997), Johnson (2008), and Muñoz (1999).

A recent review in Gender, Place \& Culture of an edited volume, in which I have a published chapter, reified the preexisting tensions in dealing with areas of queer geographies, sexuality and space, and the subfields' accompanying approaches. The reviewer asserted that the fundamental framework presented in the various chapters “demands a thoughtful consideration...for fuller - rather than competing - understanding of rural sexualities. Such a fuller understanding, however, must attend to the intersectional terms through which sexual subjectivities are produced, and this is one area that received uneven treatment across the text” (Myrdahl 2014, 135). She continues by asserting that my contribution was one of only two "exceptions that speak to spatialised co-production of identity and difference” (Myrdahl 2014, 135). Myrdahl argues further that the relationships of power are limited to only sexuality in most chapters of the book and that the relationships are disrupted only when examined in the context of race and people of color. Of course, I am honored that my essay was included as a chapter in the 
volume that Myrdahl reviewed. However, Myrdahl's comments mandated that connections to the subfield Black geographies be included in concert with feminist geographies, sexuality and space, and queer geographies.

Beyond the feminist, queer, and sexuality scholarship I initially examined, I also drew upon literatures related to gendered creation of place and its relationship to geographies of Appalachia. I employed the literature in an effort to foster connections between the Western North Carolina region and notions of Appalachian geographies. I also probed the history of Appalachia and attempted to draw connections between what was reported in literature with the Black queer possibilities. In the section on region, I maintain these ideas and introduce the paralleling discourses surrounding the U.S. South that are produced in the same ways that the Appalachian narrative has been identified. The literature argument provides the necessary background querying: 1) the significance of the relationship between place and discourse; 2) the importance of Black geographies as a site of inquiry; 3) the intersectional, multiply constituted relationship between place, Blackness, gender, and sexuality; and (4) the need to develop more critical scholarship concerning Black women's geographies in the U.S.

\section{Geography, regions, and the Appalachian South}

In the current section, I discuss the concept of region. I briefly discuss the concept of "region" within the discipline of geography before continuing into the ways regions are involved in the creation of place. Then I conclude the section by working through the concept of region and its relationship to a place called the Appalachian South. 


\section{What is a region?}

In A Feminist Glossary of Human Geography, McDowell and Sharp include an entry entitled "Region/regional geography" in which they describe a region "as a distinct, bounded area of the world” (McDowell and Sharp 1999, 232). Regions, though, are human creations. The physical environment sometimes defines regions, such as by the presence of large rivers and mountain ranges. Within the broader scope of the discipline, “region” and “regionalism” have been used to talk about major land masses, such as continental ranges. Consequently, the constructions of region have been quite problematic in their rigid and homogenous production of places and their subsequent stratification of the world. Regions are rooted in colonial domination and, as Katherine McKittrick argues “Geographic domination is a powerful process” (McKittrick 2006, xii). Though the disciplinary terminology has shifted away from dominating notions of region, globalization can be considered its replacement concept (Woods 2002).

In the United States, cultural regions have been nuanced by the intersection of historical, political and human connections that collude to formulate regional identities that may or may not be imagined geographies. The borders of the regions and the confinement of individuals within a specific set of boundaries produce a cultural identity and narrative that operates to limit the agency of a particular place and people. The power relations that are in concert with regional formation have to be recognized as the agents of knowledge formation. Clyde Woods argues for the critical importance of studying the region, asserting that it is, 
because official urban and metropolitan boundaries do not begin to encompass the dimensions of power, the weight of history, or the presence of contending ontologies. Even in the smallest of U.S. states, regional conflicts are intense. The creation and reproduction of distinctive ethnicity, class, resources, sectoral, and instructional practices are the very definitions of identity in the socially constructed region. (Woods 2002, 64)

The intervention of gender into geographical analyses and into the creation of place allows for intersectional approaches to be increasingly utilized and more nuances of race, class, gender, and sexuality to become central to an understanding of geographic locale. As Paasi remarks,

'Region building' always includes normative components because institutional structures are structures of rules, power and trust, in which boundaries, symbols and institutions merge through material practice. Once created, they are also social facts, since they can generate (and are generated by) action as long as people believe in them, as long as they have a role in publicity spaces or in governance. This action may be simultaneously reproductive, resistant or transformative. (Paasi 2002, 805)

\section{Regions and the creation of place}

It is important to understand how regions become understood in particular ways because the understanding allows for an interrogation into specificities of place. In these examinations, considerations of how the people of a place are shaped by their location, both the natural and the built environment, are brought into the consciousness of the discursiveness of place. The borders of a region are often contested. In many cases, regions are delineated by a subjective boundary while in other cases the demarcations are considered objective, formulated by quantitative measures. For example, the agencies of the federal government of the United States are not completely synchronized in their 
official definitions of region. Across the board, however, cultural regions have not actually been defined organically, but rather manifest as remnants of socio-historical processes and human-environment interactions. Strict definitiveness is problematic because it insinuates dichotomous categorizations that do not acknowledge the opportunities, or realities, for more nuanced contexts, realities, and experiences of region that can be differentiated from one area to its neighboring space or placated in a comparative across distances, such as that of the West to the Northeast. As Gail Hollander notes, "Places and regions are not mere containers or contexts for social action...Treating regions or places as constructed and contingent raises the questions of how and why regions emerge as distinct geographic entities, which leads in turn to explorations of historical struggles over systems of production and consumption, territorial identity, and political ideology" (Hollander 2008, 13). Places and regions become raced, classed, and gendered. Their boundaries operate as the gateway of dichotomous morality.

\section{Orientalism and regional discursive formation}

In understanding that regions have identities that are articulations of powersaturated interactions of a geographical imagination (Peet and Watts 1996), it is equally important to consider that the outcomes of these inventions initiate a process of othering that can be likened to Edward Said's (1979) conceptualization of Orientalism. He describes it as "fundamentally a political doctrine willed over the Orient because the Orient was weaker than the West, which elided the Orient's difference with its weakness...As a cultural apparatus Orientalism is all aggression, activity, judgment, will- 
to-truth, and knowledge” (Said 1979, 204). Said also argues that representations have specificity in purpose. "Because the Orientalist discourse limits thought, the Orient was not, and is not, a free subject of thought or action...extending this to geography, Said finds localities, regions, geographical sectors like Orient and Occident, to be humanly “made”” (Peet and Watts 1996,14). Therefore, socialized perceptions of place shape both personal identity and multiscalar renditions of place identity. Clyde A. Woods argues, "Distinctive regional identities and relations are constructed, and reproduced, through mobilization and countermobilizations (Woods 1998, 26).

\section{The region known as Appalachia}

It is important to note that Appalachia is a region that has been hard to historicize because expressions of region are myriad and diverse. Appalachia’s mountainous topography lends some definition for how the region has historically been shaped and is its primary physical distinction Additionally, it is important to understand that Appalachia is an imagined geography whose parameters have been determined by social, economic, and political hierarchies. The distribution of wealth varies. Social status in community is contingent on affiliation with certain networks, which results in a strong set of power relations. Negotiations of "difference" - religion, race, ethnicity, gender, sexuality, and class - are as present in Appalachia as in metropolitan U.S. sites and regions. The romanticism of the Appalachian region, which is discussed throughout the current section, has contributed to an Othering of place, one in which the dominant, middle-class hegemony has set as the opposition to the standardized sense of time and place. Scholars argue that such representations of place lead to the idea of Appalachia. 


\section{Regionalism and local color}

As referenced earlier, scholars have referred to the Orientalism/Othering process as prevalent in shaping Appalachian discourse and imagery (Billings, Gurney, and Norman 1999; Hsiung 2004; Massey 2009; Williams 2002). I argue that much of the contemporary sense of romanticism that connected to ideas of Appalachia and mountain living can be traced to the local color movement in the United States. Regionalism and local color are often used interchangeably, particularly in regards to creative and literary work. However, regionalism has much broader implications.

The nineteenth century local color movement highlighted Appalachia and its exaggerated nuances. The most popular phrase from the time period is "a strange land with peculiar people”, stated by Will Wallace Harney, indicating a monolithic, antinormative existence from that of an outsider (Shapiro 1978; Massey 2009). Appalachia is Othered, forced into a geographical bias that gives an entire region a monolithic existence. As scholar Ronald L. Lewis (1999) writes:

[T]he idea of Appalachia as a homogenous region physically, culturally, and economically isolated from mainstream America has its genesis in fiction...However, if we examine the region's economic evolution from the perspective of rural nineteenth-century America, without assuming prior knowledge of its fictional existence, or the industrial developments that were to come, it is clear that much of Appalachia was neither unusually isolated, physically or culturally, nor was its population uniformly more homogenous than that of other sections of rural America. (Lewis 1999, 22)

The local color literary movement occurred during the late 1800s in which popular culture writers gave accounts of how they viewed the Appalachian region and people. The local color movement lent itself to creating a series of reports that operated 
not unlike European colonial travel writing in other portions of the world, such as subSaharan Africa and the Americas in the historical period of European global exploration. There came great regard for the ways in which a distinctiveness of mountain living could be produced in print media to an audience that was in search of entertainment. Local color writing left a dichotomous sense of comparison, relegating "us” to the realm of urban, middle class and "them" as the peculiar people who were once regarded as "our mountain ancestors” (Shapiro 1978; Engelhardt 2005). Appalachians were regarded in local color writing as native-born, white, Anglo-Saxon, and Protestant people whose lifestyles were reported as conditions more akin to frontier-era living instead of urban standards of increasing levels of consumption in the spirit of industrial capitalism. The people themselves were represented as uncivilized and removed from hegemonic whiteness as well as from American ideas of aesthetic standards, making the distinction of Otherness an internal American process. The historical peculiarity of Otherness has contemporary impacts, as the perceptions of Appalachia have become "fact" and reinstitutionalized into popular culture and media In the book The United States of Appalachia: How Southern Mountaineers Brought Independence, Culture, and Enlightenment to America, author Jeff Biggers (2007) takes on the task of dispelling the “myth of Appalachia,” by particularly taking on images from popular culture and media in the formation of the ideas and symbolism associated with the remnants of Othering. Biggers argues:

"Few regions in the United States confound and fascinate Americans like Appalachia. No other region has been so misrepresented by the mass media. Four paradoxical images have enjoyed incredible staying power: pristine 
Appalachia, the unspoiled mountains and hills along the Appalachian Trail...backwater Appalachia, home of the "strange land and peculiar people" in thousands of stories, novels, radio and TV programs and films...Anglo-Saxon Appalachia, once defined by Merriam-Webster's Collegiate Dictionary as a mountain region of "white natives," despite its role as a crossroads of indigenous cultures and vast immigrant and African American migrations for centuries; and pitiful Appalachia, the poster region of welfare and privation...regardless of the tremendous wealth generated by the mountain range's mineral resources, timber, and labor force in the mines, mills, and factories, and today's tourist industry" (Biggers 2007, xii).

The ideas and categorized identities that Biggers is referring to "emerged as a fantasy of travelers, reporters, and intellectuals prepared by capitalism to detect backwardness, poverty, and signs of isolation in the people of Appalachia” (Massey 2009, 65), characterizing Appalachia filled with deficiencies which make them unfit for normative society.

Men were constructed as violent, highly masculinized figures that shot their guns for fun and drank whiskey, giving life to the iconography of the "hillbilly" in the public imagination. Women were, and perhaps still are, considered subversive homemakers who accommodated their men and reared multiple children. In fact, the Appalchians have been considered "counterpoints to the modern world, representing either a simpler rural life or a ridiculous fringe population of proficient, mysterious characters” (Maggard 1999, 229). Smith argues, "Fashioned from Adam's rib, "mountain women" are secondary, entirely compatible with the "mountain men" from whom they are derived" (Smith 1999, 2). Representations of women have followed a dichotomous series of representations in the popular imagination, particularly taking shape during the middle of the 1900s to the present day through television and film. Popular figurations are given life through "four popular caricatures in cartoons, television and film: Daisy Mae...Daisy 
Dukes...and Elly May and Granny Clampett” with the former three formulated as "voluptuous, vacuous, barefoot, and likely to be, if not already, pregnant. They tempt, confuse, and distract their menfolk, but they do not lead, instruct, or direct the events that shape their lives” (Maggard 1999, 229). On the other hand, “Granny is wizened, wiry, and wrinkled, an older Appalachian women with enough rural smarts to outwit city slicker bankers. But she tends to her goats and pigs in her urban Beverly Hills mansion, uninterested in achieving some upper-middle-class lifestyle her newfound riches would support” (Maggard 1999, 229). The idea of Appalachia, then, is an exploitation of an American region that is somehow continuously conceptualized as disparate, something other than a place of American civilization.

\section{In(visible) constructions of place}

Appalachian figurations of landscapes, materiality, and embodiment are largely regarded as representations of whiteness. Additionally and in particular, the constructions of Appalachian women institutionalize their backward, impoverished embodiments. Engelhardt (2005) reports of a halftime marching band performance during a football game between West Virginia University (WVU) at University of Virginia (UVa) that featured two female students of the respective universities who were performing as finalists on a dating show, stating “West Virginia's radio announcers were almost at a loss for word...they spoke in horror of her blacked-out teeth and tried to describe her pigtails, overalls, bare feet, and talent for sexually suggestive square dancing...Elly Mae Clampett was thus given new life ... The stereotypical whiteness of Appalachia was rebuilt...” (Engelhardt 2005, 2). Interestingly, the popular discourse 
renders whiteness invisible, in a sense, because the region is whitewashed in its discursive formation and is, therefore, made unquestionably white. Although, Appalachian regional whiteness is a subverted racialism removed from the hegemonic standard of Eurocentric or cosmopolitan whiteness. Scholars have interrogated the stability of regional racialism. Earlier, I referenced Engelhardt's account of the WVU student who embodied a broadly drawn Appalachian stereotype. In the same discussion Engelhardt further recounts the aftermath of the actions and subsequent conversations across the state, saying that the performers could not have joked about black people in the same way. Engelhardt argues "That particular variation added another layer of irony to the situation, given the number of black West Virginian players on the field and spectators in the stands. In other words, comparing Appalachian stereotypes to stereotypes about African Americans...quickly erased any black Appalachians watching the game, and by extension any other nonwhite Appalachians” (Engelhardt 2005, 2). Further, John Inscoe notes, “By simply acknowledging and including the region’s African Americans in our study of Appalachian history, we more fully appreciate the social, economic, and political complexities that have always characterized the southern highland experience but that have for far too long been obscured by more simplistic misconceptions and stereotypes, especially those that suggest a "racial innocence" and “Anglo-Saxon purity" (Inscoe 2004, 42). An intervention is not exclusive to deconstructing blackness in the region. On the contrary, it also serves to resist the idea that a bubble of Appalachian, lying outside of a progressive global context where racial discrimination does not exist. As Anne Shelby noted, "The latest cycle in the continuous recycling of Appalachian stereotypes feature Appalachia as the homeland of racists and 
practitioners of incest...While news programs report racial tensions in cities and corporations across the country, watching sitcoms would lead one to believe that racism exists only among “rednecks,” “hillbillies,” and “poor white trash” (Shelby 1999, 157). Tensions stemming from Appalachian regional identity are validated, as they serve to inhibit lived experiences of Appalachian dwellers. Indeed, as during the local color movement, external forces contribute to creating a regionalism that centers derogatory and antiquated mythology as lived truth.

Such sentiment is notably true when examining representations of Appalachian women. The two types of characters referenced in the previous section - the hypersexualized mountain bombshell and the "Granny" figure are inhibitors to reconfigurations of the Appalachian region. Smith argues, “..."mountain women” are secondary, entirely compatible with the "mountain men" from whom they are derived. Female agency (other than active support for her mountain community or her mountaineer), sexism, gender trouble--all the basic stuff of women's history--are literally inconceivable ... Either our constructs of the region or women themselves must succumb, one to the other" (Smith 1999, 2). Though Smith addresses women, I would also argue that constructions of men and masculinities are also held to the standard of the "hillbilly" character. The reproduction of men and women's lack of agency in terms of their identity formations serve to inhibit opportunities for significant interrogation of sociospatial interactions and lived experiences.

Further, heteronormative sexualities are centralized in Appalachian constructions; alternative notions of Appalachia would call for reconsideration. I would like to argue that Appalachia is actually queer. Because the hegemonic discursive construction of 
Appalachia is anti-normative and because the homogeneity of a monolithic construction is, perhaps, only partial truth, the stability of its narrative as a isolate, poor, hypersexualized, heteronormative region is troubled with the advent of deconstructive approaches to the power relations that contribute to place making. For example, the existing literature on queer Appalachia is small but growing, with the publication of Mary L. Gray's Out in the Country (2009) and Mathias Detamore's dissertation, Queer Appalachia: Toward Geographies of Possibility (2010). Both of these publications serve to interrupt the hegemony of gender and sexuality by focusing on lived experiences of Kentucky queers. Their respective projects, unfortunately, do not sufficiently deconstruct the racialisms nor do they, as ethnographic researchers, include significant racialized voices. However, Gray and Detamore have supplanted the normativities of the region by interrogating and giving voice to Appalachian lived experience.

\section{What about the South?}

"The South grew on the back of slavery and has never fully shaken off its legacy."

Bobby Wilson (1992)

Not exempt from the disparate conceptualization, the U.S. South has its own historical and contemporary complications, largely stemming from its relationship to chattel slavery and slavery's offspring Jim Crow. The mythology of the South is just that - a myth, a fantasy with an impressive and disappointing stronghold in American imaginations. There is the truth that the South faces a unique set of legacies that require hard work and deep emotion in order to heal. Geographer Joshua Inwood writes, “Any 
engagement with the U.S. South must recognize the painful legacies of displacement and dislocation that permeate the region's history. The forced exile of First Peoples from native lands, chattel slavery and the imposition of Jim Crow Segregation have left indelible marks on the landscape and continue to inform political, economic and social structures in the region” (Inwood 2011, 564). But as geographer Richard Schein, invoking author Toni Morrison, writes “all American landscapes are racialized” (Schein 2006, 4), and therefore, all American landscapes require attention to the history of white supremacy and the perpetuation of oppressions.

Yet it is not merely Southern violence and exclusionary horrors that hold responsibility for its status in geographic mythology. If there is one truth in the myth, it is that the past has never gone away but has instead been reconstituted in other forms. There are other socio-economic truths that are dismissed in the pursuit of pathologization:

We must start with the unique set of regional relations that gave rise to North American neo-liberalism. Many of the roots of this system were nourished by the reaction to the modern civil rights movement. A campaign of massive resistance slowly reorganized the political and intellectual institutions of the United States. The Southern pillars of racial supremacy and an anti-union low-wage economy effectively eviscerated the welfare state...Y Yet much of the literature on neoliberalism and globalization conveniently ignores the literature on the historic "Southern Strategy" institutional realignment in the United States. Scant attention is given to the relationship between hegemonic discourse and the regional conditions and social movements that spawned it over forty years ago. Ignoring the transformation of regional and racial regimes allows proponents and critics of neo-liberalism to also freely ignore their own complicity in a wide variety of domestic racial projects that undermine democratic institutions and constituencies: massive social spending cuts, segregated education, welfare reform, gentrification, the prison-industrial complex, employment discrimination, and electoral disenfranchisement, among others. (Woods 2007, 47-48) 
Clyde Woods has clearly outlined the multifariousness of the South and its accompanying legacies that prove the South is not just the South's problem. A concert of hegemonic alternatives to a normative geographic imagination is made possible in the oscillations and tensions that constitute the place of American scholarship, which should challenge dualisms (U.S. vs. the South) through more fluidity and intention.

Place is discursive, formed by a series of both explicit and implicit power relations. The experience of place is individual and recanted across space and time. Though individual, some experiences become larger social processes that dictate discourse. How can a tangible place be a productive space for an intangible process? There are many unknown factors that contribute to knowing a place that can be discovered through inquiry. Through the dissertation, I advocate that more nuanced inquiry involves connecting the lived experiences, the power relations at play, and their accompanying mediations of place and body.

\section{Space, place, identities}

In the current section, I will discuss the ways in which geographical knowledge about space and place has been informed by feminist, queer, and race scholarship. In doing so, I will outline the key features and contributions of the three aforementioned areas of discourse and interpret the ways in which each overlaps with one another into a more informed and complex understanding of space and place. Finally, I will integrate each of the three areas of scholarship into a discussion regarding the ways in which my research project and interests are introduced as a complement and addition to the body of knowledge on space and place. 
Space and place are concepts that seemingly create a stabilized sense of connectivity or togetherness. They are tools use to initiate boundary-making processes and are individually necessary for the other to be defined, as "Interrelations between objects occur in space and time; it is these relationships themselves which create/define space and time” (Massey 1992 quoted in McDowell 1996, 28; original emphasis). The interventions on knowledge of space and place by race, queer, and feminist scholars address the physical materiality and imaginative configurations conceptualized by the two terms. In the broadest sense, the scholarship of race, queer, and feminist academics troubles stabilizing dominance and objectification within definitions of space and place, both in their respective and in their collective efforts. Katherine McKittrick (2006) notes, "If space and place appear to be safely secure and unwavering, then what space and place make possible, outside and beyond tangible stabilities, from the perspective of struggle, can potentially fade away” (McKittrick 2006, xi; original emphasis). In the next section, I will deconstruct the ways these three areas of scholarship make their individual contributions to understanding space and place.

\section{Feminist debates in sociospatial contexts}

Feminist scholarship has made inquiry into the understandings of place and space by troubling the normative notions of women's lives, politics, and location and by introducing the gender question into sociospatial interactions as well as questioning the dominance of patriarchal, masculinist hegemony in the discipline. The separate spheres ideology creates a binaristic approach to women's place, both materially and discursively. Because the private sphere has been relegated to feminized notions of 
place, particularly to ideas about the home, the visibility of women in the public sphere has mean that women's and feminized bodies have become subjected to the process of Othering, causing feminist scholarship to interrogate gender as an axis of difference in patriarchal systems (Rose 1993; Domosh 1999; McDowell 1999; Bryant \& Pini 2011). Scholars have sought to disrupt the stability of sex and women as distinctive stable categories versus the site-specific embodiment of gender. Scholars of feminist scholarship have also introduced questions of the body and continue to interrogate how the body operates and performs within material, imaginative, and discursive formations. Gillian Rose (1993) argues that the question of the body is important because the understanding of space and place operates within an understanding of how the masculinized dictation of the public/private spheres ideology can be troubled by introducing the provocative gender inquiry as an method of hegemonic intervention. Importantly, the distinctions between sex and gender have been brought forth by feminist interventions in sociospatial contexts (Rose 1993; Bell \& Valentine 1995; Domosh 1999; McDowell 1999; Anglin 2002; Hill Collins 2007; Bryant \& Pini 2011). Feminist geographers have centralized questions of power relationships, particularly as they relate to heteropatriarchal systems and the ways that these systems make impact on the way that social life becomes more nuanced in discursive understanding. Patriarchal systems normalize a particular type of hierarchal formation that subordinates women and creates boundaries for all human-space relations. Symbolic and social differentiations are dictated according to a specific set of power relations that is creates discourse.

Feminist scholarship makes clear the need for and specificity of context. With that said, the standpoint approach of feminist scholarship allows for metaphorical 
displacement and dislocation to be undergirded with the reshaping of place knowledges by utilizing one's social location as the point of knowledge production. Mary Anglin (2002) uses the metaphor "talking back" as she writes about conducting her research on Appalachian women and labor. In her metaphorical discussion, she is making sense of a paradoxical situation that abounds in the Appalachian region - wealthy resources with impoverished peoples. Anglin allows the women to speak for themselves and communicate their own sociospatial realities. Anglin talks of the gender relations in the negotiations of local and national political economies, which contribute to the making of geographies of wealth and poverty. The standpoint feminist approach, for Anglin, allows for methodological difference in feminist research of space and place. She argues that ethnographic and ethnohistorical work make for understanding the true complexities of place and the making of space in Appalachia. The emphasis of subjectivity and reflexivity in feminist research allows for the methodological considerations that would be absent or harder to discover in masculinist, objective research methodologies.

Standpoint theorizations, as developed through Anglin’s work among others (Hill Collins 2005, 2007; Engelhardt 2005; McKittrick 2006) argue for the importance of experience and point of view. These particular knowledges of self and the social world through personal perspective offer the opportunity to make more nuanced, transformative understandings of space and place. Standpoint theories offer a perspective on power that contextualizes experiences of oppression beyond the question of gender into different understandings of oppression, which is connected to the initiation of feminist theory. These types of feminist interventions of place and space also contribute to a broader understanding of scale. In other words, the tensions and interconnectivities across 
different relations of experience work to combat generalized binarisms that suppress autonomous identity formations and reinforce dualisms in social contexts.

\section{Towards a queer geography}

Queer scholarship has its roots in an intentional relationship of feminist theory and lesbian and gay studies. Throughout its history, coming of prominence in the 1990s and gaining in popularity since that time, queer scholarship has produced knowledge about space and place, not just by explicating a "gay" identity from a particular place but also through the challenging of dichotomistic notions of sexuality (heterosexual/homosexual) and identity more broadly considered and by paying specific attention to the possibilities of fluidities within constructed space and place. If we understand an argument of queer theory's use as a tool "to investigate the historical circumstances by which 'sexuality'...can automatically render subjects the somewhat pitiable victims of a determinism that 'heterosexual' subjects supposedly remain free from” (Turner 2000, 38), then we can connect feminist and queer scholarship by understanding the necessity of interrogations that trouble power from geographies of domination. A paradoxical state of queer scholarship is its seeming necessitation of visibility, therefore meaning public knowledge of private relations. These contributions make strong connections to a politicized visibility that often reproduces hierarchical dominations within which heteronormativity is denaturalize but homonormativity continues to be reinforced (Duggan 1994; Cohen 1997; Ferguson 2004; Johnson 2008).

As with feminist theorizations, queer theorizations have evolved towards broader knowledge productions that extend beyond mapping desire and break through 
essentialized understandings of sexuality and space. A key contribution of queer theorizations involves the reframing of language to avoid what Lisa Duggan (1994) calls "strategic essentialism" and move towards new rhetorical and active strategies against identity-based imperatives. Scholarship that concentrates on ethnographic and ethnohistorical discussions of queer sexualities and behaviors has gained increasing prominence, particularly in the last decade (Ferguson 2004; Moore 2006, 2010; Browne, Lim, \& Brown 2007; Walcott 2007; Johnson 2008; Gray 2009). These scholars contribute to an understanding of space and place as they relate to queer identities and behaviors that deconstruct normative notions of hegemonic sexuality - from urban, elite, white male heteronormativity and homonormativity. Mary L. Gray (2009), for example, provides insight into issues that queer youth encounter in developing community in rural Kentucky. Gray takes note of the strategies youth use to create visibility and belonging, noticing their recognition and utilization of rural structures, pushing for a more nuanced understanding of "the public" in the rural (through technological mediation, public parks, libraries, and quasi-local Wal-Mart centers).

These discussions also deconstruct ideas about authenticity in gay space. A particular racialized, classed, gendered, and geographical experience has been branded under homonormativity as the standard of gay/queer experience. Therefore, contemporary queer scholarship articulate difference from a monolithic sexual politic and experience, often relegated to an idea called queer sexual citizenship. The essentialization of queer sexual citizenship isolates people who are not interested in ascribing to heteronormative societal inscriptions - marriage, family, consumptive behavior, and military rights (Bell and Binnie 2000). Further, queer sexual citizenship 
becomes canonized as a particular experience, which serves to be most advantageous for white, homonormative citizens. In arguing towards a queer of color critique, Ferguson (2004) states "To make sense of that [African American] culture as the site of gender and sexual formations that have historically deviated from national ideals, we must situate that culture within the genealogy of liberal capitalistic economic and social formations” (Ferguson 2004, 2). Therefore, understanding space and place requires a more nuanced regard for social location.

\section{Black geographies}

During my short tenure in geography (just under five years as I write the current section in the spring of 2014), I have become intrigued by the dismissal of race, and for my purposes Blackness, in broad strokes within geographic literature. As one involved with a project that has multiply constitutive identities at stake, I also find the oversight intentional or otherwise - troubling. Blackness should be understood as an active process that is being shaped and formed by and through power relations. With its undeniable roots/routes in European colonialism and capitalist enterprises, these processes and power relations connect humanity through hierarchical levels, which are regionally subdivided, but never without whiteness dominating at the top. The conceptualizations of race should be understood as the foundation upon which relations of power set up a series of unequal relationships among and between peoples that are continuously separated in the remnants of colonialist and capitalist enterprises and productions of power.

The section incorporates the spatial significance of Blackness, Black studies, and Black space into a more visible platform within the discipline of Geography. An interest 
in spatialities and place making is becoming more of a trend across disciplines outside of geography. Yet, Black geographies as a body of integral epistemologies continues to fight for "a seat at the table". Therefore, I intend to make an attempt at synthesizing the significance of Black geographies by highlighting a mere portion of its disciplinary contributions.

\section{What is Black geographies?}

In the Acknowledgements of their edited volume Black Geographies and the Politics of Place, Katherine McKittrick and Clyde Woods state that the book "is a reflection of our continuing interest in developing and sustaining questions about the intersections between race, blackness, and spatial politics in the diaspora” (McKittrick and Woods 2007, vii). Black geographies is both a body of work and an ontological practice that is grounded in narrating the varying matrices of Blackness. Black geographies intervenes into the discipline by presenting knowledge of racialized spaces, bodies, and landscapes, undergirded by and perpetuated through colonial legacies. Scholars of Black geographies rely on the corporeal, the aesthetic, the creative, the spiritual, and the elemental (earth, air, water, and fire) as texts with which to read into the meaning of Blackness, its accompanying implications of oppression(s), and its futuristic possibilities (Wilson 1992; Woods 1998; Gilmore 2002; McKittrick 2006; McKittrick and Woods 2007; McCutcheon 2013; Shabazz 2014). Black geographies cannot always be cartographically inscripted. Black geographies also, and perhaps more often, encompasses a metaphysical component that cannot be rigidly mapped (Brand 2002, 
Alexander 2005). Therefore, the roots and routes of Black geographies are diasporic endeavors (McKittrick and Woods 2007).

Black geographies is a necessary intervention into the endeavor of the discipline. Though certainly not solely comprised of the Untied States experience, I shall enter into an engagement with the body and method of Black geographies within a U.S context by referring to an essay by Fred Donaldson in the first issue of Antipode: A Radical Journal of Geography. In the article Donaldson argues, "Concerning its treatment of the Black American, the nature of geography is misinformation or no information at all” (Donaldson 1969, 18). More recently, Owen J. Dwyer published an article in Professional Geographer entitled "Geographical research about African Americans: A survey of journals, 1911-1995” (Dwyer 1997). Both Donaldson and Dwyer point to the severe lapses in accountability to the socio-spatial experience of Blackness and its connections to the origins and perpetuation of geography, including the relegation of Black bodies and Black space to peripheral, superficial, unjust dealings. As Katherine McKittrick asserts, “The relationship between black populations and geography—and here I am referring to geography as space, place, and location in their physical materiality and imaginative configurations—allows us to engage with a narrative that locates and draws on black histories and black subjects in order to make visible social lives which are often displaced, rendered ungeographic” (McKittrick 2006, x). McKittrick’s standpoint also relates to the argument that failing to recognize and address white supremacy and the socio-spatial nature of racism "raises uncomfortable questions about the role Geography played in perpetuating the system of segregation and the ways geography benefitted from 
the system of white supremacy in the U.S. South” (Inwood 2011, 564). We should turn then towards the possibilities of engagement with Black geographies.

Earlier representations of Black places and bodies in history come through the journal writings of European Christian clergy who ventured into Africa in the spirit of crusading and conversion. The bodies of African women are gendered and racialized such that they become simultaneously objects of desire and repulsion. In the clerical writings of religious figures, as well as other "adventurers” into the African continent, the women of the continent were particularly objectified as monstrous beasts with nonhuman abnormalities that were to become the mechanism through which African's racialization continue(s) to find bearing in societal domination (Woollacott 2006). To see these discourses in modern operation, one has to look no further than population demographics of poor neighborhoods in the U.S. urban core and understand how particular neighborhoods are demonized as dangerous, substandard, and full of women who lack reproductive control and hold no social responsibility (Collins 2007). Within such a sweeping stereotype is the modern understanding that our bodies are inscripted with certain notions about who we are which stem from these imperial regimes. McKittrick and Woods, in talking of black geographies, note that, “The dilemmas that arise when we think about space and race often take three very separate approaches (bodily, economic/historical materialist, metaphoric) that result in reducing black geographies to either geographic determinism (black bodies inherently occupying black places) or the flesh (metaphoric/creative spaces, which are not represented as concrete, everyday, or lived)” (McKittrick and Woods 2007, 7). Racialized existences are constructed in deep conjunctions with gender and sexuality as formed through imperialist 
regimes that have yet to be deconstructed and therefore must be fully considered. The discursive formation of a place is constantly met with bodily inscriptions (Rose 1993; Paasi 2002; Collins 2007; Woods 2007; Bryant and Pini 2011). Black geographies is necessarily situated in antiracist geography.

\section{Antiracist geography}

In the conclusion to his 1969 article I referenced above, Donaldson provides recommendations for making necessary improvements within the discipline regarding the treatment of "the Black American" in education and professional endeavors. He argues for a review of texts used in geographic education, the development of a commission that would “participate in a summer institute of 'soul search’”, the creation of new courses, and the AAG to devote an issue of the Annals to discuss racism in geography (Donaldson 1969, 26-27). Though I have not seen an entire issue of the Annals that fulfills Donaldson's provocation, there is evidence of increasing attention to racism and its impacts through geographic lenses. That does not mean, however, that there is enough attention. On the contrary, the work of antiracist geography (and antiracism in geography) is far from over. In fact, as Linda Peake and Audrey Kobayshi argue, "Without an explicit effort being made to address and correct the consequences of the various (and often hidden) racists practices and discourses that permeate the epistemological foundations of geography and the institutional structures and practices that shape our work environment, geography will continue to embrace the colonialist heritage bequeathed upon it” (Peake and Kobayashi 2002, 50). 
The production of space is directly correlated to an imperialist-motivated colonial history. Imperialism is characterized by the creation of an ethnocentric mindset, where one entity is viewed/views itself as superior in some way to others. Because of perceived superiority coupled with the desire for more productive space, a colonialist culture presented itself. Colonialism can be characterized by an invasion of space for the purposes of productive gain - the root of capitalism. The result of imperialism has created a geography that has been called a "direct result of material production” (Smith 2008, 107). Kobayashi and Peake note that the discipline of geography itself has been legitimized by "the inimitable relationship established between colonial power and the map as a 'rhetorical device of persuasion to justify the authority of its practitioners' assertions"” (Kobayashi and Peake 2008, 166). Further, Smith notes, "geographical expansion is synonymous with societal expansion and development.” He points out that it "occurs...only by expanding the geographical arena in which space is societally produced” (Smith 2008, 110).

Geography, as a discipline, has created "perhaps the strongest of imperial geography's metaphors" in the construction of the "moral-climatic idiom." As presumed by its naming, the "naturalization of racial differences according to climatic classifications, placed those of "the dark races" at the bottom of geography's moral terrain” (Kobayashi and Peake 2008, 166). With the production of space and the implementation of colonialist rule, Kobayashi and Peake note that the agenda of geography "is directly or complicitly racist in a number of ways, beginning with a thoroughly racialized disciplinary past” (Kobayashi and Peake 2008, 166). The discipline played a founding role in establishing the systems of imperialist expansion and 
colonial power through which the Western world became a dominant center and its white inhabitants became normative, authoritative, and privileged (Kobayashi and Peake 2008, 166). Blaut argues, “A double standard of morality was accepted by which privacy, brigandage, privateering, slave-raiding, slave trading, and slavery itself were permitted so long as the venues were extra-European” (Blaut 2009, 29). Colonialism acquired the status of natural and inevitable process, almost foreordained by the internal evolution of Europe and developing smoothly and continuously from the first voyages of Henry the Navigator to the final partition of Africa” (Blaut 2009, 29).

An antiracist geography does not avoid or "gloss over” the messy, painful legacies of racism's impact. I align with the sentiment of Ruth Wilson Gilmore, who argues, "the founding moments of U.S. nationalism, well rehearsed in mainstream histories, are foundational to both state and culture. First the U.S. was "conceived in slavery”... and christened by genocide” (Gilmore 2002, 20). As a result, national social formations of race are inextricably linked to formations of gender, sexuality, class, and power and therefore must be considered. Bobby Wilson argues, “Any analysis of the social construction of racism within the United States must begin with the slave economy” (Wilson 1992, 171). Wilson continues by centralizing the development of industrial capitalism in the South, using Alabama as a case study. Wilson argues that geographers should understand that "greater sensitization to spatial differentiation of global capitalists is essential to understanding the geography of race in the post-Fordist phase of capitalism” (Wilson 1992, 196). Wilson's rumination draws attention to the existence of structural racism, which "is so deeply embedded in normalized social and 
political practices, because of its pervasive geographic effects, and because it restricts the life chances of people of color” (Peake and Kobayashi 2002, 52).

The present dissertation takes seriously the "agenda for antiracist geography" put forth by Linda Peake and Audrey Kobayashi: "We need to build on and extend traditional geographical scholarship to understand more about the geographies of racism. We need to change the basis of the discipline by extending the principles of antiracism throughout our institutional practices. And we need to change the face of the discipline by increasing the participation and the contributions of geographers of color" (Peake and Kobayashi 2002, 58). Their suggestions speak to Fred Donaldson’s concluding remarks, arguing, "that it is vitally necessary that geographers review old and develop new theories and methodologies which can be used in the solution of our problems of race and poverty" (Donaldson 1969, 26). Donaldson's essay was published 33 years before Peake and Kobayashi's essay. The lapse in time, and the similar refrain, between the two reinforces the necessity of disarticulating "commonsense couplings of sites and struggles” (Gilmore 2002, 15).

\section{Theorizing geographies of difference}

Scholars of racialization have increased attentiveness to the imagination of racial disparateness and its concrete consequences. Scholars of race have delved into research that exposes the oppression of racialized peoples by maintaining connections to histories of colonization. Scholars of race studies, particularly in the Americas, reconnect to the Atlantic slave trade to reconstitute their arguments on and about racialized populations. In her discussion of black geographies, McKittrick (2006) argues "that space and place 
give black lives meaning in a world that has, for the most part, incorrectly deemed black populations and their attendant geographies as 'ungeographic' and/or philosophically undeveloped” (McKittrick 2006, xiii). Her arguments are in alignment with other scholars (Ferguson 2005; McKittrick and Woods 2007; Hill Collins 2007; Johnson 2008; Moore 2010) who that the dismissal of blackness by hegemonic scholarship only supports a recolonization of ideas about race studies and its related spatial matters.

McKittrick and Woods' (2007) discussion takes on black geographies by talking through what they call 'the unknowable figures' (i.e. the Black Atlantic) that creates the narrative of space production. McKittrick's aforementioned argument on black lives making meaning of space and place lays the foundation for the impact of black studies on space and place. One of the central characteristics of race scholarship that contributes to knowledge on space and place is the attention to the body and geographical embodiment. Critical scholarship of racialization processes simultaneously conceptualizes the construction of knowledge as deeply embodied. Hill Collins (2005) argues about sexualized black bodies are mediated in "a social context that routinely depicts men and women of African descent as the embodiment of deviant sexuality” (Hill Collins 2005, 35) and discusses the public objectification Jennifer Lopez, Beyonce, Josephine Baker, and Sarah Bartmann as examples of the ideological associations of African diasporic embodiment in a constant hypersexualized state. Race scholarship addresses the infiltration of residual colonialist thought onto social perceptions of black bodies and makes visible the connections important to understanding why the history of sociospatial identity formations need to be theorized through time and in place. As McKittrick and Woods argue, "The dilemmas that arise when we think about space and race often take 
three very separate approaches (bodily, economic/historical materialist, metaphoric) that result in reducing black geographies to either geographic determinism (black bodies inherently occupying black places), the flesh (metaphoric/creative spaces, which are not represented as concrete, everyday, or lived)” (McKittrick and Woods 2007, 7). Walcott (2007) inserts a related argument that dismantles ideas about the unquestioned heterosexuality of diasporic blackness. He argues "a black queer diaspora remakes the boundaries of the black diaspora, not only making its reach more inclusive of the unruliness that is diasporic blackness, but also raising difficult concerns and questions for the category of blackness (Walcott 2007, 235).

\section{Intersections of feminist, queer, and race scholarship}

In conversation, the race, queer, and feminist disciplinary approaches provide critical interrogation of sociospatial interactions and allow for an interrogation of axes of difference, as they coincide and interrelate. Additionally, they contribute to a deeper and more nuanced knowledge of the localization of social life, which enhances an understanding of the intricacies of space and place. Further, it is my argument that a discourse on space and place is incomplete if the variance of human attributes is not fully considered. With only one facet of an individual space or place considered, the notion of knowledge is only a partial deterministic one. Rather, the relationships between feminist, queer, and race scholarship is a also metaphysical one and would be counterproductive to their individual disciplinary philosophies on social life and human interactions in space and place as well as how space and place are created within the context of human interaction within a particular environment. 
In her research on lesbian/gay/bisexual transgender LGBT inclusion in the Black community and Black LGBT protest, Mignon Moore’s discussion of tensions across multiple vectors of identity produces a sense of placelessness for queer, black people. The placelessness results from incomplete or missing applications of queer and feminist theories to critical race scholarship that leads to partial analyses of place and space. As Moore notes, "African Americans with a strong sense of linked fate see their futures as importantly shaped by the position of Blacks in the larger social structure. Race and experiences that results from being Black are understood as one critical determinant not only for the future of Blacks as a group but for their own individual futures... When taken together, the persistent sense of disapproval of gay sexuality in Black communities, combined with on-going geographic and personal ties to networks of Black people, make the open practice of homosexuality a cross-cutting issue for gay African Americans” (Moore 2010, 318).

Similarly, in a provocation of abject sexuality, Ferguson (2004) discusses the implications for African American identity and makes rationale for the compulsory negotiation of material and discursive components within African American culture. He argue “...the material and discursive production of African American nonheteronormativity provided the interface between the gendered and eroticized properties of African American racial formation and the material practices of state and civil society” (Ferguson 2004, 21). Ferguson and Moore are calling for a multi-lens perspective on epistemological subjects in space and place that contribute to deepening reflections within queer, feminist, and race scholarship. Not unlike her colleagues, Lorena Muñoz (2010) reflects on the multiplicity of subjectivities in fieldwork and argues 
for racialized queer consciousness in research in her work on queer Latina streetscapes. She argues that queer theory by itself is inadequate for observing the intricacies of spatially produced identities. As she denotes in reflections on Mexican immigrant women, "stable" language, including terms such as "queer" are not referent categories of identities for some populations. Collective consideration of feminist, queer, and racebased scholarship complicates the normativities within each discipline and makes the interlocutors localized in space and place become visible.

“Black matters are spatial matters” (McKittrick 2006, xiv), and therefore, “a systematic approach to the study of power is needed if geography and the other social sciences are serious about fleshing out the many layers of identity and racism. Discussion of race and racism in an abstracted form is preferable to some scholars, because it devalorizes a rich and often troubling historical record that varies greatly by region” (Woods 2002, 65). I argue that the justice required in starting my research cannot be done without paying attention to these legacies with deeply embedded implications that can be analyzed in the empirical chapters of the dissertation.

A necessary intervention can be seen in two recently disseminated special issues of Gender, Place, \& Culture genders and sexualities of Blackness, organized by gender and Black studies scholar Marlon Bailey and geographer Rashad Shabazz. In their introduction to the second issue they argue, "Studies of black gender and sexual geographies bring forth a better understanding of the quotidian constraints that black gender and sexual minorities confront and how those constraints necessitate transformative spatial relations and practices” (Bailey and Shabazz 2014, 450). 
Moreover, the legacy of racism-sexism produces Black women as unknowable figures in the production of space (McKittrick 2006).

\section{Engaging intersectionality}

One useful approach to examining Black gender and sexual geographies is through intersectionality. In the current section, I will discuss the ways that intersectionality has been theorized as a tool for critically examining race and difference. In doing so, I will address the variance of arguments and usages for intersectional analyses. Further, I will communicate the usefulness of intersectionality in geography. Finally, I will articulate the possibilities for understanding the theoretical opportunities for the use of intersectionality in the current research agenda.

\section{Intersectionality in critical race studies}

Intersectionality came about as a critical theoretical framework to handle colorblindness in feminist and anti-racist practices, birthed out of critical race studies. The initiation of intersectionality as a theoretical tool came from legal scholar Kimberle Crenshaw in her arguments of the reasons that black women could not be considered equal to white women because of their different lived experiences. She argues that race is a social construction but insists that the consequences of racialization processes are real and of great importance to understanding gendered experiences. Crenshaw (1991) looks at the complexities of violence against women, specifically as it relates to women of color and the issues of identity politics and necessity of intersectionality for these women's considerations when looking at gender, race, and other identities. She uses two 
categories of intersectionality - structural and political - to further explain her dispositions. Intersectionality represents for considerations of multiple dimensions of experience based on one’s social location. Patricia Hill Collins (2008) suggests that while Crenshaw is the known initiator of the term intersectionality and its trend as a theoretical tool, black women sociologists have long discussed the mutually constructive systems of gender, race, and class. Hill Collins utilized a similar framework to pursue her treatise on black feminist theory. The intersectionality framework has been particularly noted in the critical race studies of institutions - such as labor, welfare, prisons, and education.

\section{Key elements of intersectionality}

Intersectionality is about creating representation within feminist and anti-racist scholarship that is otherwise peripherally considered or made invisible within gender and race practices. A key element of intersectional is to create an initial and persistent understanding of socio-structural difference. An acknowledgement of the limitations of a particular social location becomes the opening opportunity to give regard to a social location and delineate the historicized differences in identity that create a unique experience for an individual or politicized group of people. Intersectionality denotes that experience is shaped by the way that race and gender interact and create a multidimensional experience for a particular person and, at times, a group of people. At the inception of intersectionality, Crenshaw was focused more specifically on black women and the impact that attention to multidimensional analyses of black women's identity can inform about structures' impacts on certain feminist interventions, in her case 
in the differing lived experiences of women who are victims of domestic violence (Crenshaw 1991). Another key element of intersectionality is the ways that overlapping and mutually exclusive marginalities that serve to impact the ways individuals and/or groups experience the sociocultural world. For Crenshaw, black women and other women of color who are victims of domestic violence have different needs in regards to feminist interventions because of the history of oppressions within each identity that collude to formulate a differing individual experience and need. Finally, Crenshaw notes that “...delineating difference need not be the power of domination; it can instead be the source of social empowerment and reconstruction” (Crenshaw 1991, 1242). Therefore, a final crucial element of intersectionality involves advancing the practices of feminist and anti-racist work.

\section{Critiquing a theoretical model}

Over the past two decades, intersectionality has evolved into a mainstream method of theorizing of difference. It gained intense popularity because of its aforementioned mediations. However, many feminist and queer scholars have noted a number of hesitancies in the usage of intersectionality as an operational framework. A notable critique involves the ways that intersectionality operates empirically is of a substantive concern (Nash 2008; Valentine 2007; Bryant \& Pini 2011; Puar 2007). Scholars note a deficiency of a clearly defined methodology for intersectionality making the contextualization of the social construction of meaning difficult to operationalize when encountering multiple intersectionalities and interlocking systems of oppression. 
A second critique of intersectionality has been what Jennifer Nash calls "the use of black women as prototypical intersectional subjects” (Nash 2008, 4). Scholars who have interest in theorizing difference may not be able to comprehend and/or fully analyze the theoretical reliance on black women's experiences that have been foregrounded in the use of the theoretical framework (Nash 2008). Further, the theory is intended to speak to multiple marginalities; however, scholars notate that race and gender are heralded while other identities - such as nation, sexuality, and ability - are not given the consideration necessary to produce encompassing knowledge about the collusion of multiple marginalities in the social world.

Scholars have also questioned how to make clear and coherent the theory of intersectionality and its cohesion of lived experiences. In other words, intersectionality as it has been framed essentializes the meaning of being black and adds to it the meaning of being woman. Adding multiple modernist notions of identity on top of each other does not produce productive knowledge because the addition of one social identity in conversation with another alters meaning and become more intensely complex and diverse experiences of self within the social world.

Finally, gendered variations in race and raced variations in gender are or have been understood through making one’s position as a subject visible in social as well as economic and political worlds. Given the changing political and economic systems, present-day contextualizations of processes of race and gender may not or are not consistent with historical representations. One provocation of the tension involves the increasing bi-/multi-raciality of racialized identities, where the axes of difference are 
more complex than intersectionality alone and without evolution can manifest in theoretical relationships.

\section{Intersectionality as scholarly intervention}

As has been explained throughout the current section, intersectionality has been highly regarded in feminist and anti-racist research over the past twenty years. Initial research utilizing intersectionality focused more heavily on the racialized experience in spite of its conceptualization of multiplicity. More contemporary conceptualizations have had a high regard for deconstructing sexualities in multiple contexts. For example, Gamson and Moon (2004) talk about the ways sexualities research has been merged with intersectionality, arguing that within queer theory, investigations of family structures, power relations and how they shape identities, collective identities, the challenges of binary systems, and investigations of religion and morality are included. Intersectionality has lent sociology the interrogation of a collectivity of identities constructed in society (race, class, gender, and sexuality) as well as providing an avenue to expose meanings within sexuality and nation. Gamson and Moon also consider the political economy of sexuality and discuss the emergence of "how sexual meanings, processes, and identities have been shaped in response to transnational institutions and globalized flows of people, capital, and information” (Gamson \& Moon 2004, 56). Indeed, the impact of

globalization has reconceptualization of intersectionality has involved moving into more global feminist considerations as well as an adaptation in sexuality studies.

Largely, scholars argue for grounding identities of race, class, gender, age, and sexuality and a recognition of the intersection of said identities while understanding the 
limitations of situational politics. Dei (2000) argues that oppression is not merely multifaceted but oppressions are effectually interrelated and compete within dominant power structures. Dei utilizes the axis of difference model to theorize and separate issues, namely the implications of: understanding oppression; understanding community and community politics; how we seek to represent ourselves through experience and subjective social practice; and for the creation of "new epistemologies" based on emotions and spiritual knowing as legitimate knowledges. Indeed, many theorizations of difference that have gone towards spiritual and affective primacies, rooted in intersectionality and its consideration of multiple dimensions of self (for example, see Morin \& Guelke 2007).

I would argue that many contemporary uses of intersectionality are less about historical, institutionalized oppressions and their effects on one's identity mediations in society and more about a multiculturalism style framework that operates to explain differences. A handful of scholars have reconceptualized ideas from intersectionality to serve for more varying theorizations of difference. Weiner and Young (2011), for example, consider theoretical articulations of queer bonds that have been previously rendered separate from sociality and are presenting a genealogy of queer theory in its already existent pronouncement of social theory within itself. They use the terms "extimacy" and "extrasectionality" to forge a clear connection to something outside of self, a bond. Extrasectionality is a re-imagining of the intersectionality concept, defining it as "the bonds formed between multiple, incommensurate positionalities, which at the limit need not be human” (Weiner \& Young 2011, 232). Puar (2007) makes a debate of the role of affect in "temporal differencing" in terms of race, gender, and sexuality. Puar 
advocates for the use of assemblage, rather than intersectionality, as a method of representational analyses because assemblage invokes a fluidity of boundaries that identity does not. Assemblages could be useful in countering hegemonic discourses and their influences without structural adherences seemingly supported by intersectionality.

\section{Engaging geographic intersectionality}

Feminist and queer geographic scholars have intentionally sought the use of intersectionality as a theoretical concept because of its usefulness in the exploration of shifting and multiple identities as they collude and interlock. Further, scholars understand the ways that intersectionality makes headway into deconstructing power, understanding the category (Bryant and Pini 2011). A key concern of geographic inquiry deals with the notion of scale. Intersectionality offers feminist and queer theorizations that interrupt hegemonic structures and deconstruct scales of power. The experiences, particularly related to structural inequalities, are made visible by the provocative value of such a framework. Intersectionality also "enables feminists to focus on the social and material aspects of women's lives without abandoning modernist categories of race, class, and gender” (Bryant \& Pini 2011, 12). Under such consideration, feminist and queer geographers are able to regard meaning-making processes within space and place.

The trend of using intersectionality as a theoretical framework has been more commonly made present in conversations within feminist and queer geographies. As intersectionality has moved, by scholars, into the topic of sexuality over the last decade, queer geographers in particular have taken on a conversation of using intersectionality in the deconstruction of queer sexual identities, landscapes, and sociospatial interactions. In 
geographic consideration, the ontologies of place become crucial concepts from which theorizations of difference become significant for geographical knowledge production.

The use of intersectionality as a theorization of the collusion of social location in geography has been limited. Moreover, as I previously mentioned, more recent usages of intersectionality have come to be more representative of difference rather than vehicles for social change, as optimistically put forth by Crenshaw. In the current section, I will cover examples of how difference is theorized under intersectional analyses that produce knowledge about the multi-dimensionality of experience.

One example of intersectional analyses of race and difference comes from Clyde Woods (2007), who uses Blues epistemologies for a "project designed to recover and expand indigenous African American forms of consciousness, social investigation, community development, and democratic governance' (Woods 2007, 49). Woods discusses Blues and Blues Knowledge as it originated a cultural, intellectual, political, social and economic movement for black peoples. Woods does not explicitly focus on gender but does implicate Blues geographies place "regional schools of working-class organic intellectuals at the centre of the production of geographical knowledge. Therefore, families, events, venues, work sites, travel, neighborhoods, households, and prisons become critical sites in the construction of theory, method, and praxis” (Woods 2007, 60). The statement supports an observation that blackness has been presented as reducible to ' measurable "facts”' (McKittrick \& Woods 2007, 6) rather than having been dealt with from a framework that explores the intricacies of lived experiences of race and racism. 
Further, Peter James Hudson (2007) narrates the experiences of British Columbia’s heralded early twentieth historical figure Joe Fortes. Hudson's discussion notes B.C.'s lack of black indigeneity when encountered with Fortes, a black man from the British West Indies. Hudson argues:

"Fortes was grafted onto a racist geography of blackness, a diaspora of white racial imagery. In this sense, the transnational circulation of white racism through the dispersal of white cultural forms like the minstrel show and Foster's plantation lullabies offers both a supplement to and a critique of the futile discussions of the nature of black Canadian identity and its possible sources by denaturalizing white Canadian identity through an inquiry into the sources of race thinking that made white Canadian identity possible” (Hudson 2007, 162; original emphasis).

The social construction of race and gender in the geography of blackness here is very apparent and Hudson argues that it is reliant on the economic, social, and structural implications of Canada's history. Burman (2007) adds to the arguments of Hudson, Woods, and McKittrick when talking about black migrant women between the Caribbean and Canada, stating "Black migrant women are among the stock figures whose spatial inbetweeness and "chaotic bodies" make their expulsion from nation-space and their reintegration equally important to the besieged authority of the host” (Burman 2007, 189). As previously noted, intersectionality has made headways into more globalized inquiries of difference, involving identities of race, gender, sexuality, nation, and class. 
Swarr and Nagar (2004) introduce and analyze two case studies that highlight the complexities of "lesbian" life in the rural Chitrakoot district of India and the Soweto township in South Africa. These accounts of the four women living in these areas problematize notions of feminism and queer theory, which are dominated by Western theorists, by taking on the issues of naming in relationships (not necessarily using the term 'lesbian'), by challenging dynamics of partnership building (particularly masculinity versus femininity), and by making disparate connections of partnership survival that counter popular contemporary notions of queer life (by not considering much about class). Swarr and Nagar utilize an analysis of intersectionality at their primary framework for looking into the complexities of the peripheral global society, making reference to the Hindu caste system and its role relevant in the community formations and socioeconomic situations in the Chitrakoot society and connecting the role of religion for spiritual development, emotional support, and a social community in relationship to Soweto social life.

Bryant and Pini (2011) utilize an intersectionality framework to outline their text on gender and rurality. Their treatise is divided such that each of their six empirical chapters focuses on the intersections of gender, rurality, and a third social construct (indigeneity, ethnicities, class, heterosexuality, disability, and aging). Their goal is to acknowledge the difficulties of dealing with difference and desire to make advances towards the production of knowledges on gender and rurality in the ways that rurality has been socioculturally theorized. 


\section{Intense intimacies}

To encapsulate these intersectional components of geography, body, and social identities enunciated through gender, race, and sexuality, I introduce the concept "intense intimacies.” As a concept, intense intimacies does three things. First, it offers a space of pedagogical representations of these intersectional components. It takes seriously the argument it "is important to realize that identity is multiply constituted and that race is not the only axis of social power in people's lives or embedded in and working through everyday cultural landscapes” (Schein 2006, 7). Second, its raw engagement of the intersections produces a consciousness about fundamental changes in relationships to place, space, and landscape, aligning with the argument that "geographic alternatives are best displayed through communicative acts—geographic expressions that cite/site underacknowledged black geographies” (McKittrick 2006, 143). Finally, it predicates the spatial encounters as entangled manifestations of bounded rebelliousness. Intense intimacies maps the figures and pains of Black space and utilizes spatial politics and forms to reconstitute and produce co-constituted, interconnected, intersectional spatial bodies that are raced, gendered, and queered.

\section{Methods and reflections}

In a critique of Western imperialism’s impact on indigenous research projects, Linda Tuhiwai Smith (2012) argues that every aspect of the production of knowledge must be understood in order for decolonization of research to occur. In pursuing geographic projects, the validity of "research" and "method” are brought into question when a researcher is interested in population and region-based narratives that do not 
constitute traditional approaches to geography and geographic knowledge. Likewise, questions about representation, benchmarks, and quantifiable measures are often posed in an effort to understand where and how a project "fits" into the discipline. The section highlights the approaches I used to conduct qualitative geographic research. Following the methods description, I offer reflection on my experiences. In my reflection, I pose the following questions: 1) What constitutes "good” geographic research? 2) How do power structures in the discipline inform and terminate the possibilities of queer Black geographies? and 3) What are alternatives to hegemonic knowledge production systems when considering race, class, gender, sexuality, and region in the research process?

\section{The research experience}

The dissertation project formally began in 2010. Entering the second semester of the graduate program, I became rather frustrated with the perceptions about the lives and experiences of Black Southern lesbian, gay, bisexual, transgender, and queer people. Rather impulsively, I presented a theoretical musing at the UM/FIU Queer and Transgender Student Symposium that took to task what I termed at the time the “invisibility” of queer people of color in the rural United States. One year later, I completed a mini-project for a qualitative methods course that involved the role of technology in queer women's community and identity formation processes by doing a netnography of the queer social networking website DowneLink. Though broadly cast, the project provided important critical analyses of place and life for the women I interviewed virtually. 
The dissertation is supplemented by data collected through a diversity of research methods. The central component of the research was the semi-structured interview process. Other methodologies include discourse analysis of digital and print materials, informal conversations in the community, participant observation, and auto-ethnography. In the proposal phase of the dissertation, I had not intended to do anything close to autoethnography. However, as a Black feminist geographer, it was imperative that I resist the "easiness" of objectivity by incorporating my personal life and experiences into the current project. I am, after all, one of the women of the region, and I carry the identity of a Black queer Western North Carolinian with me everywhere I go. Kobayashi and Peake argue, "Geographers of color can provide (although they are not necessarily obligated to do so) a personal perspective on their own communities, and can link meaningful research to activism in ways that can often only be achieved as community members” (Peake and Kobayashi 2002, 52). My identity is a basis of the current project. The project, as a Black feminist endeavor, reinforces the assertion that "geography and black women have always functioned together and that this interrelated process is a new way to 'enter' into space (conceptually and materially), one that uncovers a geographic story predicated on an ongoing struggle (to assert humanness and more humanly workable geographies)” (McKittrick 2006, xxiv). Therefore, I use my gender and sexual identity as well as my upbringing to inform certain reflections in the current project as well as an opportunity to find ways to assert integral ways of producing knowledge.

Initially, I had planned to conduct the research in four distinct phases, with each subsequent phase building on the foundation of the previous one in order to create a linear-style process. However, it became apparent that the project would follow a more 
circular methodology, where the past, present, and future colluded simultaneously and inextricably. The project, then, owes its theoretical and methodological foundations to Black geographies and Black feminist thought. Black feminist geographer Katherine McKittrick argues, "Black matters are spatial matters. And while we produce, know, and negotiate space—albeit on different terms—geographies in the diaspora are accentuated by racist paradigms of the past and their ongoing hierarchical patterns” (McKittrick 2006, xii). All bodies and places are texts. The ways they enter and exit are crucially important.

\section{*Informal interactions}

In the fieldwork period of the research experience, informal interactions consisted of general email and in-person conversations I had with community members. During my first visit to Western NC as a researcher, I started in Asheville by scheduling a meeting with the Executive Director of the budding grassroots organization, Campaign for Southern Equality. I used the opportunity of meeting with her to understand the "big picture” of Western NC. As someone who grew up 60 miles from Asheville but had not spent much time there as an adult, I documented our conversation as foundational to understanding a sense of place and to build an argument for the type of intervention I desired through the research process. Additionally, I exchanged conversations with other community members as well as visitors to the mountains. These conversations were held with people primarily from Buncombe County, where Asheville is situated. The exchanges may not be quite as explicit in the writing of the dissertation as the interviews I conducted and the material culture I used for analysis. However, I did use these 
encounters to help me think about place, region, race, gender, and sexuality. One such encounter, not even experienced in North Carolina or even the South, opens Chapter III.

\section{*Observational research}

Participant observation is defined as "A fieldwork method in which the researcher studies a social group while being a part of that group” (Hay 2010, 382). Conducting research in non-urban settings produces an interesting set of challenges that is not common in urban areas, such as the lack of highly concentrated public spaces. Asheville proved to be easier to find spaces and communities for controlled observation because of its demographic concentration and resources. In conducting observational research, the simplest thing was to go to lgbq-identified spaces, which was a similar thought pattern to my initial focus on queer geographies/sexuality and space for the current project. So I did. I should assert that I recognize, and did from the beginning, that lgbq-normative spaces are often segregated or racially homogenous (see Whittier 2001, for example). However, I thought I would "give it a shot” because I considered the ways that scale comes into play in non-urban spaces. For example, the 2006 documentary Small Town

Gay Bar, filmed in Mississippi, provides evidence of an interracial, multi-gendered lgbtq community. Observation in lgbq-normative spaces, such as those documented in Small Town Gay Bar, prove to be supplemental to documented experiences of lgbtq Southerners in academic literatures, such as the edited volume Out in the South (Dews and Law 2001) and Men Like That (Howard 2001) as well as experiences documented by scholars of Black queer studies, such as Sweet Tea: Black Gay Men in the South (Johnson 2008). For example, sociologist Mignon Moore asserts, “As with other areas of social 
life, gay and lesbian communities are often racially segregated" and, therefore, require different strategies to recruitment in research (Moore 2011, 228). So I was certainly equipped with awareness. However, it was important for me to enter into lgbq-identified or "gay-friendly" spaces to understand the landscape from that particular perspective.

Over the course of two years, I visited a variety of fixed places, including "gay bars”, attended events such as Blue Ridge Pride, the annual regional festival celebrating the variances of gender and sexual identities, and enmeshed myself into the everyday during my trips to the region, including activities such as eating in area restaurants, going to the library, shopping at the local malls and Wal-Mart, and watching the local news. What I (re)discovered in doing so is gaining an understanding that the "enclave" nature of major urban centers is not the same in small towns around WNC. In other words, the visible residential concentration/segregation that forms lgbq neighborhoods in major urban areas (such as West Hollywood in southern California and Wilton Manors in South Florida) are not constitutive of WNC landscapes. Perhaps that might be an obvious conclusion; however, I want to argue that it reinforces routinized, everyday life in WNC. In other words, the communal fabric of small town Mountain South, and arguably for small towns on a global scale, rely on varying scales of kinship networks that might appear as barriers to "outsiders” but serve to protect the community and its people. Therefore, lgbq people are incorporated into the community at large rather than segregated into residential enclaves. 


\section{*Semi-structured interviews}

As previously stated, the semi-structured interview process proved quite vital to the completion of the dissertation. In fact, the interview process is the core of the dissertation project, as I discuss my participants’ personal lives in Chapters 3, 4 and 5. Iain Hay argues that in semi-structured interviews, "the questions asked in the interview are content-focused and deal with the issues or areas judged by the research to be relevant to the research question” (Hay 2010, 110). I chose to ask my research partners three basic questions that informed my research objectives. These questions are listed in the interview protocol, located in the Appendix.

Over the course of four months (May 2013-August 2013), I completed six semistructured interviews with women from locations throughout Western North Carolina. I only interviewed six women because they were the only individuals from whom I received responses to my outreach. Details about recruiting and interviewing the women are narrated in Chapters III and IV. The women interviewed for the project are profiled below. Each woman gave me permission to use her given name, which I argue is significant in three ways. First, the naming of self is a radical act, giving rise to the decolonization of the discipline. I refer to Tuhiwai Smith’s offering of research possibilities in indigenous studies. While it would be a dangerous and disrespectful assertion to equate these six women with indigeneity and its accompanying concerns, there is a power in a coalitional politic that allows for marginalized, pathologized, and peripheral communities, situated as “research subjects”, to break through the boundedness of discourse. To make reference again to Linda Tuhiwai Smith, I want to call their self-naming (and their interviews overall) an act of testimony. Tuhiwai Smith 
makes an argument for testimonies, in parallel with the notion of collective memory, as a method "for making sense of histories, of voices and representation, and of the political narrative of oppression” (Tuhiwai Smith 2012, 241). Second, the presumed "lack of anonymity” offered by using one’s given name in a research process deconstructs the situatedness of one's life. Rather, the naming of one's self in an interview situation requires attention to the lived experiences of an individual and that individual's network in the world - who she loves, who are her neighbors, with whom does she find meaning, and who she talks about. Finally, the concept of naming reminds me of the interconnectivity between the interviewees and me. In a traditional sense, we would call the process “building rapport”. However, the women did not know much about me before consenting to and showing up for an interview. Perhaps because of shared identities or perhaps because of an understanding of a broader purpose, they instilled a sense of trust in me and in the role that I was undertaking. As noted earlier, the women are profiled below:

- Stephanie is a 49-year-old stay-at-home parent and a co-founder of a non-profit performing arts collective that seeks to produce theatrical and artistic work that supports the diversity of talent in Western North Carolina. At the time of the interview, Stephanie had lived in Asheville for sixteen years and moved to the city because of a personal need for a “change of scenery”.

- Rebeca is a 27-year-old student at a regional university in a Doctor of Physical Therapy Program. She moved to the region - Cullowhee/Sylva/Jackson County in 2012. 
- Karen is a 46-year-old woman living in Hickory, which is in Burke County, North Carolina. Karen is trained as a cook and also describes herself a civil rights activist and an advocate for HIV/AIDS. She grew up in Greensboro, located in Guilford County, North Carolina. She has lived in Hickory for almost 5 years at the time of the interview.

- Nicole is a 23-year-old student, artist, and founder of a local organization in Asheville that is centered on the empowerment of Black and Latino communities and open dialogue in the greater region about issues affecting the aforementioned populations. At the time of the interview, Nicole has lived in Asheville for around nine years and had moved to the area with her mother following her parents' divorce.

- Vern is a 54-year-old substance abuse counselor and is completing her Master's in Counseling at a regional university. At the time of the interview, she had lived in Asheville for approximately ten years. She moved to North Carolina from Long Island, New York, to be with her partner.

- Tausha, 31, is the only native Western North Carolinian in the current project. She grew up in Waynesville and currently lives in Canton, both in Haywood County. She works at a domestic violence shelter and helps run a local community center.

\section{Reflections in research}

Conducting a Black queer geographic project is difficult. Black queer studies is an increasingly "hot” topic in contemporary academia. Queer geographies as a body of scholarship has also maintained some popularity in the discipline. In fact, research on 
sexuality has grown exponentially across multiple disciplines, even sparking name changes in women's and gender studies departments around the United States to include sexuality in the program name. The focus on what it means to do a disciplinary intervention by asserting Black queer geographies is an important academic interruption to traditional queer geographies and sexuality and space, a point that I made earlier in the current chapter. In the remainder of the current section, I offer a few reflections on my experiences in the research process, which includes my experiences presenting the work in public spaces in the months that have led up to the completion of the writing process. I have actually been hesitant, and perhaps afraid, to conduct and present the current body of work. As I stated earlier, the current project stems from a personal space. Moreover, I am concerned about how well I can renarrate the interviews and other experiences that highlight hindrances and complexities but do not diminish the beauty of everyday lives. But, as E. Patrick Johnson said to me once, "If not you, then who?" In the grand picture of my career so far as a scholar, I have found that my work and ideas have been pretty well received. My conference presentations have gone well. My lectures have resonated with people, perhaps because I talk so openly about human life and experiences. Additionally, though, I've encountered stoic faces, rapid fire questioning, and notes being passed between audience members when I have presented my work outside of my institution. One of the first outcomes of my work came in the form of a conference paper that stemmed from an early iteration of Chapter IV and dealt with the issues involved in the racialization processes of three of the women I interviewed. I chose these three specifically because they all happened to live in the 
same mountain oasis called Asheville. After one presentation of the work, I was asked the question “How many Black lesbians do you think live in Asheville?”

I do not look at the body as an object of sexual relations or a representation of sexual relations. Rather, I look at what they can tell us about place because of their experiences. They are one component of the story of place. When I am asked to quantify the number of Black lesbians in Asheville, it confuses me. My project is not merely about finding and enumerating Black lesbians in Asheville or Hickory or Waynesville or Canton or Cullowhee (which are all affiliations that my participants represent). I cannot simply go to the "gayborhood" and ask for Black folks, even though Asheville has a very visible (and very white) lgbtq population. Rather, the point of the research is to destabilize the assumed stabilities of place and bodies. Doing Black queer research is nuanced by the presence of multiple and contesting identities that impact one's lived experience and how these experiences are placed in connection to their environments. As McKittrick argues: "In examining how identity and place are mutually constructed and how the psyche, or mind, is interpolated by place, race, gender and class...bodies and minds disrupt the meaning of geographical scale, and how black female subjectivities disrupt and foster seemingly stagnant places and scales through specificity, interpretation and lived experiences” (McKittrick 2000, 126).

A second question posed to me went along the lines of, "You only interviewed three people? How can you say this is representative of anything?” I had given an introduction at the beginning of the talk to indicate I would be doing a case study based on three of the interviews that I had conducted. I grouped the interviews together because three of the women I interviewed happened to live in the same place and they 
could tell a specific spatial story that was antithetical to the ways Asheville is popularly discursively spatialized. Rather, the research closely examines the lives of a specific set of people to propose a different understanding of place.

I would now like to turn to the questions I posed for myself at the beginning of the current section. The U.S. based professional association for the discipline describes geography as: "the only subject that asks you to look at the world and try to make sense of it. The field never stops being exciting because that's what geography is all about trying to make sense of the world" (AAG 2014, n.p.). They continue by stating, "You want to understand the world. Why not start with a river, a city, a mountain, a village, a road, and follow it to the ends of the earth? Geography asks the big questions — Where? How? Why? What if? — and gives you the perspective to answer them with advanced technology and a solid knowledge of the world in which we all live. (AAG 2014, n.p.) If I am indeed looking at the world and trying to make sense of it, asking big questions, and using a geographic perspective to search for the answers, then how does the current project measure up to "good" research?

How do power structures in the discipline inform and terminate the possibilities of queer Black geographies? Power structures maintain an essentialist, noncontextual dominance of typical Western understanding. Tuhiwai Smith critiques Western research and the idea of Western science, fraught with imperialist understandings, presumptions, and assumptions. Referencing the now late cultural theorist, Tuhiwai Smith states "Stuart Hall makes the point that the West is an idea or concept...[that] functions in ways which (1) allow 'us' to characterize and classify societies into categories, (2) condense complex images of other societies through a system of representation, (3) provide a standard model 
of comparison, and (4) provide criteria of evaluation against which other societies can be ranked” (Tuhiwai Smith 2012, 42, original emphasis). The system of classification noted by Tuhiwai Smith leads to a fragmentation of indigenous peoples. The conceptualization of colonization is also intimately connected to racialized discourses that exist to rationalize difference. These racialized discourses intersect in multifarious ways with gender, rationalizing the roles of women into a patriarchal system. These discourses of race and gender also served to objectify indigenous women and construed their representations. Tuhiwai Smith describes the concept of the individual as the basic unit for the building of societies, connected to ideas of human nature. She also problematizes the romanticism involved in describing some indigenous peoples, regarding them as 'noble savages’ (the author references notations of women of the South Pacific as an example) (Tuhiwai Smith 2012, 49). Though I am not focused on a people indigenous to a land, as Tuhiwai Smith, I am focusing on a people who have been displaced because of colonialism, taken from the African continent, enslaved, and dealing with the residual effects of the colonial project. These residual effects tell unique and complex stories of place. Unfortunately for the person who asked me the first question, their stories cannot be reduced to a static identity that I can quantify with a regulatory box - Black lesbian.

Now, I move to my final question: what are alternatives to hegemonic knowledge production systems when considering race, class, gender, sexuality, and region in the research process? It is a good question, and I do not have all the answers. I hope to pursue answers to the question as the current research moves into different trajectories and spaces of knowledge production. There is certainly ample opportunity to explore as, to my knowledge, there are only two people doing U.S. Black queer women’s 
geographies. One of them is me. My colleague and I find ourselves trying to working through making research an opportunity for an intervention in existing knowledge and presenting new knowledges or showing different ways that knowledges can be produced or co-produced. Howitt and Stevens argue that decolonizing research requires using "the research process and research findings to break down the cross-cultural discourses, asymmetrical power relationships, representations, and political, economic, and social structures through which colonialism and neo-colonialism are constructed and contained" (Howitt and Stevens 2006, 42). So that, I suppose, should be the starting point. 


\section{CHAPTER III}

\section{CALL-AND-RESPONSE: THINKING "PROGRESS"}

"Do you think the South will ever progress?”

In the wood paneled seminar room with its grand stained glass windows beaming brilliant glows across attentive faces, a young woman of color peeked her head up from the back row. If I had to assume, she was roughly 20 years of age. Her gender presentation and the rainbow sticker on her cheek led me to make another assumption, that she embodied queer sexual and gender identities. Had she lived in the North Carolina Mountains, I would have tried to interview her for my dissertation.

I hesitated when she posed the question, not quite sure how to respond to her provocation. I had just finished giving a lecture about early iterations of my dissertation research analyses, particularly surrounding the implications of race and racism in the lives of the women I interviewed. ${ }^{1}$ In spite of my best efforts to contextualize the South and Southern culture in the New England seminar space where I found myself standing at a lectern and in spite of casting sexual identities as fluid and not always derived from urban inventions, I seemed to have missed a necessary connection with the young woman.

The chapter is entitled “Call-and-Response” because of the metaphorical way I interpreted the relationship between the young woman described above and me as well as

\footnotetext{
${ }^{1}$ The lecture I delivered was comprised of analyses of interview data, discussed primarily in Chapters IV and V of the dissertation.
} 
the academic canon of sexuality/queer studies, more broadly, to me. Rooted in African religious tradition, call-and-response is an interactive style of communication, common in African American and African Diasporic churches worldwide, where a worship leader or pastor will sing or shout a line to an audience. The audience is then compelled to sing or shout a response back to the worship leader or pastor. I take the young woman's question as the call and the current chapter is my response, what I intend to be a collaborative effort to broaden understandings of Southern "progress" and my active participation in the study of sexuality and space. As DJ Lynee Denise posed it in the description of her latest mix, progress is a "politically and socially charged question” (WildSeed Music 2014, n.p.). The hegemonic notions of progress that are enacted through daily ritualization of a global gay identity coupled with a discursive, bounded idea of the South limits the potential of the South and devalues the lives of its residents. In the present chapter, I argue that notions of progress are limited to public markers of sexuality. As such, the potential and realities of progress discourses are limited in scope. I argue for a more contextualized and transgressive understanding of the South, Southern politics and history, and sexualities in place. To repeat the words of Jasbir Puar, the chapter asks and proposes, “Can we keep our senses open to emergent and unknown forms of belonging, connectivity, intimacy, the unintentional and indeterminate slippages and productivities of domination, to signal a futurity of affective politics?” (Puar 2007, xxviii).

The South (broadly construed) has always been queer, if that is what meant by enunciating a term like "progress" onto the region. However, the varying ideas that come with "progress” are limited in scope, particularly in relationship to the South. Naming the South as a site of or related to "progress" has been delimited because the region has 
"been an easy repository for all that is backward and hurtful in the United States, past and present, and while the South should be accountable for its shameful past and contemporary political and social failings" however "it seems not a little disingenuous of the United States to heap all of the racism, bigotry, and ignorance of an entire nation upon one region” (Law 2001, 3). If by “progress” one means the legal regulations of lives, then the idea of progress is severely anti-South, as the region is largely pro-states rights and anti-government. If the enactment of progress is limited to state and federal political change, then Southern "progress" remains to be seen. If "progress" is an affective measure, do people really need government to be happy? If that is the case, then it delegitimizes the general life satisfaction, exempt from state and national bodily regulation, that lgbq couples have been experiencing in the South for decades. The South as a region, however, has its identity defined in its relationship to "Others". Or rather, the South is defined as the "Other". The processes and outcomes of "Othering" are universalized without context.

For the current chapter, I will consider two notions of what would be deemed progress. The first idea I consider concerns the ways that progress is that which is connected to the gay, lesbian, bisexual, transgender, and queer civil rights movement. The second is the notion of progress as the enactment of agency, which provides an opportunity to stake claim to the land - a particularly powerful notion for people of African descent. I map these varying - and overlapping - scales of progress in order to counteract the narrative that the region is discursively "standing still". In the first section of the chapter, I use a series of emails as objects of analysis, which are considered against three thematic considerations: (1) framing "the South"; (2) framing "equality"; and (3) 
approaching "equality" in "the South”. In the second section of the chapter, I utilize the information provided by three of the six women who participated in the semi-structured interview process.

\section{Public sexuality: The marker of progress}

I grew up in North Carolina. I was educated there and consider myself to be a proud North Carolinian. The personalized license plate from the first vehicle I ever purchased is proudly displayed in my office at the University of Connecticut, where I am completing a dissertation year fellowship. On all standard license plates issued by the state of North Carolina reads the slogan "First In Flight”, immediately making reference to the Wright Brothers' historic airplane flight at Kitty Hawk, North Carolina. However, the slogan has taken on many manifestations amongst the state’s residents and historians. Indeed, I internalized the motto as a way to denote my state pride. North Carolina boasts outstanding natural resources, diverse industries, some of the best institutions of higher education in the country, and serves thriving tourism and retirement markets. It has also been one of the states that has, overall, been politically moderate in the last three or four decades. That is, until recently. In May 2012, North Carolina voters passed an initiative known as Amendment One that has now made the recognition of same-sex marriages and civil unions unconstitutional, expanding on the state-ordained definition of marriage already in place - that being between one man and one woman. Further, it criminalized individuals who attempted to officiate a same-sex union. The present section provides an understanding of the South’s connection to the gay and lesbian civil rights movement by exhibiting the spatial representations of queer geographies that are connected to the ways 
in which progress has become prominently conceptualized. In doing so, I offer a description of the Campaign for Southern Equality (CSE), its work, and its impacts. In analyzing their work, I provide discourse analysis of newsletters periodically emailed to individuals who subscribe to the listserv via the organization's website. While I embody and propose a critical stance to the work and discourses put forth by CSE, the critique of CSE is not the focus of the current section. My standpoint will be written more fully in a separate publication. Rather, I am interested in provoking a conversation about the labor of sexuality through CSE's work.

I was introduced to my informant Stephanie when I began circulating a call for interviews through various individuals and agencies in Western North Carolina. I emailed the Reverend Aubra Love, who was the Executive Director of Building Bridges of Asheville. Building Bridges is an organization in Western North Carolina whose mission "is to enable our community to confront and overcome racism through a continuing process of changing attitudes and hearts through education, consciousness raising, nurturing, and ongoing support. Our goal is to be intentional in respecting diversity within our community” (Building Bridges Asheville 2014). They provide regular seminars that serve as "an introduction to the dynamics of racism and is an opportunity to explore how race has impacted our relationships, communities and institutions” (Building Bridges Asheville 2014) which are open to the public and provide continuing education credits for educators and clergy. In an email exchange, Reverend Love suggested that I contact Reverend Jasmine Beach-Ferrara at the Campaign for Southern Equality and Stephanie Hickling Beckman at Different Strokes Performing Arts Collective. I responded to Reverend Love with a note of gratitude and informed her that 
I had contacted Reverend Beach Ferrara in 2012. I emailed Stephanie, informing her that Reverend Love suggested that I forward her my call for participants and requested that she let me know if she could connect me with individuals to interview. Stephanie responded to me, stating that she would be glad to speak with me as participant in my research. After exchanging a few emails, we settled on meeting in Asheville at a date and time in early May.

Stephanie's interview was particularly important for me because it was the first formal interview for the current project. There were fifteen days between our initial contact and the actual date of our meeting. I was particularly nervous as the day approached. I wondered if I was prepared enough as a researcher, to solicit stories from the women I was attempting to recruit. Even more, I wondered if I would be able to capture their lives and experiences through writing and analysis that was grounded in maintaining their integrity and humanity. As I prepared to interview Stephanie, I reviewed no less than twenty times the interview protocol I had created. I meticulously packed an expanding file folder complete with five copies of the protocol, a journal for taking notes during the interview, a couple of ink pens, a digital recorder, an unopened pack of batteries for the recorder, and fifteen copies of the cover letter to be given to each participant, describing the details of the project, approval by and contact information for the Institutional Review Board at FIU, and the contact information for my dissertation advisor.

I interviewed Stephanie on a muggy, overcast afternoon in Asheville. We met at the Women's Wellness and Education Center. I arrived at the Center thirty minutes before our interview (scheduled for $2 \mathrm{pm}$ ). I parked on the street facing towards the 
Center but intentionally positioned my vehicle a few spaces back. I wanted to have the time to prepare for the interview in my car without being seen by anyone who might be in the Center who might wonder about the random person sitting outside in her car. My vehicular position happened to give me the perfect opportunity to see a woman pull up in a black jeep with an identifier on the vehicle alluding to an interest in the performing arts. I immediately assumed the woman who exited the jeep - wearing blue jeans, a black shirt, and black boots and with her hair in locs - was Stephanie. I let a few minutes pass before I approached the front door of the building, giving both of us time to prepare for the hour ahead.

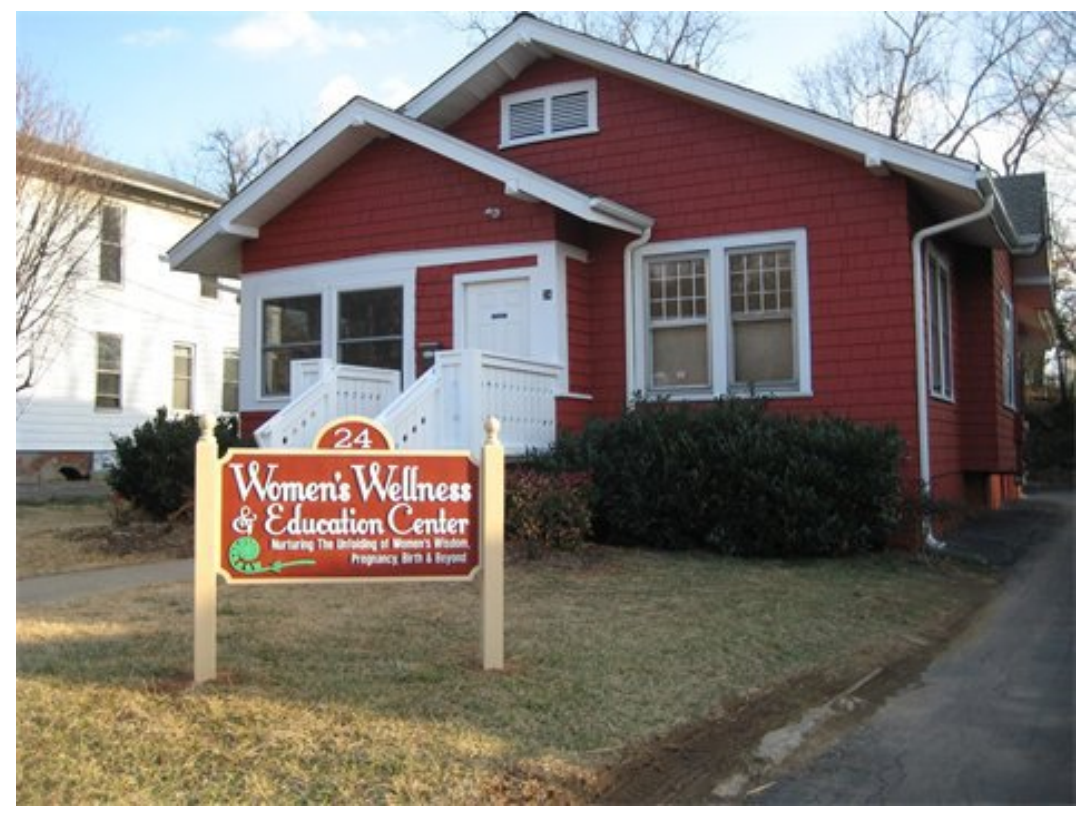

Figure 2. The Women’s Wellness \& Education Center, Asheville, Retrieved 2014.

When I entered the Center, Stephanie greeted me and invited me to have a seat in the foyer area. She told me that there was a massage session going on in the back of the 
building but that we should be undisturbed in the front entrance area. The room was well lit because of four prominently placed windows, two of which are on the left in the photo above, that allowed for the Carolina skies to set the ambiance. The walls and tables in the foyer were covered with literature and news stories related to the work of the Center. I learned early on in our conversation that Stephanie's wife Trish is a co-founder of the Center and that the Center operates as "a collective of expert health professionals committed to creating a community that nurtures and empowers all women and their families through the childbearing years and beyond" (Women's Wellness and Education Center 2014).

In my interview with Stephanie, she talked about how she came to found Different Strokes Performing Arts Collective:

[M]y dream has always been to be part of an ensemble kind of theatre company. And I've been putting that off and putting that off. And then realizing that as a black person, as a person of color rather in this particular population, and wanting to act knowing that I have skills but I couldn't get on stage because they couldn't match me up. There wasn't another black man or black family to identify to match me up with on stage. So, you know saying we're doing this colorblind casting and then not. When I would get cast it would be in roles that weren't really related to the other characters in any way...the other calls that I would get would be to play a maid or some kind of other subservient role. So I started this boycott and the other black actresses in town that I knew... you know we talked and they're like "We're not doing any of it either. You're not doing, we're not doing it." So it started this big boycott. So then that made them have to not be able to do black plays or black roles in white plays. So the next step from that was my mom said, "Stop complaining about it. Do something about it." And then Trish said, "Let's start the theatre company". So we started Different Strokes, and Different Strokes is primarily meant to diversify the performing arts, to get more color on the stages. 
As we continued in our conversation, Stephanie discussed her organization’s commitment to supporting the work in the local community. She stated, "[W]e take all of our shows, and we tie them to a cause in town. And $20 \%$ of what we make in ticket sales, we donate to that agency...we're a true community theatre.” She went on to state that the nonprofit beneficiary of proceeds from her company's 2012 production of Romeo Loves Juliet was the Campaign for Southern Equality.

\section{CAMPAIGN FOR SOUTHERN EQUALITY} If you have lived as an LGBT person in the South, you have more than enough strength to change the laws of this country." - Rev. Jasmine Beach-Ferrara

Figure 3. Banner graphic, Campaign for Southern Equality Website

The Campaign for Southern Equality (CSE) is an organization headquartered in Asheville, North Carolina, that "is a national effort to assert the full humanity and equality of lesbian, gay, bisexual and transgender people in American life and to increase public support for LGBT rights” in the South (Campaign for Southern Equality 2014). The organization has solidified its position as one of the most recognizable lgbtq organizations. The organization claims the South receives less than $5 \%$ of national lgbtq organizational funding because of the assumption that there is no reason to organize or make a presence in the South in regards to lgbtq rights - that the South will "never change”. The Campaign for Southern Equality launched in 2011 out of a partnership with the Massachusetts-based Progressive Project. The Campaign for Southern Equality operates with an official staff, an advisory board, and a board of directors. As of 2014, 
the CSE staff boasted 4 people, including an executive director, a communications coordinator, and a field organizer, and an intern in addition to their team of volunteers. The advisory board is comprised of six people who herald from various places around North and South Carolina as well as Massachusetts and Missouri. CSE conducts a variety of initiatives aimed at advancing lgbt civil rights in Southern states. On the organization's website is a detailed outline of their standpoint and mission:

\section{A New Approach:}

Across the South, LGBT people lack basic legal protections, face robust opposition to our rights and have limited resources for advocacy. LGBT people in our region are also at an elevated risk of poverty. Beyond this, the South receives less than five percent of the total annual funding that goes to LGBT organizations nationally. Factors like this contribute to the commonly held belief that the South is "unwinnable" when it comes to LGBT rights.

But we hold a different view and feel deeply hopeful about what's possible in the South.

1) We believe there is a pressing need for advocacy, legal and crisis response services for LGBT people in the South.

2) We believe that federal equality is the most efficient and effective pathway to equality for LGBT people in the South. We also believe LGBT people and allies in the South are uniquely positioned to accelerate winning full equality on the federal level by directly resisting discriminatory laws and systems.

3) We believe that every person - including those conflicted about or opposed to LGBT rights - can become an ally.

As a result, we're taking a new approach, building upon a rich legacy of civil rights organizing in the South and working in close partnership with other LGBT and civil rights groups.

Mission:

Based in the South, the Campaign for Southern Equality is a national effort to assert the full humanity and equality of lesbian, gay, bisexual and transgender people in American life and to increase public support for LGBT rights. 


\section{Ethical Basis:}

CSE's work is based upon empathic resistance, a new ethic which calls for 1) resisting persecuting systems by expressing the authentic self; and 2) approaching those who oppose your rights with empathy. (Campaign for Southern Equality, 2014)

I joined the e-mail list for the CSE on July 24, 2011, not long after I learned of its existence. In the first email I received from the organization, entitled "Full Speed Ahead”, CSE’s Executive Director Rev. Jasmine Beach-Ferrara writes²:

In December 2010, the NC State Supreme Court issued a ruling, Boseman v. Jarrell, that banned second parent adoptions for same-sex couples. In June 2011, the US Census released data showing that same-sex couples are one of the fastest growing groups in our state and that approximately 25\% of same-sex couples in NC are raising children. In September, the NC State Legislature will gather in a special session to discuss proposed amendments to our state constitution, including SB 106/HB 77, the anti-gay amendment that would ban the recognition of same-sex relationships.

On the other side of these facts is a human reality: a person or family whose fundamental rights and humanity are being denied by our state. Such injustice is a way of life here, and as a gay person who grew up in North Carolina, it was something I learned to live with. The message I heard, both implicitly and explicitly, was that inequality was the cost of staying "safe."

But submitting to an unjust system is a slippery, dangerous slope. It taxes the spirit. It insists that we conduct our daily lives with a vigilance that can be exhausting. It asks us to accept in both subtle and overt ways that we are less than our neighbors, our family, our friends. One can only do this for so long.

My faith, and the lessons of history, have taught me that a dark seam lies at the heart of any status quo which asks people to submit to injustice. There comes a time when it must be both exposed and excised. We have reached such a time in North Carolina and across the South, where we face laws that ban second parent adoption and marriage equality and laws that fail to protect LGBT people from

\footnotetext{
${ }^{2}$ Rev. Beach-Ferrara wrote most of CSE's emails. Occasionally, another staff member would pen the correspondence. In the remainder of the discussion, I conceptualize the emails as CSE's versus Rev. Beach-Ferrara's.
} 
discrimination in the areas of employment and housing. These laws are all unjust because they deny a fundamental moral truth: LGBT people are fully equal.

This truth is the core premise of CSE's work. To act from this premise means to resist unjust laws, not to comply with them. To act from this premise means to disrupt a status quo that tells LGBT people in the South to just be patient as we wait for a federal court ruling that will grant us rights, that tells us to be grateful that things aren't worse than they are.

I feel such hope about achieving equality for two reasons. First, we are acting from a clear, moral truth and we are on the side of love. Second, each day I meet LGBT people and allies who are living with courage, resilience and authenticity. People who know that the truths we hold in our hearts and spirits sometimes transcend the letter of the law. ("Full Speed Ahead", 7/25/11)

In the following three subsections, I discuss emails sent from July 25, 2011 through July 18, 2013 (roughly “the end” of my fieldwork stage). Through , I propose a broader conceptualization of "progress" in the South that connects the activities and language of “equality” to which the young woman who opens the current chapter might find herself more connected.

\section{CSE framing the South}

Rev. Beach-Ferrara immediately identifies one of her articulations of the South, by opening up with a story about North Carolina. Throughout the two years of emails examined for the dissertation, CSE represents the South by naming the following states as representative of their goals, in varying ways: North Carolina, South Carolina, Georgia, Alabama, Mississippi, Virginia, and Tennessee. Moreover, CSE emails contain references to specific locations and towns around the South - Asheville, N.C., Wilson, N.C., Greenville, S.C., Hattiesburg, M.S., Mobile, A.L., Henderson County, N.C., and Arlington, Virginia. Moreover, CSE asserts that there is a border to the South, which 
ends when one can cross into a place of “equality”: “During tomorrow’s action, 16 LGBT couples from across the South will apply for marriage license in Arlington, Virginia, knowing they will be denied. Then we will begin a 4.5 mile march into Washington, D.C., ending at the Jefferson Memorial for a blessing of the legal marriage under D.C. law of one couple from North Carolina, Mark and Tim....If you are a LGBT person in the South, you must travel all the way to our nation's capital before you become equal under the law” ("Marching toward equality”, 01/16/2013). They allude to the border-crossing perspective again in an email one week later: "When I heard [President Obama] say the words 'our gay brothers and sisters,' images of the past few weeks flooded my mind. I thought about standing alongside LGBT friends in Mississippi, Alabama, Georgia, Tennessee, South and North Carolina, and Virginia this past month, as we called for federal equality and humanity in town squares across the South. I thought about marching with many of you from Virginia into D.C. this past Thursday on the final day of Stage 4 [of the WE DO Campaign]. About how we crossed into our nation's capital and, in that instant, became equal citizens under the law, a status that you feel in your bones and yet that dissolves as soon as you recross the border into the South" ("From Stonewall to the South”, 01/23/2103). Aside from the naming of specific sites that represent Southern spaces, CSE names varying participants in its programs. Most of the naming comes from the WE DO Campaign emails, when CSE provides the names of the couples who will participate in their actions: “The first couple to request - and be denied - a [marriage] license was Rev. Kathryn Cartledge and Elizabeth Eve” (“WE DO Campaign”, 10/10/2011). In doing so, they are abiding in the mission to "assert the full humanity" of their constituents. 
CSE's emails also serve to frame the South in regards to the significance of family and kinship networks (which would include relationships to community, including friends and neighbors). The opening section of the email describes the judicial issues around second parent adoptions for same-sex families. Naturally, it is intriguing to think about family formation in the nuclear, two-parent sense when the reality is many Southern families, particularly those I grew up around, have operated on a communal family structure that incorporates extended relatives into everyday familial operations. The Southern families I grew up around and have met over the years have typically lived on the same land for generations or maintain residence in close proximity. My own paternal aunt actually maintains the same area of land that my grandmother owned and, to my knowledge, family members owned before her. My father felt a particular urge to taking care of the land, even after she transitioned in 1990. Though my father transitioned nearly 10 years ago and my paternal relatives are spread throughout the Carolinas, Georgia, D.C., and Maryland, they recognize the sanctity of family and family for us is represented in the land. Moreover, as I will discuss in 3.1c, the communal nature of these networks is significant when thinking about CSE's approach to the South.

Finally, CSE frames the South around the enactment of faith. While I discuss the connections to faith in more depth in Chapter 5, it is important to note that faith, morality, and religion are significant characteristics of Southern identity, or the identity of the South. Religion and the South are almost inextricably linked, in spite of the increased secularization of the United States. Discourses of faith are built into political, social, family, and personal life in ways that would be peculiar (or, if I may, queer) and probably overwhelming to individuals from other regions of the United States. The deeply 
heralded standpoint of Christianity in the South is embedded into Southern landscapes from billboards with messages from God to church steeples emerging frequently against Southern skies to the Ten Commandments being displayed at state government facilities. CSE's office is headquartered on the lower floor of a church in Asheville. Many of their programs - legal clinics, trainings, and meetings - have been held in church spaces. CSE's events, such as those affiliated with their We DO Campaign, have often been supported by and included clergy as integral players in validating and pushing their agenda forward, as documented in the photo below from a CSE march.

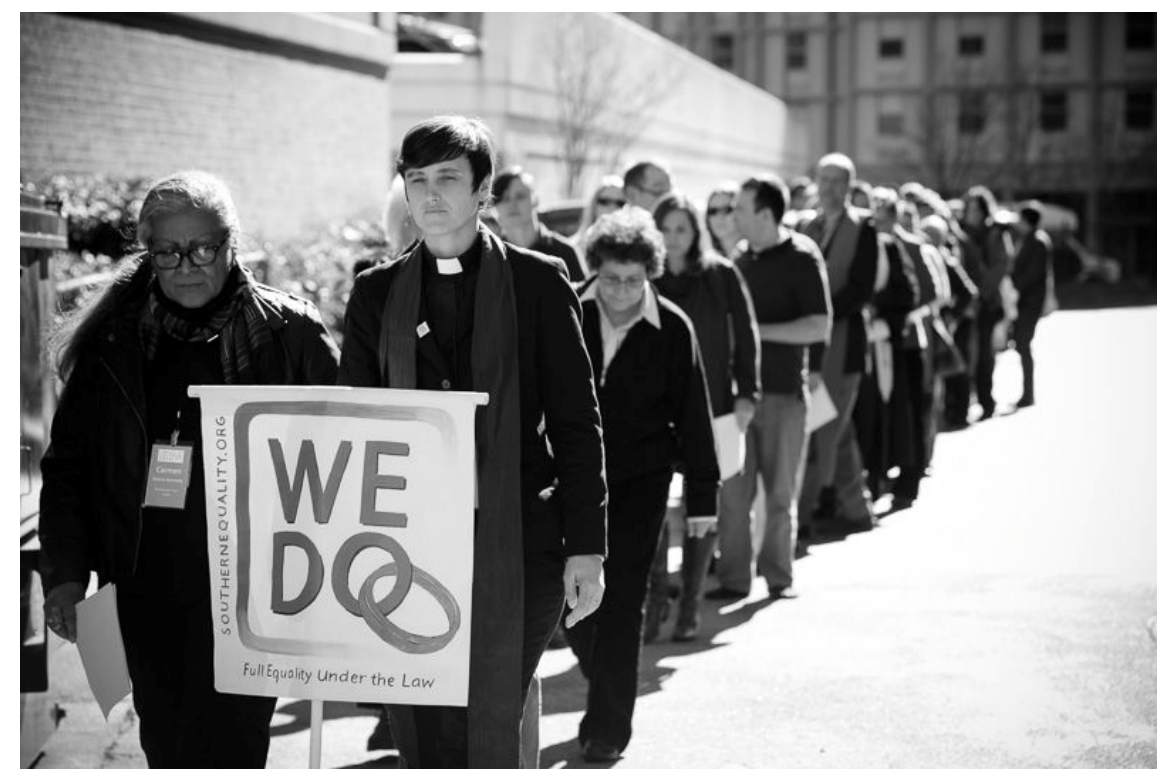

Figure 4. Campaign for Southern Equality We DO Campaign March

The labor of sexuality cannot be taken lightly, particularly because there is no singular way to do sexuality or inhabit the space and identity of queer. But rather, there are multiple angles from which to view the idea of progress in terms of lgbtq civil rights. Understanding and thinking through place is crucial for understanding Southern 
"progress" under the terms of civil rights and for providing a framework from which to act more effectively. CSE's important contribution is to provide a vessel for public solidarity in a stand against state-ordained discrimination against the sexual lives of people. Though CSE largely deals with the legal and structural implications of LGBTQ life, through a standpoint of civil rights that grant full humanity under the law, there remain issues. The trouble with an idea of progress is its association with LGBTQ equality. That equality most frequently manifests as a fight for same-sex marriage rights. However, there are other standpoints from which to view progress and its spatial enactments. The South is positioned as a prime example.

\section{CSE framing equality}

The Campaign for Southern Equality speaks to a narrative of "equality” with regard to the relationship between the people and local, state, and federal government. One of CSE's concerns, then, is that Southern lgbt folks need to rely on government regulation, which of course comes with a substantial number of government-controlled benefits, for the betterment of their lives. To find evidence of the concern, I revisit the full-length email “Full Speed Ahead”, posted above, as CSE discusses inequality as legal spatial activities "that ban second parent adoption and marriage equality and laws that protect LGBT people from discrimination in the areas of employment and housing” (“Full Speed Ahead”, 07/25/2011). They repeat similar sentiment 18 months later when discussing the end of Stage 4 of the WE Do Campaign, expressing hope for "achieving full federal equality for LGBT people in all spheres of life - employment, housing, health care, family rights and relationship recognition” (“From Stonewall to the South”, 
01/23/2013). Therefore, the contextualization CSE makes for equality is to mark these specific legal matters as the benchmarks. Moreover, CSE frames equality as a dichotomous entity, whose counterpart is inequality. In one of their emails, CSE also creates the dichotomy of "us vs. them" by analogizing those who "stand in the way" of equality and its accompanying benchmarks as "a dynasty": "I like rooting for the underdogs, and I like being one because it’s so much more compelling than being a dynasty, especially when - as in this case - they dynasty in question is in the business of fueling bigotry and restricting the civil rights of a minority group” (“A Season of Action”, 08/23/2011). In a similar vein, CSE functionally proposes that equality is where law and humanity equate. In talking about the couples who have participated in the WE DO Campaign, they express that each couple "did precisely the thing that LGBTQ people are told our entire lives to never, ever do: express our full humanity by directly confronting the very systems that insist that we are less than and that treat us as secondclass citizens. Such action is hard, but it is also a necessary step in our liberation” ("WE DO Campaign”, 10/10/2011).

The Campaign for Southern Equality utilizes the concept of “coming out” when thinking about one of their early actions (in 2011). I will discuss its usefulness to their mission in 3.1c. Aside from that, "coming out" is one of the major rhetorical strategies of the lgbtq equality movement. The major lgbtq advocacy organization the Human Rights Campaign (HRC) has published pamphlets on “coming out” and have them posted on their website. HRC has even made a point to make separate pamphlets for people of color (African Americans, Hispanics \& Latino/as, etc.) and for individuals who follow specific religions (Christianity). The concept of "coming out” feeds into the discourse of 
visibility as a necessary component of the equality project. The "coming out" process is fueled by particular characteristics, such as "courage and clarity” ("LGBT rights in Mississippi”, 05/30/2013), living “life with love and joy” and expressing “our full humanity” (“WE DO Campaign”, 10/10/2011).

\section{CSE framing equality in the South}

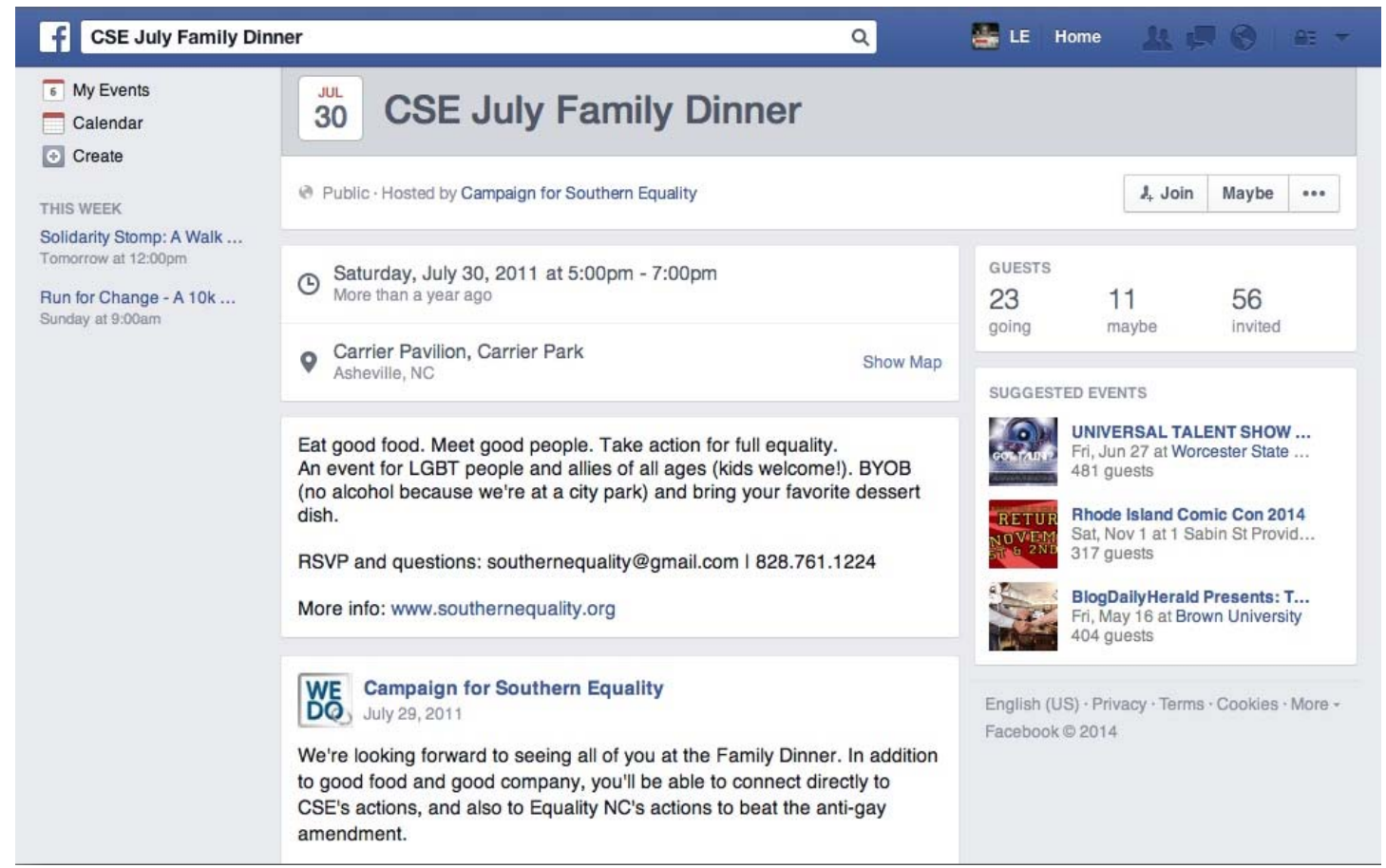

Figure 5. Screenshot of Facebook event page for CSE’s July 30, 2011 Family Dinner

In a side banner of the first email I received from CSE, there was an invitation to CSE’s Family Dinner, being held on July 30, 2011. The invitation on the email banner has three purposes "Eat good food. Meet good people. Connect to equality actions” ("Full Speed Ahead”, 7/25/2011). In the earlier period of CSE's existence, CSE relied on the Family Dinners in the formation of ideas, strategies, and to network with volunteers and 
allies in Asheville and the surrounding area. Traditional Southern families routinely organize dinners, many occurring on Sundays (post-church hour Sunday suppers), to maintain the tight-knit connections of Southern people to each other and to cultivate the families' traditions to the next generations. I should note that I am not arguing that families in other areas of the United States do not rely on the familial network in similar fashion. Rather, I want to assert the extent to which family is crucial to the survival of Southern people. It is almost an insult for a Southerner to disregard family and kinship networks. From a standpoint that understands the significance of kinship, it is no surprise why CSE would choose to do Family Dinners as an opportunity for community support and engagement and to cultivate their pool of volunteers and constituents. In the same email where CSE introduces Rev. Kathryn Cartledge and Elizabeth Eve as the first couple to participate in the WE DO Campaign, they also described their family: "They have been together for thirty years. They raised two daughters and have four grandchildren” (“WE DO Campaign”, 10/10/2011).

In the first section of the current chapter, I discussed the enactment of faith as an important construction of the South for CSE. I would like to continue that discussion, I would like to point to CSE's continuous references to faith and religion in their emails. In Stage 4 of the We DO Campaign, which occurred from 2011-2013, same-sex couples are accompanied by a group of supporters (including clergy) to apply for marriage licenses in sites all around the South, is an effort to support the legal recognition of families. Highlighted in many of these efforts was the inclusion of clergy. Or perhaps the better language is that clergy was a term singled out in the communication. CSE's emails often contained phrases such as, “Over 60 clergy and supporters stood with 
[couples who applied for and were denied marriage licenses] as they took action calling for full LGBT equality under federal law” ("WE DO Update: Day One in SC and International Coverage”, 1/17/2012). Another email opens, “This morning, we're in Asheboro, N.C. At 9:30 am, we'll stand with Barb and Angela as they request - and are denied - a marriage license in their home town, surrounded by friends, family, and clergy" ("Daring to call for gay marriage in the South”, 5/14/2012). In a number of emails, CSE advertised interfaith blessings as an important aspect of their work. The first couple to take part in CSE's WE DO campaign was comprised of two women, one of whom is an ordained minister and is addressed as "Rev." in a number of emails. Though what is now the United States was organized under the auspices of Puritanical [Christian] values, the region known as "the South" has been inextricable to religious principles in the United States. As I argue in Chapter V, it is almost impossible to talk about a place called the U.S. South without talking about religion, especially varying facets of the Christian faith. It is clearly evident, then, that: 1) Rev. Beach-Ferrara and CSE understands the interrelatedness of place and religion; and 2) the relationship of clergy and faith provides an important foundational conversation in their public campaigns. In the previous section, I discussed CSE's use of “coming out” as an integral part of their framing of equality. In showing its relevance to approaching the notion of equality in the South, CSE created their "Coming Out Campaign", which they described as a vehicle "through which LGBT people and allies will come out in new ways in the South...The goals of the campaign are to (1) increase the visibility of LGBT people and (see the email...cutoff in the printout) (2)...is our home and we are unwavering in our commitment to full equality” ( "Full Speed Ahead”, 07/25/2011, original emphasis). In 
the month that followed, CSE included a hyperlink to two individuals' stories as representatives for the campaign. As mentioned above, their use of the strategy in their efforts requires a public visibility that will in turn express a human component to law and discrimination. Therefore, it is not surprising that the WE DO Campaign strategies have been described with specificity to personhood as CSE often describes their campaign participants as being accompanied by a group of “friends, family, and clergy” to participate in asserting “full humanity”.

$* * * * *$

In the previous section, I have made a point of positing the ways that an idea about Progress, linked to the discourse and movement of lgbtq rights, is present in the work of CSE, creating a space in the South that is active in its pursuit of "equality". By identifying the ways that CSE frames the South, equality, and approaching equality in the South, I have utilized CSE's emails as texts from which to garner a perspective of the South in position to the national/globalized discourse. I would like to argue that while CSE's work and position is useful for some individuals, it is not necessarily so for others. Perhaps the better way to say it is that the CSE's work maintains an alignment with the monolithic engagement of Progress evidenced in the larger movement - one that relies on legality as equality and rarely speaks to the intersectional considerations of race, class, and gender (and other peripheral identities) in its operations. For that reason, I would like to pursue a different way to look at an idea of progress that is operating with more attention to different types of discrimination in society. 


\section{Redemption: Multiple lives, multiple Souths}

"Redemption: because we believe that while the South is a physical geography of white supremacy and poverty and how they form plantations, mountaintop removal, and slave labor, it is also more than that. It is a place of redemption and hope for many: a place where folk reconcile with past in an honest and painful way; a place where people can stay in lands riddled with pain and remember old traditions; and birth new ways.”

Southerners on New Ground (SONG)

Headquartered in Atlanta, Georgia, Southerners on New Ground (SONG) “is a regional Queer Liberation organization made up of people of color, immigrants, undocumented people, people with disabilities, working class and rural and small town, LGBTQ people in the South” (Southerners on New Ground 2014). As such, their endeavors and interests are organized around the varying communities identified in the previous sentence. In their organizing framework, they are intentional about why they look at the work that they do and why they chose the South. In the excerpt from their organizing framework, listed above, they use the word redemption. Redemption is defined in the dictionary in three parts: “1) an act of redeeming or atoning for a fault or mistake or the state of being redeemed; 2) deliverance, rescue; and 3) deliverance from sin; salvation” (dictionary.com 2014). Based on its definition, the idea of redemption lends itself to recognizing the legacies of the South that is topographically and otherwise spatially rendered into landscapes. In other words, it is a productive act intended to make amends with the root causes of contemporary issues. The idea of redemption in the scope used by SONG lends itself to radical possibilities. By offering to create space (“on new 
ground”) and to birth new possibilities, it is also lends itself to the term and conceptualization of Thadious Davis' “southscapes”. In his book Southscapes: Geographies of Race, Region, and Literature, Thadious Davis outlines the term:

My term "southscape" is intended to call attention to the South as a social, political, cultural, and economic construct but one with the geographic 'fact of the land.' It references landscape in broad geographical-social contexts and mediated symbolic structures. As a concept, "southscape" has both subjective and objective elements, but primarily it acknowledges the connection between society and environment as a way of thinking about how raced human beings are impacted by the shape of the land...My formulation of "southscape" engages, then, the natural environment and the social collective that shapes that environment out of its cultural beliefs, practices, and technologies. This notion of a collective shaping carries with in an assumption of a power dynamic that can obscure how a society's practices or beliefs take shape. (Davis 2011, 2)

In thinking through the activist framework presented by SONG and the theoretical framework of Davis' “southscapes”, I would like to utilize the interviews of the women who participated in the dissertation project in order to articulate a different sense of progress that continues to assert humanity, as CSE calls for, but placates intersectional experiences into what I would posit as informed alternatives to hegemonic indoctrinations, including the spatial formations, of Progress. Too often, Black women’s experiences have been made peripheral to the creation of knowledges. Therefore, a goal in the current section is to connect their voices to the spatial organization of Western North Carolina and, therefore, I describe the ways in which the research participants embody progress. These embodiments have spatial implications that are not simply located at the scale of the body but rather become implicated in local and regional scales. In the current section, I analyze the relations of the participants on two scales - the body 
and the local/community - to progress. The notion of progress used here demonstrates action oriented verb form of the word. Progress is defined as: "to grow or develop, as in complexity, scope, or severity; advance” (dictionary.com 2014). In the current section, I discuss the ways that three of the interview participants are using a platform of growth and development through recognizing intersectional complexities as necessary standpoints for progress.

At the end of my interview with Stephanie, she asked me if I needed other participants. I told her that, indeed, I was looking for more women to interview. She told me to contact Nicole, who is the Founder of the Color ME Brown Project. Stephanie remarked that Nicole was young, impressive, and "has a passion for change”. I contacted Nicole later in the summer of 2013, immediately after I moved to Connecticut for the dissertation year fellowship. I was able to find her on the social networking website Facebook (per the direction of Stephanie), and she agreed to participate in the interview process. After exchanging messages, Nicole agreed to meet me and suggested a Barnes \& Noble bookstore in South Asheville. We met on a Friday afternoon in mid-July. I waited for her on a bench in front of the store. When she arrived, she found me in front of the store. We shared a hug and walked inside. I asked Nicole if she had a preference for where to sit in the store. Prior to her arrival, I had scoped out the children's area of Barnes \& Noble and noticed a couple of open chairs. Nicole stated she had no qualms about being in the open, and we decided to sit in the café area of the store. Over the course of roughly 90 minutes, Nicole and I discussed a variety of topics - from family to activism to "being country". Many of the topics from our conversation will be discussed 
in Chapters IV and V. For the purposes of the current chapter, I will discuss Nicole's organization, the Color ME Brown Project.

In building up to the discussion of the Color ME Brown Project, Nicole discussed the variations in the connections to different sites around the region, particularly Asheville (which is where she lives). Nicole asserted that she feels misrepresented in Asheville as a Black lesbian:

[I]n the sense of... when there's rallies or when there's a gay pride, the only Black lesbians I see are me, my partner and maybe a couple of my friends who are hanging out because we're there. Or when I go to events, when I'm asked to speak at different events, it's like the Black lesbians I see are there to support me not to support the event - "Oh we're lesbians. We should partake in this and be involved in our community".

The lack of "the self" being reflected in lgbtq oriented events coupled with the consistent disruption and dislocation of Black communities in the area (and, really, for most people of color in the United States) leads to Nicole's compulsion for using her talent and abilities to advocate for her most salient identity - Blackness/Browness.

As outlined on the organization's website:

The Color ME Brown Project is a non-profit organization with a mission to empower and support the Black and Latino communities as well as strengthen and inform its allies. We do so by building platforms to openly discuss concerns and issues through creative vehicles such as film, art, and spoken word. Furthermore, The Color Me Brown Project connects people within these communities to resources and opportunities in order to better their livelihood (The Color ME Brown Project 2014, n.p.) 
The organization is not explicitly Southern; however, given its founder's Southern roots and the current scope of its programs and initiatives (most of which are located in WNC), it can arguably be considered a Southern project. Beyond that, the Project comes out of Nicole’s desire to create space and platform for Black and Latino voices, issues, and celebrations within a regional space that has often peripheralized people of color. As Nicole noted in her interview:

We don't have a huge Black presence here. And what bothers me is that as I'm learning more about Asheville...because what I do, I have to learn about Asheville and what it once was...Asheville was booming for Black people back in the [19]50s, 60s, and 70s and then, all of a sudden, there's none of that. And I'm questioning, where did that go? How did the City allow certain things to happen?

In its fairly short existence, one of the major contributions of the Color ME Brown Project (so far) has been the creation and production of a documentary, entitled "color ME brown: Conversations with Unmuted Voices". On the GoFundMe fundraising page, created in 2012, Nicole describes:

[color ME brown is] a documentary primarily focusing on the Black \& Latino communities. The primary questions that will be explored in this film are the following:

- What does it mean to be brown?

- How does it feel to be brown?

- How do you think life would be if you were not brown?

- How has being brown affected how you live your life?

- How important is religion to brown people?

- Are Blacks \& Latinos overcoming or playing into stereotypes? 
The title of the documentary is perhaps enough to understand the critical necessity of self-defining and narrating personhood that is noted by Black feminist and queer of color scholars as well as from decolonization in research, outlined by Linda Tuhiwai Smith (see Chapter II). The word "ME” is capitalized, which does three things. First, it creates a "proper noun", the linguistic function that calls attention to a unique entity, distinguished from the "common noun" - "me". Second, in the present day, the use of capital letters - particularly in texting and social media - denotes that one is yelling or shouting, which indicates the demand that one pay attention to the message being given. Third, the use of the word "me”, as an object pronoun, announces a call for action. From a grammatical standpoint, the object of the sentence receives the action of the subject. In the statement "color ME brown", the subject is not named. In these cases, the subject is recognized as an understood "you". Therefore, if the statement is now read as "you color ME brown", the object is doing something unusual. The object "ME" is demanding the subject "you" to recognize the ways that which race creates a definitive experience that is worth creating conversations around.

In the subtitle, the word "conversations" and the phrase "unmuted voices" are paired with each other. As seen in the questions provided by the organization on the fundraising webpage, the documentary is meant to show the way(s) that brown identity is essentially and explicitly marked and that the construction of space around brown identity is removed from everyday recognition. The use of the word "conversations" indicates an informal and intimate exchange between social bodies. By using the word "unmuted", the documentary is positioning brown bodies into the center of discussion, allowing them to self-narrate their experiences. While I have not been able to attend a screening of the 
documentary, the fundraising arm of The Color ME Brown Project included an excerpt from the film in a YouTube video created as part of the marketing effort to raise funds for their organization. The analysis of the title is certainly supported in the content of the documentary. These questions posed by the documentary, then, are directly attributive to and significant for Nicole’s personal experiences.

Similarly, Karen, a resident of Hickory, N.C., utilized her personal experiences to ask questions around creating space for social change. In our interview, she discussed her motivations for starting the organization CAFE, which stands for Community Alliance for Equality:

Me and my wife kind of put that together based on our other connections with organizations. We felt the need for different people, people that just care about equality. Not so much lgbt. It's just joining existing groups that were already together and having those people come together and meet. Because you've got so many organizations - which actually birthed out of loss of the Amendment One thing here in North Carolina - part of the problem was you had several different groups, one, they started fighting the Amendment thing kind of late in the game. The other thing was you had several groups that were actually fighting for. The problem was there was so many people fighting that they didn't necessarily get to fighting against each other but the time and the resources could have been better spent if they all joined forces.

Karen's sentiment reminds me of the work of SONG, described at the beginning of the current section, because her work relies on building a coalition across varying systemic issues in order to work towards the common good, recognizing that a socialized hierarchy of oppression is not fruitful for creating social change. Karen continues: 
CAFE is a way to bring people together who care about political and social justice issues and sit them all down at the table and everybody bring his or her expertise. And really their leadership. We were looking at issues that are big in North Carolina. One of them being the voter ID suppressions, workplace discrimination...Like I said, when you got 10, 12 groups all fighting the same thing, it would be better to have those 10-12 groups sit down at the table, pool their resources, and then fight. Because then you have a lot more people and you have a lot more resources than someone in Hickory trying to fight and then somebody in Hendersonville trying to fight. Somebody in Winston-Salem trying to fight. You see what I mean?

The other great potential in the coalitional work that Karen represents is its ability to garner support across differences. In a mainstream movement for Progress, very rarely will an organization have productive conversations with existing organizations or individuals or make an attempt to understand local contexts. As evidence, I submit the work of the Human Rights Campaign and their decision to devise an initiative called "Project One America”. In order to do that, they decided to assert themselves as the largest lgbtq organizer in the South and made a commitment to focus resources in Arkansas, Alabama, and Mississippi in order to make "bold" and "historic" moves in the South and not tolerate “partial equality” (HRC email, 04/27/2014). HRC’s email raised several curiosities for me. I have to wonder what coalitions were formed in the planning of "Project One America" and what conversations were had that ensured the feasibility of HRC's "bold move”. In the same vein, I wonder if HRC will actually be welcomed into the communities where they will set up offices and how they will characterize any resistance to their presence. SONG followed up with an email of their own challenging HRC's "One America” discourse, problematizing the idea that there are two Americas and going on to say, "SONG agrees that there are vast differences in the daily, lived 
experiences of LGBTQ people in this country, however these differences are not solely based on policy protections available in some states and not in others. The primary division of an LGBTQ America is divided along lines of race, class and other oppression that criminalizes LGBTQ people of color, trans people, poor people and immigrants for being who they are” (“Life or Death”, SONG email, 04/29/2014, original emphasis). Again, these issues can and will be taken up later. What I would like to point out is that Karen and Nicole and SONG align with an understanding of certain types of solidarity and bringing a diversity of voices to the table to work with and for each other. Which brings me to Stephanie’s work.

An important aspect to the work that Stephanie and her company - Different Strokes Performing Arts Collective - produces revolves around troubling the societal normativities through performance. In our interview, she discussed two specific shows from her season:

Stephanie: So Different Strokes does cutting edge shows. Shows that have already been produced but we produce them in a different way. We take them and twist them. Ernest Gaines wrote a book, A Lesson Before Dying. Are you familiar with that?

LaToya: Yes.

Stephanie: We did that last May [2012]. What we did with it was we took the traditional cast, and we ran it with the opposite cast. So rather than a white black man on death row, young black man - we put a young white man on death row...And then a couple of nights we switched it up even more and we had the young black man on death row with the white teacher teaching him or the young black man on death row you know. So we just switched it. Or the grandmother was white and there was a black young man. So we switched it up a lot. And we did talkbacks with the audience after each show to hear their input. And everybody was pretty much blown away. So we called it A Lesson Before Dying 
in Black and White. So it was pretty cool. We got a lot of, a lot of recognition for that so I'm proud of that one too. So that's the kind of stuff we do.

Like Karen and Nicole, Stephanie has made a choice to be a public figure through working with theatre and doing so in a way that creates paradigm shifts. Stephanie, and her company, intentionally makes people think. In June 2013, I had the opportunity to attend a performance of Incongruence, a play produced by Different Strokes. The production was “an original work by Carla Pridgen, which features monologues and vignettes derived from interviews with transgender men and women of all generations, and backgrounds. This fascinating work embraces the fact that we are all on the same journey despite gender, orientation, race or ethnicity” (Different Strokes Performing Arts Collective 2014). I had the opportunity to have first-hand experience in watching a performance that caused me to grapple with topics and identities of which I thought I had a decent knowledge pool. Different Strokes operates to create dialogue in the local community around multiple and intersecting issues.

$* * * * *$

Let us now return to the "politically and socially charged question” of Progress/progress. I argue that that changing culture, thereby utilizing progress, is not merely grounded in discussions of legality and policy changes, the focal point of Progress. Merely focusing on legality and policy changes perpetuate hierarchical systems that accentuate differences across individuals in the nation and around the world. More 
specifically, the legalities and policy interests presented by the Progress movement, more often that not, support a system built on white supremacy (which is deeply embedded in colonization and capitalism). Progress is violence when it requires the homogenization of a people and bodies and fails to account for the multifaceted cultural politics that are endowed in spatial inequalities. Progress then falls trap to a discursive dualism, a false dichotomy that relies on law and policy as its boundary. As Urvashi Vaid argues,

[C]ivil rights do not change the social order in dramatic ways; they change only the privileges of groups asserting those rights. Civil rights strategies do not challenge the moral and antisexual underpinnings of homophobia, because homophobia does not orginate in our lack of full civil equality. Rather, homophobia arises from the nature and construction of the political, legal, and economic, sexual, racial and family systems within which we live. (Vaid 1996, 183)

Without critical analyses of intersectional identities in the consideration of legal and policy-oriented impacts, many of these seemingly democratic measures will fail those who do not assimilate to or operate in the monolith of Progress. Such necessity has been well documented by other scholars, including Vaid, and extends into other systemic issues as well. For example, Clyde Woods described the reconstitution of the plantation into the abjected landscapes of the Mississippi delta: "Plantation regimes create, institutionalize, and manage extreme levels of conflict. Therefore, the current crisis in the Delta is not one of failed policies, underclass behavior, illiteracy, rural poverty, labor market mismatch, or social "backwardness". Responsibility for the coexistence of great poverty beside great wealth rests squarely at the feet of a dominant region bloc that has 
fought every effort to expand the parameters of social, economic and cultural justice” (Woods 1998, 40).

Finally, legality and policy changes are aesthetic interests and do not change people's minds. Individuals can and will continue to operate from a standpoint of bigotry and ignorance. The South, unfortunately, is often the iconographic symbol of "bigotry and ignorance", as demonstrated by the question that opens the current chapter as well as throughout the analyses of CSE's emails. In the sense that the South has operated, and continues to operate, as the scapegoat of "bigotry and ignorance" in the United States, the idea that it is a region of variant and multifarious life choices is dismissed. The South becomes incapable of achieving Progress. The reality is that bigotry and ignorance inescapably exist on a national scale. In conversations with colleagues and friends recently, I made the point that "the North" is what they think "the South" is. In other words since living in New England, the microaggressions around my Blackness have been some of the most violent of my life. The reality of my lived experience does not match the law of Connecticut.

I actually agree with the emphasis on kinship and community that CSE has strategically utilized in their work in order to change people’s minds. The personal narrative is a powerful tool of social change. I also agree with the work of Nicole, Stephanie, and Karen in that they emphasize different ways to approach changing society and our perceptions of each other. The bottom line, though, is that we cannot expect legislation and law to be a complete project. Rather, the better approach is to be justiceminded. There are vast differences between Progress (the noun) and progress (the verb), just as there are cavernous differences between equality and justice. 
“and just cuz civil rights is law / doesn’t mean we all abide / so tell me are you free?”

Meshell N’degeocello

In the current chapter, I have discussed the ways that "Progress" has been indoctrinated as a synonym for the lgbtq civil rights movement. I take to task the proposition that the South has failed to act in favor of Progress by outlining the contributions of the Campaign for Southern Equality through their email lists. I then critique the monolithic stance of Progress by offering different ways to situate progress utilizing the public contributions of three Black women I interviewed for the dissertation. I included a lyric from a song by recording artist Meshell N'degeocello to demonstrate that Progress has its limitations. I argue that other considerations should be made in the advancement of alleviating oppression deeply embedded in United States landscapes. No space is without complication, as I have attempted to demonstrate in the current chapter, and in the following chapter I will continue to interrupt "both the conventional epistemological and ontological renderings of the body” (Puar 2007, 13). In Chapter IV, I build upon Chapter III by expanding analyses of my discussions with six Black queer and lesbian women by explaining the multifarious nature of identities and their construction in place. 


\section{CHAPTER IV}

\section{THE IDENTITY SPACE DEMANDS}

In the previous chapter, I took up the varying ways that Progress is enunciated in the South. I also problematized Progress by discussing its inherent dismissal of other projects that are characteristic of growth, change, and movement (progress). In the current chapter, and (to an extent Chapter V as well), I take to task exemplifying the ways in which the idea of Progress is complicated when you consider the lived experiences of people who should be considered under the guise of Progress but who experience multiple, inextricable identities that could be considered "marginal” or "peripheral”. So often, the geographies of Black women are dismissed in the pursuit of neoliberal projects. Specifically, for the case of the dissertation, they are dismissed in the pursuit of legal parameters that focus on bettering quality of life for same-sex people (specifically through "gay marriage”). While they might take advantage of the pursuits of Progress by virtue of their sexuality, it was evident that, based on the interviews, there were other more salient aspects of their lives that more often than not seemed to be shaped and spatialized by the experience of racialization. In the current chapter, I am interested in looking at the construction of space as enunciated into the corporeal, raw material of Black women’s geographies.

In The Production of Space, Henri Lefebvre poses an argument about what space is and how it is produced. In the text, he focuses more specifically on social space, arguing that space is a result of a series of spatial relations continuously being produced. He says that social space "is not a thing among other things, nor a product 
among other products: rather, it subsumes things produced and encompasses their interrelationships in their coexistence and simultaneity” (Lefevbre 1992, 73). He promotes his treatise into a relevant discussion stringing back to the idea of a conceptual triad. The triad has three points: spatial practice, representations of space, and representational spaces. Spatial practice "embraces production and reproduction, and the particular locations and spatial sets characteristic of each social formation” (Lefebvre 1992, 33). In terms of Lefebvre's focus on social space, "this cohesion implies a guaranteed level of competence and specific level of performance” (Lefebvre 1992, 33). Representations of space refers to the relations of production and the order in which they are imposed, creating knowledge. Finally, representational space embodies symbolisms that are linked into aspects of social life. In his work, he argues, "social space is produced and reproduced in connection with the forces of production" (Lefebvre 1992, 77). As these forces develop, they "are not taking over a pre-existing, empty or neutral space, or a spaced determined solely by geography, climate, anthropology, or some other comparable consideration” (Lefebvre 1992, 77).

In other words, no space is without complication. I have used arguments against a monolithic South and an institutionalization of Progress in the South to provide examples. The production of space is the result of a process in which humans interact and integrate with space. Geographical space is viewed as a social product (Smith 2008,107). Smith notes that the "notion that space and society 'interact' or that spatial patterns 'reflect' social structure is not just crude and mechanical in its construction, but also prohibits further insights concerning geographical space” (Smith 2008,106). 
The title of the current chapter, “The Identity Space Demands”, gives a nod to the 1991 choreopoem The Love Space Demands: a continuing saga, by Ntozake Shange. The title The Love Space Demands marks the complexities of conceptualizing something called "love" - the challenges, contradictions, joys, affirmations, and transformations. In the same spirit, I chose to think about the questions, nuances, “ah-ha” moments, and comforts in the concept of identity as they are situated in space. Space takes on varying scales - body, home, locality, region, and nation. In the current chapter, I will discuss the multiple materialities of space through wrestling with the polysemic nature of identity. I attempt to take on and trouble normativities, as argued by Katherine McKittrick: “Geography’s discursive attachment to stasis and physicality, the idea that space 'just is,' and that space and place are merely containers for human complexities and social relations, is terribly seductive: that which 'just is' not only anchors our selfhood and feet to the ground, it seemingly calibrates and normalizes where, and therefore who, we are" (McKittrick 2006, xi).

The chapter is organized around the following themes: Naming/un-naming; belonging/un-belonging; and discovering. The theme "naming/un-naming” deals with the production of the human experience. Through the section, I highlight the ways in which these six women produce spaces that deconstruct the normativity of "stasis and physicality”, and I explore the consequential realities of being a body in space. As such, the theme belonging/un-belonging enters a conversation about the spaces that the women who I interviewed enter and exit, creating and challenging landscapes of power. Finally, the theme discovering highlights the unfinished business of these women's lives. In other 
words, I discuss the points of discovery, where the women move on and look towards enacting a self-satisfactory lived experience.

\section{Naming/un-naming}

The theme of naming/un-naming works within the context of Linda Tuhiwai Smith’s assertion of naming as a decolonizing project, in which she suggests, "By 'naming the world’ people name their realities” (Tuhiwai Smith 2012, 262). Naming/unnaming also gives a nod to the feminist interest of the personal narrative as a tool of deconstructing power systems and hierarchies, particularly thinking from the frame work of bell hooks, who argues, "If any female feels she need anything beyond herself to legitimate and validate her existence, she is already giving away her power to be selfdefining, her agency” (hooks 2000, 95). I turn to the process of renarrating the interviews.

As discussed in Chapter II, I relied on social media and Internet-mediated communication as part of casting a wide net for reaching potential research participants. For example, as previously stated in Chapter III, I found and contacted Nicole via Facebook through a direct message with her. In April 2013, I also posted an advertisement on Craigslist (original advertisement included in appendix). An anonymous person replied to my post with the following message: 
PhD student:

I may meet the qualifications for your project and would like more information.

Specifically:

1. What is the purpose of your project?

2. Are there any risks/benefits of your project? If so, to whom?

3. Are the interviews by phone, web, or in-person?

4. Are the interviews audio or video-recorded?

5. What collected information is shared for project purposes and with whom?

Thank you for your time.

Prospective Subject

Figure 6. Screenshot of Email from Prospective Participant, May 8, 2013

I responded to the email immediately, paraphrasing much of the information found in the Cover Letter. I received a reply that offered a variety of times and locations in Western North Carolina where she would be willing to meet - Asheville, Fletcher, Candler, Cherokee, Waynesville, Sylva, Cullowhee, Cashiers, Franklin. The “Prospective Subject” from the above screenshot listed her name on the reply as Rebeca. I confirmed a date, time, and place for our interview as well as provided her with my cell phone number in the event she needed to contact me.

I interviewed Rebeca on a Saturday afternoon at Blue Ridge Books in Waynesville exactly 24 hours after interviewing Stephanie. Waynesville, a town of just under 9700 residents (U.S. Census Bureau 2014), is located thirty miles west of Asheville. 


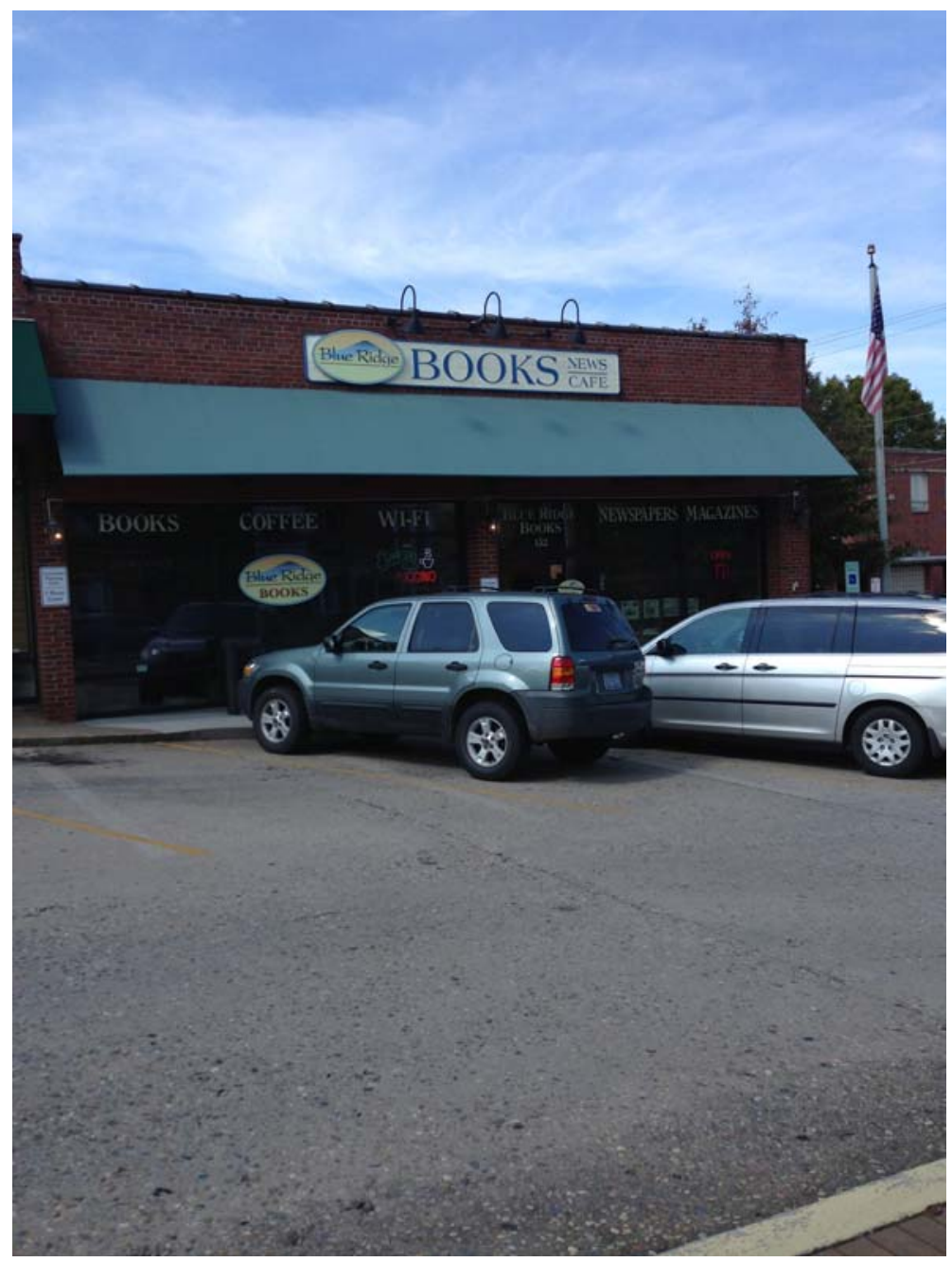

Figure 7. Exterior of Blue Ridge Books, Waynesville, NC. Photo by LaToya E. Eaves

Like the day before, the afternoon was warm and partly cloudy. Because Waynesville sits at a higher elevation than Asheville, the humidity was noticeably easier to manage on that particular late spring afternoon. I arrived in Waynesville an hour before our interview was set to begin. After ordering an espresso, I sat down in the café area with a full view of entrance and waited for her to arrive. 


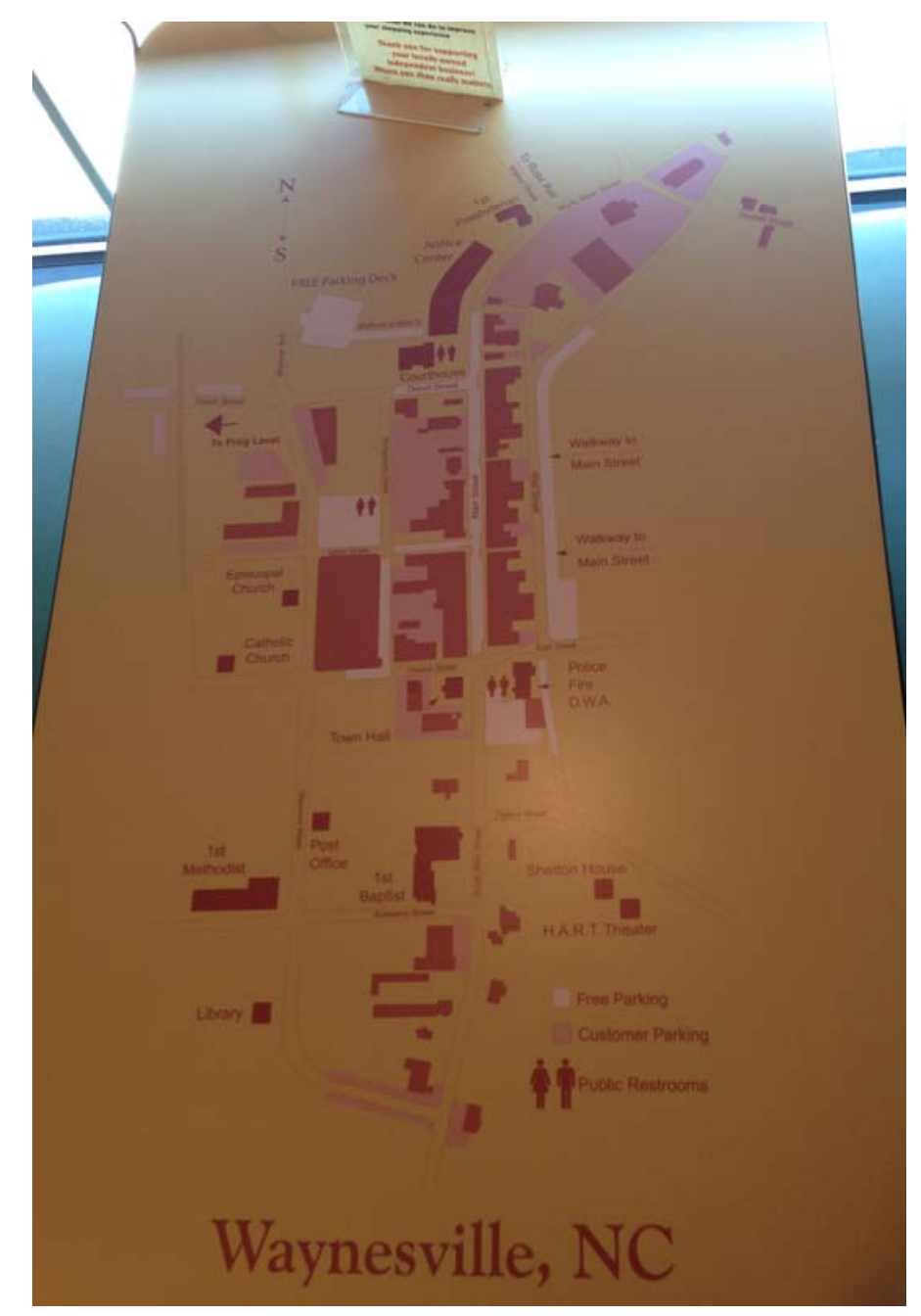

Figure 8. Table in the café area of Blue Ridge Books, Waynesville, North Carolina.

While I waited for her, I studied the table in Figure 7. All of the tables bore an imprinted figuration of downtown Waynesville. The map pointed out the important fixtures of the town's center, including the town hall, the police department, and several churches in addition to walkways and public parking. Rebeca arrived shortly before our scheduled time, and we decided to move our interview to the outdoor patio of the bookstore. I provided Rebeca with the assurances she needed to alleviate her skepticism - giving her a copy of the IRB Cover Letter and giving her more information about the project. After 
receiving consent to proceed with and record the interview, I asked Rebeca for the same demographic information requested from all interviewees, which included age and a request to describe the following: racial identity, gender identity, and sexual identity. When Rebeca answered the question, she hesitated before saying "I guess bisexual”. Later in the interview, when answering the question about identity on the interview protocol, Rebeca revisited her previous answer of sexual identity:

"I'm kind of surprised that [bisexual] even came out of my mouth because I've never had a boyfriend. I'm still not comfortable identifying with being a lesbian or bisexual. I just want to be considered as having options. Maybe I haven't taken those options, but is there anything for a check box that says 'other'? I'm the 'other' that checks the box.

Rebeca did not feel compelled to fall within the tropes naming and confining herself to a specific intonation of politicized sexual identity. The only other person who shifted a bit from using the word "lesbian" in terms of sexual identity was Karen, who I introduced in Chapter 3. When I asked Karen the question, she told me that I could use whatever term I "need[ed] it to be” before saying, "I'm ok with lesbian”, as if it was an ancillary piece. When I asked Karen to "tell me about" herself, she rattled off a list of aspects of herself that she considers the most important: "activist, advocate for HIV/AIDS, Christian, fun-loving, good sense of humor.” In the interview, she expressed that sexuality was not something that she singled out.

Throughout her interview, Rebeca was able to wrestle with putting words to her lived experience, expressing at one point that she was "rambling” (though I tried to 
assure her that she wasn’t). She, like Karen, was less interested in “singling out” her sexuality:

Even with being gay or bisexual or something like that, in Western North Carolina, I feel like I've had to define myself less by who I love...than it is for me to define myself by my academic background, my career choice, my ethics, and things like that. I need to project that more than anything else.

Not surprisingly, Rebeca argued, "Identity is defined as perception or self-perception, in my case... what I project to the world”. Such negotiation of identity and what becomes experienced in the world was also apparent in the interview with Stephanie:

I walk through the world as myself. I've never had this whole coming out and being a lesbian. Because it's who I am so I've never had the need to present it to anyone. So it's just who I am. I've never had the coming out. It's like I've never had the coming out 'Hey I'm black.' Some things just aren't necessary. You are who you are and people respond to that.

When I asked each woman the opening question of “tell me about yourself”, I found it interesting that either the first (Stephanie, Tausha, Nicole, Vern) or second (Rebeca) sentence uttered in response was about where they came from, as in where they were originally born and raised (Tausha, Nicole, Vern, Rebeca) or where they live now (Stephanie). I woud argue that the women recognize the spaces that shaped them and place of origin is one of the ways that gets enunciated. The women interviewed for the dissertation project help to add new knowledges based on their personal contexts, which is at times antithetical to the popular discourses of region. In her interview, Tausha noted, “When I tell people that I’m from Western North Carolina, they’re like 'Oh my 
God! They have black people there?’ And I'm like, 'Uh...yeah. Totally. Totally have black people here'”. In addition to the attribution of whiteness to Southern identity, black people in Appalachian space are often made peripheral due to the discursive formation of the region as well as the smaller ratio of black residents as compared to other southern and U.S. geographies. From a historical standpoint, Western North Carolina and its adjoining Appalachian sites did not support the southern plantation economy because of mountainous terrain and, therefore, did not attract slave ownership in mass quantities. Nonetheless, Western North Carolina still maintains a connection to the plantation in unique ways and, therefore, to the legacies of enslavement, racialization, and racism (the neo-plantation, as argued by Clyde Woods 1998, 2002, 2007). Black people, though demographically smaller in number, have lived in the region for generations. As the only native-born Western North Carolinian in the project, Tausha provides important insight to understanding how race and racialization manifest in the region. In describing her childhood experiences, she talks about being educated in Haywood County:

In my graduating class, I think we graduated me and probably six other black kids. And that's just how it was. My sister and I were the only two black girls in our school for years. Like in elementary school, for years. Which was never really a problem for me.

In these two quotes from Tausha, she represents the nuances of Black life in certain spaces. First, she asserts that they exist, that they are geographically situated humans who make Western North Carolina home. Second, she dismisses the idea that because a large enclave of Black people does not surround her, she is not socio-spatially 
"ok". In the ways that Rebeca, Karen, and Stephanie dismiss the need to project their sexualities, Tausha declares that her home life, her personal history, may be complicated by factors besides or in addition to race.

\section{Belonging/un-belonging}

Admittedly, the current section is organized around "bounded" notions of institutionalized place/space. In other words, I think through the scales of home and locality to explore the geographic situatedness of identity in place. In doing so, I recognize "that black subjects and communities are openly and complexly geographic, but distanced from sanctioned geographic knowledges, [which] problematizes how we know the world and organize our knowing” (McKittrick 2006, 14). From the interviews, I recognize four common spaces of belonging/un-belonging: religious institutions, the home, educational spaces, and "gay” spaces. Because Chapter V is devoted entirely to religion and the lived experience, I will refrain from discussing it in the current chapter.

I want to begin by inserting a moment from Stephanie’s life. In providing an example of how she deals with racial violences, she recounts the following experience that also includes her wife Trish, who is a white woman:

[Trish and I are] foster parents. And we had a 16 year old white girl in our house first. And she's pregnant. And her mom was still in the picture because the whole thing was getting her to go back home...So her mom was in the picture. And it's funny that whenever Trish was with me and we would be talking to her, she would not have a conversation with me. She would only talk to Trish.

The description of a particular situation of being explicitly ignored connects to a statement Stephanie made earlier in her interview: “So my identity is I’m a strong 
woman. Outside forces recognize or remind me that I'm a black woman.” The last quote from Stephanie demonstrates that even though she is in her own private home she is still subject to dismissal by an outside encounter, her body a transparent presence.

For Vern, wrestling through identity in the home space proved to be a crucial element for creating her space of self-discovery. In the first half of the quote from Vern's interview that follows, home is construed as space created by views of intimacy. The second half of the quote engages Vern's movement through the home, negotiating her new identity experiences:

Vern: Just as my daughter was finishing high school, I became really good friends with a lesbian couple. The one woman was my massage therapist. And I'd never really had a close relationship with a lesbian couple before. And so this couple was actually moving to Asheville, and they were like my best friends at that time. And so I drove one of their cars down here to Asheville. And when I got here, I just watching their relationship and something went off inside me. Like ohhhhh, this is what's been going on inside me all this time. You know, I had some crushes on women and didn't know what that was about. Couldn't label it, couldn't name it. I don't know...just wanted to be in the presence of women for many, many, many years. I can remember from high school, my best friend, liking my best friend's touch. But not knowing really what that was about. I just didn’t know. I mean I guess... I just didn't know. And so [after] watching them interact, I had a conversation with them and I said, "I think I too am a lesbian. And it just seems like the way you interact with each other is what I've been looking for all my life”. And so I left Asheville...stayed here about a week...went home.

LaToya: Which was where at the time?

Vern: Long Island, New York. [I] went home and told my husband that I was a lesbian... at that point, I didn't quite know what I was going to do with that information. [I would] just kind of sit with it. I think at that point I may have been in therapy and was working through some other things - probably having to do with this. Actually, I was in therapy for many, many years, and the therapist never asked me anything about sexual identity. And he should have. Well not that he should have, but considering my issues, it's surprising that he didn't because I wasn't comfortable in my marriage. Physically. So it's interesting that 
I was never asked. [Which is] one of the reasons why I want to be a counselor. One of the reasons why I am a counselor. So at that point, I didn't know what I wanted to do with that information. But interestingly enough, when I came out to him I realized that I didn't want to drink anymore either. Because prior to that, I drank to have sexual relations with him. And I actually said, "I will not have to drink again”. And I have not since that day, and that's been 13 years ago...

I would say maybe 3, 4 months after I came out, I decided that I was going to leave the marriage. But I stayed in the household for about, I don't know, I'm going to say about a year. To make sure our finances were kind of separated and things were paid off and taken care of and blah blah blah. Eventually, I moved in the basement of our house....like a little apartment in our house. And then I moved out.

In her complex and vulnerable reflection, Vern remembers and narrates the ways she troubles her home space. Her quotidian experience in her home shifted as she moved into a new self space that meant separating from a past space that had supported and loved her but was not the one to which she now belongs.

But not all of the experiences revolved around a bounded concept of home, in terms of what happens inside four walls. There are others that incorporate the landscape outside of a building. For example, I still consider Shelby, North Carolina "my home”. I have not lived there in 15 years and the house I grew up in was demolished by the city some ten or so years ago. But the sights/sites, smells, and people of Shelby give me a sense of peace and comfort that nowhere else can. I believe to also be true for Rebeca. At the time of her interview, Rebeca had been a resident of rural Jackson County for just under a year, and she wholeheartedly regards it as her home space. In her quest to embed herself into the community, she encounters the limited worldview of lifelong residents in the region. She was shocked when she was categorized as an outsider by virtue of her race. She noted that black people seemed to be “foreign” to some local residents, as few 
had interacted with black individuals or communities, stating "I find I'm often surprised by the amount of people who say, 'We really don't see a lot of you around here' and who say the only black people they see are on the Maury show". The nationally syndicated talk show, in recent years, has become popular for its theatrical and exaggerated displays of individuals who are often pathologized in society. The show features people of color and poor whites in disadvantaged situations, largely dealing with affairs, secret lives, and pregnancies. Maury has become infamous for conducting paternity tests for women who are unsure of their child(ren)'s father. Some women appear on the show multiple times, bringing one or more past sexual partners. "You are NOT the father" has become an oftquoted tagline of the show, and it’s pronouncement from Maury Povich sends the audience into a frenzy. The show highlights the long standing, problematic ways that black women's bodies have been viewed in society.

The stigmatization of black bodies and their sexuality has deeply rooted histories in the United States racial formation. Indeed, as Ferguson notes, "As a technology of race, U.S. citizenship has historically ascribed heteronormativity (universality) to certain subjects and nonheteronormativity (particularity) to others. The state worked to regulate gender and sexual nonnormativity of these racialized groups in a variety of ways. In doing so, it produced discourses that pathologized nonheteronormative U.S. racial formations” (Ferguson 2004, 14). The discourses concerning black women's bodies is integral to completing the dissertation project, in the sense that they can contextualize queer black women's sense of self and their bodily performances in the varied productions of space. Black women's bodies have historically been connected to discourses of sexuality. Hill Collins argues sexualized black bodies are mediated in "a 
social context that routinely depicts men and women of African descent as the embodiment of deviant sexuality” (Hill Collins 2005, 35). Dating back to the antebellum period, black women's bodies became formulated into stereotypical imagery - the Mammy (the black domestic slave-type), the Jezebel (the hypersexualized seductress), the Sapphire (the emasculating black woman), and the Matriarch (the maternal figure). These representations continue to regulate the ways black women's lives and behaviors become restricted. The stereotypes have been reconceptualized (Stephens and Phillips 2003) to reflect the ways contemporary culture reflects back on black womanhood, particularly through the rise of hip hop culture.

To counter these long-standing images, a segment of black womanhood developed norms and behaviors that encompassed the politics of respectability (Higginbotham 1992; Hill Collins 2005; Moore 2011). In her work, Hill Collins (2005) talks about the politics of respectability after tracing the spaces where the Mammy, Jezebel, Sapphire, and Matriarch were produced - the rural U.S. South and the racially segregated urban ghettos. The politics of respectability became a middle-class doctrine argued to be for racial uplift and to gain status in the eyes of whites (Higginbotham 1992; Hill Collins 2005; Moore 2011). Rather than uplifting black people, however, respectability became a way to distance the black middle-class from the black workingclass and rural dwellers. Respectability also became a way to regulate black women’s sexuality and currently maintains influences over the ways same-sex sexuality is explored and expressed in black communities and in the public sphere as a whole (Moore 2011).

The Maury show and the discourses on black bodies outlined above simultaneously limit and expand the possibilities for Rebeca’s residence in Jackson 
County. Rebeca has to work through the challenges of being in a community that has a limited engagement and socially constructed perceptions of black people. She must also work through her own expectations of life, after having lived in larger towns and cities with more "diverse" populations:

I can't even say it's a varied culture, which coming to the area I thought that it would be. Knowing that the Cherokee Indian reservation is nearby and Hispanics are everywhere. It's really not. It's not a diverse population here so when I do try to find a community - and not just a community of black people, just a community like me that is diverse and who has known and worked around a lot of people and been around a lot of people - that's a little bit more challenging. They've lived in their box and that's pretty much all they know.

Rebeca's choice of home space does have its challenges. It is a very white racialized geography that is sparsely populated. The families who live there have likely been there for generations. On the other hand, by Rebeca's residence and her process of becoming connected to the local community, she has the opportunity to augment white people's perceptions of black people and people of color more broadly. She would then be in alignment with a similar charge that Stephanie brought on herself at an early age:

[My hometown] was white. It was lily white...I was the token. I was the one they wanted to invite over to their house because they never had black people around. They wanted to get to know black people, and that was fine with me. Because I'm happy to be the one that lets you get to know that black people are not all criminals and want to beat you up and stuff. 
Stephanie's reflection brings up the notion of tokenism, the burden of one person who holds the responsibility of bearing witness to the identity of an entire group of people. Tokenism is not limited to race, but also includes classed and gendered bodies. Tausha also became tokenized, but only after she left the confines of her small town. She did recall other experiences prior to that time. For example, Tausha, having grown up in a rural community in the region, describes that her experiences growing up as a black child in a predominantly white community were:

I really just have like two incidents that I can remember happening. And not necessarily to me but kind of around me, about me. When we were enrolling in kindergarten, a janitor said something off to himself as my mother passed him about "Well there goes the neighborhood." Like "you let those people in, and there it goes." She immediately went to the principal, and he was fired And that's all that I remember. And the other thing that happened, I was either nine or ten. And there was this huge Christmas party at the Elks' Lodge or the Moose Lodge or that somebody was doing. And my grandmother had told us about it and we were just gonna go... And we got there, and they wouldn't let us in. And that's all that I remember. I'm sure at that point, my mother sent us back to the car. I remember sitting there for a while and watching her and my grandmother raise hell... and then we went off and did something else.

For Tausha, her Blackness was not truly formulated into a deep sense of self-awareness until she went to college in her late twenties:

When I went to UNC-A[sheville], it was the first time that I was very aware how black I...it was the first time that I had ever felt really black, which is crazy to me because I've never been in any majority black situations. I've always been with white people, for everything for all the time. And I've always been the only black girl in the class. But it seems like once I got to UNC-A... at times people would ask me how I felt about [this or] that which is interesting that it took me going to college to have that put on me in a place where, that's the last place that you would expect it to be put on you. To speak for somebody, for an entire race like 
that. This is an educational institution. You're supposed to know that I don't have that capacity.

Interestingly, Tausha's identity is marked by Blackness in a different way from Rebeca and Steph that, for her, only exists outside of her hometown of Waynesville. Her deep connections to place make for an interesting case. She is seemingly normalized into the spaces and flows of her home and actually stated in her interview that she had no desire to leave.

Nicole was also not immune from tokenism and was perhaps equally as frustrated as Tausha with its process of creating difference by virtue of race. In her interview, Nicole described her past involvement with a local lgbtq advocacy group. She enjoyed and valued the experience but stated there were no people of color. Nicole noted that the visible marker of her racial identity led her to feel and be tokenized in a group for lgbtq advocacy. Nicole was often, and still is, called upon to be the connection to people of color in queer spaces around Asheville. In her interview, Nicole referred to a voter registration event at a local nightclub organized by a friend of hers. The budget for the event was minimal and the entertainment (a drag show) was organized on a volunteer basis. Those who volunteered all turned out to be Black people. The next day, a complaint was made to her friend that the entertainment was not "diverse enough". Nicole remarked, “It was hurtful to see that if it’s not white enough, it's not good enough.”

Even though Nicole was dissatisfied with her experiences with lgbtq advocacy groups, she was able to enjoy and take advantage of a local nightclub that catered to an lgbtq audience. She remarked that her first visit to one specific nightclub gave her a 
sense of relief, particularly and perhaps mostly because she was able to commune with other Black gay people that she had had not been able to find elsewhere in Asheville.

The nightclub became a space of belonging for her, evidence by her eventual employment at the venue.

For Vern, her direct engagement with lgbtq-oriented spaces was during her time in New York, prior to moving to North Carolina. After her divorce, she worked through another set of spatial negotiations that took on the scale of locality to give her a sense of space place and belonging:

I started dating. It was a lot of fun. Did a lot of Fire Island on Long Island. That was wonderful. It was really nice. Really active in AA. Gay AA. There's a huge gay AA on Long Island. So I got involved with that. And basically for me it was kind of like a safe place to come out and learn. Well, I do not identify myself as an alcoholic. I do identify myself as someone who chose not to drink because I didn't need to anymore. It was not a situation where I had to withdraw from alcohol or anything like that. But it was just not necessary for me anymore. And so [I] became really active with that and my social life basically kind of stemmed from the Gay AA on Long Island. There was a lot of activities. They had dances. That's who I went to the beach with in the summer time. And dated some folks in there (laughs).

I think it is interesting to point out the ways in which the "gay space" that Vern encounters and works her way through is actually more organized around her connection to people in Gay Alcoholics Anonymous. Prior to the point in the interview transcribed above, as Vern was discussing her process of understanding her sexuality, she talked about the need to drink alcohol in order to engage in physical intimacy with her former husband (which was quoted earlier in the current chapter). Once she understood that aspect of herself, she stopped drinking because she no longer needed to use alcohol as a 
coping mechanism. As she stated in her quote, Gay AA it was a safe space for her "to come out and learn”, being able to explore her thoughts, feelings, and interests by gaining companionship with other folks who were perhaps moving along a similar continuum of self discovery by becoming sober.

For Stephanie, the token aspect was not necessarily the issue. Her concerns came in negotiating lgbtq spaces directly relates to the one earlier in the section, having her body dismissed:

So on the lesbian side of it, Asheville is really not the place to have a problem being a lesbian. Asheville has one of the largest lesbian populations per capita. It's as if San Francisco was a small as us, we'd have more than San Francisco. So Asheville is not a problem with that. So I can't really use Western North Carolina in that one because there's an acceptance there that's not in Atlanta necessarily. You know, where I came from before. Or not in some other places. But it is interesting, though, being black and lesbian. Because, believe it or not, there are lesbians who are also racists. Which, to me, it blows my mind. It blows my mind that you can be in a class that is disrespected....and you can treat somebody else that way. I don't understand that so yeah there are racist lesbians. So I get overlooked in that way.

In addition to dismissal, she discusses the other otherness of her body in space:

Then there [are] the white lesbians. [You know] the white girls who just need to be with a black man? There are the white girls that just need to be with a black woman. And it's interesting trying to sort that out. Before I got married, I [could] be in the club and, for the most part, I was ignored. Unless another black chick happened to walk in. And that was only so that she could come over and we could talk about how we were being ignored. So we'd be ignored or either what would happen, I would get a woman that's coming over to talk to me, and [then] she'd start talking about my hair and all this. And then she starts trying to "talk black”...Then I'm like yeah I'm done. I know where you coming from. And then I did drag for a while. And I remember this chick coming to me after I performed and she was into the character, she was not into me. So that's another problem 
too. Because I don't fit in this femme or stud or butch categories. I'm just here. I'm in the gray area. I'm just me. I don't fit either way.

Such geography of the body promotes the fetishization of Black women's bodies. While Stephanie’s experience does not fit in the mold of Mammy/Jezebel/Sapphire/Matriarch discussed earlier, it does connect to a fetishized desire that is problematic, whether in the pursuit of a sexual experience or for the appropriation of Black culture.

\section{Discovering...}

The production of space is ongoing. Stephanie's example from being in a nightclub demonstrates such a reality. The narration from Stephanie and the other women represent a process that lends itself to presenting how the past is now, in rich, beautiful, and nuanced ways. However, they also maintain that these new spaces create an intimacy of discovering place and purpose that exists in alternative ways. The concept of discovery was discussed in part through Chapter 3 situation of creating spaces of progress made available through the public works of Stephanie, Nicole, and Karen. To continue, Vern offers the idea that:

[Identity in space] creates all kinds of things. So I think my case, interestingly enough, my father knew I was a lesbian before I realized [it]. He told my sisters "I think Vernetta swings the other way, and if she ever wants to talk about it, I'm here.” He died before I came out. When I came out, my sisters told me that. But it was a beautiful gift. My mother freaked out. [She] has since come around. But I felt more awkward in my family initially and then this funeral that I just went to, my partner went with me. And I felt the most comfortable. 
Discovering lends itself to the collusion of past and present in creating new self-spaces. Admittedly, such an idea waxes poetic about positive possibilities in lives fraught with identity-based violences. However, discovering presents itself as type of coping mechanism. I would like to refer once again to the scenario that opens the previous section that involved Stephanie and her wife Trish. When Stephanie talked about the unnamed mother who dismissed her in her home, she says,

At one time in my life that would have made me make her talk to me. I would have been in her face, following her to make her talk to me. But now it's like, "that's your problem. That's not even my thing. That's your problem". So that's how I deal with the race part of it now. It's not my problem if somebody has a problem with me being black. I don't have to go home to them. And I don't have to continue to interact with them. I've got a large enough circle of people who don't feel that way. So encountering people like that on the outskirts, yeah it kinda pisses me off a little bit, but I keep moving.

Stephanie does not dismiss the experience and the violence, but I believe her past experience gave her more of an impetus to participate in the theatre she creates.

Tausha is open about her life with both her family and community and has felt free to embed herself into place with no apologies. Similarly, Rebeca seems to experience a lack of limitations in the ways that she can involve herself in the community (once she has moved past the initial shock of local culture). She notes,

There's a sense of independency [in Western North Carolina]...I'm free to think however I want. The people in this area do. We are who we are. Well they're mountaineers. Whether their country people. Whether they're granola types...They're true to themselves. I feel free to explore who I am here. I don't feel as confined as I do in urban areas. 
By confinement, Rebeca means that does not feel she is delineated to only being involved in the black community, which is a direct relationship to identity politics and, most certainly, black communities as a site of abjection. Instead, she understands and utilizes place and region in ways that allow her fluidity to discover herself and make a comfortable home, as she describes it, on "fertile ground."

$* * * * *$

I have not really taken the time to talk about the fact that three women included in the dissertation project are residents of the town of Asheville, with a fourth who has other ties there. Asheville is a peculiar fixture in the American South with global popularity for tourism and retirement economies and a reputation as a progressive, open and affirming town for a diversity of people. In fact, I would hypothesize that some visitors and new residents in the region attempt to distance Asheville from the mythologies of the South. Nicole reified a similar sentiment during her interview, stating "Asheville seems so progressive...beautiful and open" but when you "get down to the nitty gritty, it’s not diverse at all”. Ironically enough, Tausha noted that her undergraduate institution - the University of North Carolina at Asheville - has an underground reputation:"UNC-A is supposed to be on that secret list...it's one of the top 5 places, supposedly, of the 15 places to send your kid to college to ensure they will not run into a minority”. With such a reputation, it is not so peculiar that the progressive label of Asheville is more antithetical to the ways it is experienced by people who live there. These spaces are not 
without complication, which I have argued before in the dissertation. These women fight for their spaces and endure varying types of violences. However, their ability to situate themselves in space, particularly in white Southern mountain spaces, speaks to an opportunity to place them in seemingly homogenous places. They have opportunities to wrestle with the painful legacies of the past and birth new ways (a la Southerners on new Ground, noted in Chapter III).

In their interviews, I never brought up race as a potential probe. Instead, all of the participants brought up the ways their lives intersect with race and place, solidifying evidence for examining these nuances on an individual basis. Pointing out the commonality among the interviewees is certainly crucial because "Identity-research which avoids thinking race both materially and politically risks the elimination of the experiences of modes of oppression, rupture, mimesis, self-hate and denials. Instead, a polished rather than ruptured version of identity in contemporary research is encountered; the violences are narrated out of the dissemination, or indeed evaded in the process of conceptualization” (Tolia-Kelly 2010, 361). Moreover, Katherine McKittrick argues that to contribute to such a project requires a recognition of varying identity-based perspectives, arguing "the landscape, our surroundings and our everyday places, the vessels of human violence, so often disguise these important black geographies; they can hide what Sylvia Wynter calls 'the imperative of perspective in struggle’” (McKittrick 2006, xi).

Before I conclude the chapter, I would like to situate the language I have used in the chapter as I also consider them important in contributions. Related to the space identity demands, I utilize verbs to encapsulate the space of identity. After all, the 
chapter is titled The Identity Space Demands. Therefore, it is important to point out that identity, space, and geography are not fixed. Rather they are unstable, messy, and continuous processes. I not only used verbs to organize the chapter - name, un-name, belong, un-belong, discover - I used the present participle forms of the verb (also called the infinitive) by adding “-ing” to the end - naming, un-naming, belonging, unbelonging, discovering. The present participle form of verbs specifically refers to things that are still happening. Therefore, my word choices are intended to reflect the processes in spatial production that the women represent.

When I wrapped up my interview with Stephanie, I asked her why she thought people were so intensely attracted to living in the mountains. She responded by saying,

People say it's this magnetic pull. I forget what you call it. They have a name for the thing. They say that it's somewhere in the mountains. But they say that it draws people here. And I believe that only because all the people that you meet that have come here from other places, they need to be healed. There's some hurt that's there that they've come here for some reason to find that healing place. So there's something about Asheville that does that. I don't know if it's just what the universe intends and Asheville is the place to come and heal. Asheville is kind of like a halfway house. You come here to get yourself together and to renew your spirit and to become this different person.

In the current chapter, I have discussed the ways that space demands something of identity. In doing so, I have highlighted the inscriptions, challenges, and nuances characteristic of the production of space. The women whose stories have been 
transcribed in the chapter represent sites for the production of geographic knowledge through narrating their spaces of material trajectories of interlocking, multiscalar lives. In turn, they become knowable bodies, rather than unknowable, and in a sense, they reclaim the margins and connect them to present struggle and beauty. Towards the beginning of the section "Belonging/un-belonging”, I referenced the varying, "bounded” spaces that became common threads across the discussions with each woman. The space that I decided needed to be a separate discussion is religion. In Chapter V, I expound on the creation of spaces presented in the current chapter by focusing on the ways religion, particularly Christianity, permeates the Southern and Black experience simultaneously. 


\section{CHAPTER V}

\section{BLACK WOMEN, SEXUALITY, AND RELIGION}

In an email entitled “There Comes a Time”, sent September 13, 2011, Rev. Beach-Ferrara of the Campaign for Southern Equality announced the launching of the organization’s latest campaign they were calling “We DO”. Beginning online on September 19, 2011, the campaign would call "for full equality under the law for LGBT people”. CSE's strategy for the campaign was to hold (using the language of activism) “actions” beginning October 3, 2011 and continuing every day through October 13, 2011. The actions called for same-sex couples to file for marriage licenses in Asheville, knowing ahead of time that the couples would be denied their requests. In the email, Rev. Beach-Ferrara states that clergy members, as well as other witnesses, were prepared to accompany each couple as they committed their acts of civil disobedience. On October 14, 2011, the couples would come together and submit themselves to repeating the same act of civil disobedience accompanied by a group of clergy and witnesses. Rev. Beach-Ferrara writes that prior to action, "we will be holding a public interfaith blessing for all LGBT families in downtown Asheville” (Campaign for Southern Equality 2011).

The email described above uses clergy as subjects in the "equality" narrative, connecting them, their bodies, the lives, and their religious practices to lgbtq people. In fact, in 2014, a lawsuit was filed by a group of clergy in North Carolina. In their complaint, they argue that the inability to perform same-sex marriages inhibits their right to express the freedom of religion. 
It is no secret that the South and Southern people have maintained close connections to religious institutions over the past few centuries, particularly with Christianity. I recall being a first time visitor to a non-denominational, multicultural church in September 2009, shortly after moving to Miami to pursue the PhD at FIU. As I was entering the church, a woman from the ministerial group charged with greeting visitors and parishioners greeted me. After learning that I was new to the church, the woman invited me to the hospitality room after service, where they would be serving coffee and pastries and where visitors and members of the ministerial group would be able to get to know each other more intimately. After service, I took advantage of the coffee offer. The woman who greeted me before service approached me again in the hospitality room, asking me a couple of questions about my background and how I found the church. After explaining that I was originally from North Carolina, she exclaimed, "You're from North Carolina? Oh, you must be a Baptist.” While it is true that I am Baptist-born and raised, perhaps the more interesting aspect of my encounter with the her is that the woman instinctively, without a second though, associated place with religion. North Carolina is located in the "Bible Belt". Though subjectively mapped out, the "Bible Belt" region of the United States spans much of the U.S. South and geographically parallel areas of the Heartland, including Kansas, Oklahoma, and Missouri. The association of geography to religion is commonplace and, in some ways, a compulsory relationship. The compulsory nature of Christianity to Southern land is enunciated through Rev. Beach-Ferrara's email announcement described in the opening of the chapter. As an ordained minister in the United Church of Christ and a native North Carolinian, Rev. Beach-Ferrara strategizes her campaign to include the support of 
religious figures. The Campaign for Southern Equality’s strategy simultaneously announces and addresses the tension between discourses of religion and same-sex sexualities. Having religious figures accompany same-sex couples as they attempt to challenge the state through applying for marriage licenses stands in contrast to the commonly preached "homosexuality is sin" standpoint.

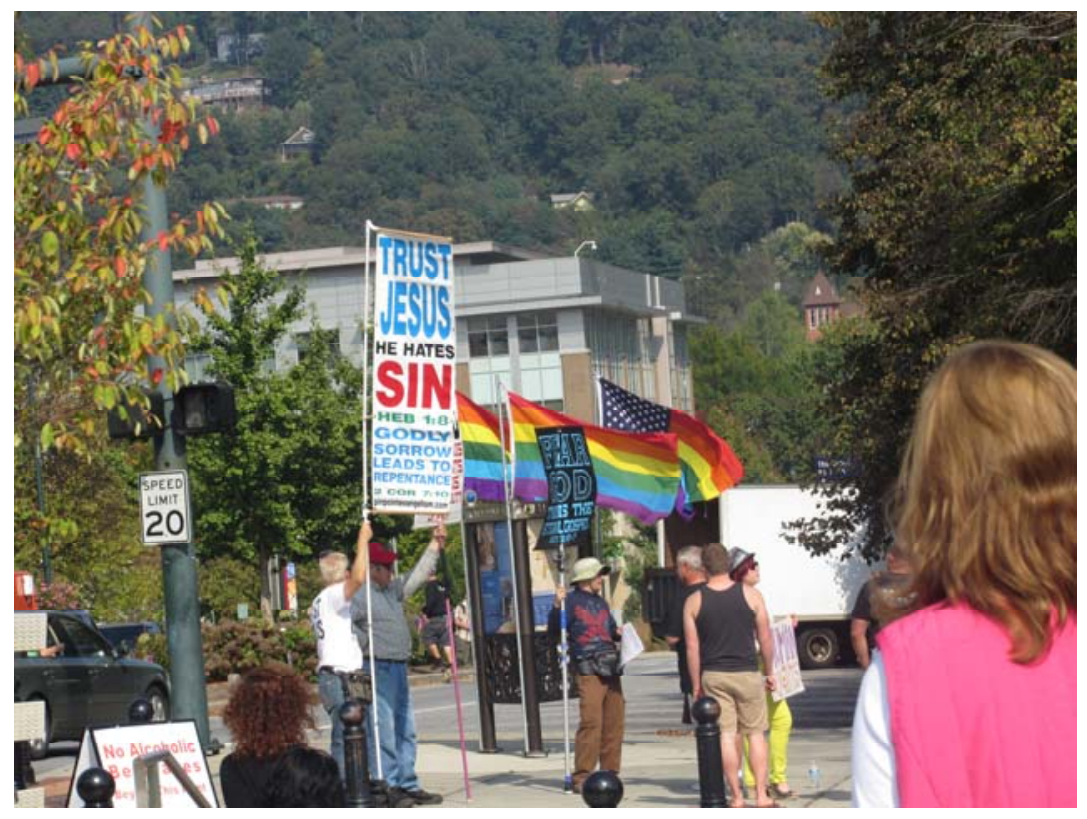

Figure 9. Religious protesters at Blue Ridge Pride, October 2012

I think it is almost impossible to have a discussion about gay and lesbian identities without connecting it to a conversation about religion. While attending the 2012 Blue Ridge Pride festival in Asheville, I saw the protesters shown in the photo above were located on the periphery of the festival grounds. They, like other Christian-oriented individuals and groups, have become regular fixtures at lgbtq pride festivals and events across the country. Their consistent presence is a reminder of the regulatory relationship 
between Christian theology and gay, lesbian, and queer sexualities. Even more so, because my research deals with the region, a discussion of the South warrants that religion be included in a discussion of place as religion is integral to Southern identity. If there is a boundary to mark the South, it is evidenced by noticeable changes in spatial energy upon crossing the borders of peripheral states, such as Pennsylvania and Delaware, into states such as Maryland and Virginia. The increased visibility of Christian-based thinking demonstrated by a higher number of Christian radio stations and other media, highway and interstate billboards with varying topics of common religious discourses, and the prominence of church buildings throughout Southern landscapes all provide evidence of the intensely intimate relationship between the South and Christianity. Moreover, I think it is also important because it continues to highlight the continuing significance of religion in Black communities and with Black people. The Black church, simultaneously an imagined and material geography, has a stronghold in the thought and actions of Black people and communities. Moreover, the Black church is often brought up in the context of social issues, poignantly in contemporary times around discussions of lgbtq rights. During the Amendment One campaign in North Carolina (referenced in Chapter 3), special attention was paid to African American communities, particularly the Black Church, because members of black congregations were largely expected to support Amendment One (criminalizing the recognition of same-sex marriages in the state). ${ }^{3}$ Whether or not people actually follow Christianity, it certainly impacts their lives. In a summary of contributions of religion, space, and place to the

\footnotetext{
${ }^{3}$ See, for example, http://www.wcnc.com/news/Black-churchgoers-break-with-leadingDemocrats-on-marriage-amendment--148405205.html
} 
discipline, submitted to Progress in Human Geography, Catherine Pace, Adrian Bailey, and David Harvey argue that "geographers have been slow to fully acknowledge the place of religion alongside such axes of identity as race, class, nationality, and gender in their analyses” (Brace, Bailey, and Harvey 2006, 28). They continue by asserting that “in order to understand the construction and meaning of society and space, it is vital to acknowledge that religious practices, in terms both of institutional organization and of personal experience, are central not only to the spiritual life of society but also the constitution and reconstitution of that society” (Brace, Bailey and Harvey 2006, 29).

During my interviews with the six women who comprise the core of the dissertation, I never directly asked them about religion. Instead, like race, it was an organic and natural progression of conversation for them. When they brought up religion or the church, I would occasionally probe for additional information if I judged it would be useful. Other than race, religion represented the most explicit, pronounced, violent and reflective spaces and moments in their lives. Consequently, I chose not to ignore such a significant aspect of their selfhood. In the current chapter, I discuss the ways religion is embedded into the lives of Black queer and lesbian women by using the following three themes:
A. Black queer women's religious backgrounds
B. Religion shaping women's lives
C. Moving forward with/out a religious identity 
My participants come from a wide range of perspectives and experiences, which is evident by what has been exemplified and discussed throughout the dissertation. Their ages range from 23-54. They work in diverse professions. Some are married or partnered, and others are not. They have lived in a variety of places, including New York, New Jersey, Kansas, Missouri, and Georgia, as well as other parts of North Carolina. I use these demographics to assert that church conservatism is not limited to the South. Vern and Rebeca are from New York and New Jersey respectively. Vern's New York placement could talk about the tension of church versus sexuality in an area that's heralded for its significance of visibility of lesbian and gays through other markers of global gay identity and its placement in the era of lgbt movements. New Jersey is not the same as New York. The very present role of the Christian sacred transcends space and time. Even in the increasing secularization of the United States, the dominance of Christianity is undoubtedly interconnected. The other women, on the other hand, were connected to religion as natives of Southern and rural geographies.

\section{Religious backgrounds}

All of the women I interviewed identified experiences with Christianity, having all been raised in and had, at least at some point, practiced the Christian faith. Out of all of my participants, Tausha probably had the least pronounced experience with Christianity and, therefore, does not appear very much in the current chapter. She told me that she grew up African Methodist Episcopal (AME) Zion and did not indicate any continuous or regular involvement (though she may very well still attend every Sunday). 
The other five women are discussed more in depth, both in the current section and the two that follow.

Vern contacted me over email in June 2013. I am not sure, nor is she, about how she came to know about my project. She emailed me from her work account, which is immediately something that stood out to me in terms of her trusting me before she even knew me by giving me a type of direct access to her life. After some email exchanges, she and I set out to meet on a Wednesday in July. Our meeting was moved because she ended up having to leave town to attend a funeral. We rescheduled the following Wednesday afternoon. I contextualize the conversation because I believe that Vern attending the funeral was significant and put her in a reflective space that, in turn, allowed her to think through and respond in a more open and vulnerable way during her interview. She pointed out her age and end of life and those types of things as if they were at the forefront of her thoughts. As outlined in Chapter IV, she came to understand her same-sex desire late in life. She was married to her former husband for over twenty years. In her marriage, she gave birth to a daughter and adopted "a whole truckload of kids" into the home. She raised her kids in the church and, as evident by her regular religious involvement, Christianity was a very present reality. Moreover, Vern was the chaplain for the children's agency that she worked for in New York and had worked there for 20 years by the time she left for North Carolina. In her "coming out" experience, she notes that she had been fortunate in the overall ease of coming out, though noting that being at the children's agency “was awkward because I was this straight, protestant chaplain woman and then, at the end of my 20 years there, came out as a lesbian.” 
Stephanie also had a long lasting relationship with Christianity. She grew up Southern Baptist before her family moved into the Methodist tradition. She describes the deep religiosity of her family life:

My family is very religious. They go to church four times a week, kind of religious. Before I moved here, I started in a Baptist church. And then somehow, as we do, we migrate into Methodist. I don't know how you go from Southern Baptist to Methodist but it's funny that the Methodist is still the Southern Baptist, just under a different name.

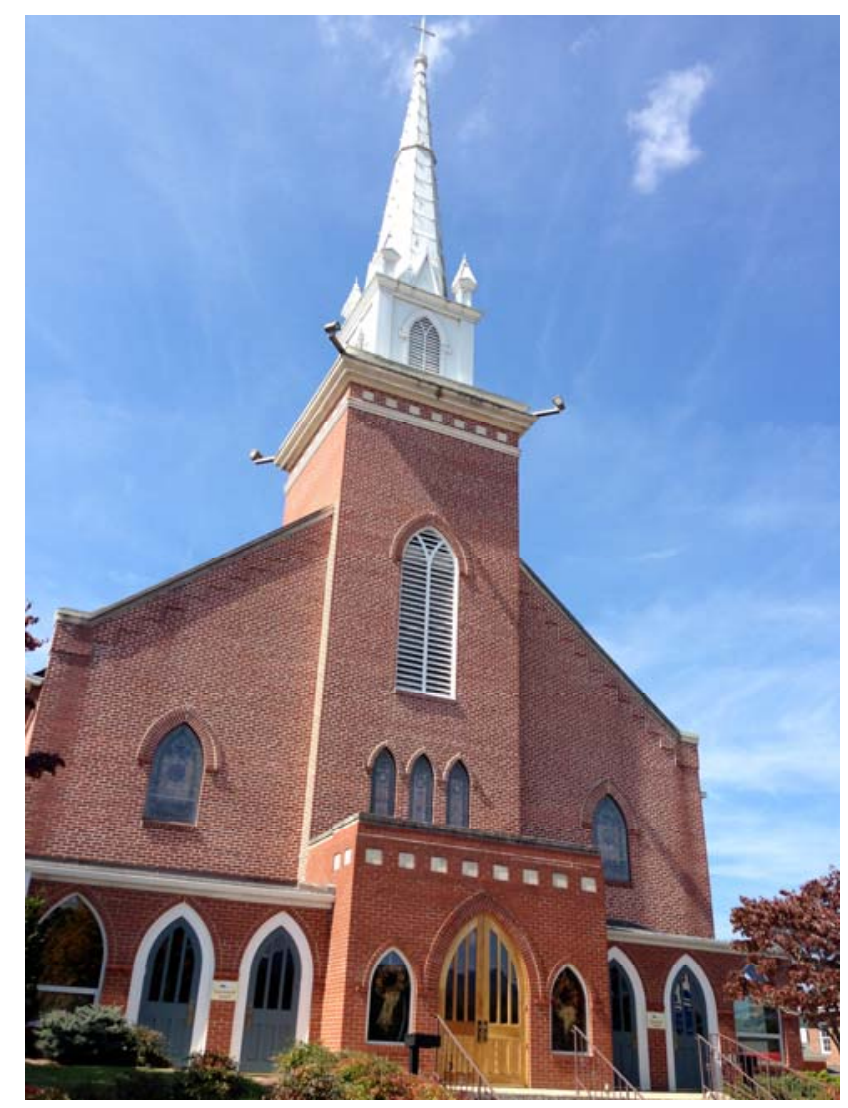

Figure 10. First Baptist Church, located next to Blue Ridge Books in Waynesville, North Carolina

When walking to Blue Ridge Books for my interview with Rebeca, I walked past the church above in Figure 9. It is located next to Blue Ridge Books and is prominently 
positioned at the peak of a hill in downtown. Churches like these are the massive and ornate fixtures of the South that cannot be metaphysically or materially ignored. They are always present. In her interview, Rebeca talked about her experiences growing up in New Jersey. When she talked about a religious identity, she says, "I grew up for 22 years in fundamentalist Christianity, very similar to $7^{\text {th }}$ Day Adventist, but keeping a lot of the Jewish traditions. We didn’t celebrate major holidays like Christmas and Easter and even birthdays.”

I interviewed Karen over the phone. Like Vern, Karen didn't know where she got my name or information. She emailed me in May 2013 offering herself to be interviewed. Karen is very grounded in religion, more so than anyone else I interviewed. In each interview, I asked each woman to talk to me about their background. She listed off a series of identities she claimed, including "African American, female, lesbian, activist, advocate for HIV/AIDS, fun-loving, good sense of humor, all around good person". And "Christian". She is the only person that I interviewed who really identified in that way, meaning as presently identifying as a member of the Christian faith. Nicole is the only other person who has come close, as she called herself a "non-practicing Christian”.

\section{Religion shaping women's lives}

In current section, I detail specific experiences that have shaped the women's connections to their faith. Vern, Rebeca, and Stephanie all shared the moments when their relationships to the church were severed. Karen's experience varies somewhat 
because she has found ways to satisfy herself with institutional religion and her personal convictions.

Given that she raised her children in the church and that she was a chaplain at her past employer, it can be understood that Vern's relationship with religion was a very close one. In her interview, she reiterated these connections saying, "We were churchgoers" and adding, "My husband was a deacon in the church.” A church deacon is a highly regarded member of the congregation, typically privileged as a position for men in Protestant denominations. The process for selection and training can range from a few months to a few years. Deacons are typically assigned specific church members and are charged with caring for practical needs in the congregation. Given that Vern's husband was involved in church as a deacon, it can be understood that she was held in high regard as well, by virtue of her marriage to him.

Vern's commitment to the church was also signaled by the decision to go, with her husband, to their pastor after she came out to her family:

And so one of my first stops with [my husband] was [with] our pastor, who basically said I couldn't be on the female softball team after I told him this news. But my husband said, "That's ridiculous", and so I [was able to stay] on the female softball team. My daughter was playing on the softball team at that time as well. I stayed on the softball team, but I was basically not allowed to do too much more in the church because of my sexual identity. Eventually [I] just stopped going there because I didn't feel welcome.

It is unclear how long Vern stayed with her congregation. In spite of her evident commitment and involvement to the church, her coming to terms with and sharing her sexual identity became the cause of the rift. 
As mentioned in the previous section, Stephanie’s identity with religion has been very grounded in her family’s traditions. She says, "I migrated to [Methodism from Southern Baptist] with my family. We were all in the same church. I was the Sunday school superintendent. I was choir director, and I was a youth leader.” Because Stephanie held major roles in church leadership, it can be inferred that the church held her in high regard and that the church served the same purpose for her. Stephanie's story of leaving the church resonates in a disheartening way.

I would argue that Stephanie and Rebeca had what I would term the most violent experiences with religion. I make that argument because in their interviews, their respective tonalities and body languages signaled the scars that their experiences left behind. In her interview, Stephanie describes the occasion that made her leave the church:

[T]he United Methodist women, every year, would have a lock-in. Now my partner at the time used to go to church with us. So, they have a lock-in. And we had a fellowship hall. There were three floors in the fellowship hall. So what the women decided to do was on the first floor, they had hair and makeup. On the second floor, they were doing fingernails and pedicures. And they were doing all this stuff on the 2 floors and...that's not me. I was at the lock-in, but it's not me. And it's not her [my former partner] either. She's just like me. We're both in the gray area [in terms of gender presentation]. So we brought our scrabble game, and we stayed on the $3^{\text {rd }}$ floor where everybody was sleeping. We played scrabble all night. Now, keep in mind, we lived together. So that [following] Wednesday, I'm at whatever meeting we were having on Wednesdays. It's usually Bible study or something. So the pastor's wife says, "I need to talk to you about the new Sunday school books” because I'm [the Sunday school] superintendent. I'm like cool. So we made an appointment for the next day in [the pastor's] office. So I get there and he's not there, the pastor. So I get in there, and I've got her and three other sisters from the church. And the first thing she says to me is, "We heard that during the lock-in, you and [your partner] were upstairs having sex, and we have some people that are concerned. Because they say when you are sitting in church, sometimes you look at each other like you 
want to eat each other up.” So I get all this stuff about what they're hearing from different places and all that. And so she says, "We need to know are you a lesbian?” I said, "First I'm going to answer your first statement. [She] and I live together. We can have sex anytime we want to. And we definitely would not do it here. I said, number two, yeah, sometimes I do want to eat her up because I love her. And number three, yes, I am a lesbian.” And [the] next thing I know, I get this letter telling me that I need to step down from all of my positions in the church. For the youth leader, they felt like I would end up impressing the kids in the wrong way, setting a bad example. And for the other ones, that until I could renounce being a lesbian and ask for forgiveness for that, that they did not want me in any leadership role. I said cool. And never went back. Never looked back.

I should emphasize that at the time of the interview, it had been 18 years since the experience with the church that made her leave it. It remained very painful for her to move forward from the experience. She talked about "breaking out in a rash" when even thinking about going into a church. It is hard to swallow that when you invest so much energy and love into something that is violently taken from you. Moreover, it is also problematic that the pastor's wife decided it was better to lie about why she (or rather, the pastor) needed to meet with Stephanie. Had she known the actual reason behind the meeting and who would actually be meeting her there (four women from the church instead of the pastor), there might have been a less violent outcome.

In his essay " Feeling the Spirit in the Dark: Expanding Notions of the Sacred in the African-American Gay Community”, E. Patrick Johnson writes that when Black churches address sexuality, it reifies a heternormative ideal, even when members “married and single — engage in out-of-wedlock, multi-partnered, and even anonymous sex, the condemnation these members receive (if they are condemned at all) is tempered by the fact that the sex in which they engage is still heterosexual” (Johnson 2000, 401). Because Stephanie explicitly delineated her needs and desires at the lock-in (playing 
scrabble rather than doing her hair and fingernails), she became the subject of scrutiny about her personal life. She then became very visibly frustrated as she continued her story:

Because those same women that were sitting in that room asking me those questions, their husbands were the same ones calling us asking us for a threesome. Or passing notes in church. There was one day that our air conditioner was out, and so the pastor had us sit, had the choir, sit down in the first few pews. The audience [muffled] normally sit behind [muffled] he said I need to preach to all of y'all today. So he had us sit down [in the pews]. [I]t was hot so I was coming out of my robe. Before I sat down and the next thing I know I get this note. And it's from one of the husbands telling me "You shouldn't take your clothes off like that in front of me. You know what it does to me”. That's the kind of stuff, you know. But because I'm a lesbian, I can't be in these leadership roles. And you [have] all these perverts sitting out here, and that's ok. I can't handle it. I can’t handle it.

Patriarchy and sexism in religious communities have been and remain commonplace practices. Though churches have made some strides in dismantling their patriarchal practices by welcoming women ministers and having them involved in other capacities (including the deaconship in some cases), there are issues in the hierarchy, particularly for conservative or fundamentalist groups, that remain and consequently create a double standard. As bell hooks argues, "Concurrently religious fundamentalism imposes on females and males repressive notions of sexuality which validate sexual coercion in many different forms” (hooks 2000, 109). The unnamed husband in Stephanie’s story would likely have been forgiven if had "committed adultery" and would have likely had the issue dismissed. He likely would not have lost any positions he held, and his wife would have stuck by him while demonizing "the other woman” (likely calling her a Jezebel). 
I would like to shift to Rebeca's disconnect with her community of faith. I actually almost missed Rebeca's story about her religious identity. Earlier in the interview, she had mentioned being a part of a fundamentalist Christian faith for most of her life. Towards the end of my interview with her, I asked her how her transition to North Carolina (or really, the South) had gone and tried to get at the root of why she had moved. Given her initial skepticism and hesitancy, indicated by her interview and our initial encounter at Blue Ridge Books (see Chapter IV), I am not too surprised that she now comfortable enough with me to divulge a vulnerable story about her life. She began by explaining to me that she had moved to North Carolina at 18 years old and had gotten here by "running away from home”. Because the teenage years are riddled with desires to move, run away, and discover, that piece was not surprising. However, as she continued, I understood better the position from which she was coming. She said, "I was struggling spiritually at the time" while trying to work through her "same-sex attraction.” She continued by narrating her growing tensions with her family around her sexuality:

At the time, I hadn't come out to my parents. I was having problems with my mom and so I talked to my family. And my dad even agreed at the time, you know, it's probably best if you leave. And an opening came up. Another church member, who claimed to have been going through the same experiences years prior, was kind of key in doing this kind of intervention thing with me. Where she was going to pull me out of the environment that she thought I was in - that was temptation. I had a person that I was seeing at the time, a woman who was older than me. And [the church member] felt like if I got out of that environment and came to a remote town in east North Carolina, I'd be cured of it eventually. That went on for a few years. I eventually headed west [towards Greensboro, North Carolina]. And the cure didn't happen, but the religion was the one to go. Sexuality was the one to stay. 
Though I do not hear much about conversion these days, it is clear that some folks, especially in very fundamentalist communities of faith, still vie for "the cure". What is more common is the message of "repent from your sins" and the discourse of "abomination", which are still incredibly violent for someone looking for the space to explore a spiritual relationship with a God who is said to love everyone.

As mentioned in the previous section, Karen is the only one who actively identifies with Christianity. Her religious life is shaped by her interest in contributing to her community. She serves in several mission-oriented auxiliaries in her community of faith, including the homeless ministry and prison ministry, that are additive to her interests in other community issues such as HIV/AIDS organizing. I regret that I was not able to ask Karen about which church or the type of church with which she affiliated during our interview. Nevertheless, it maintains an active and important space in her life. When asked about negotiating these identities, she stated, “I don't have to be gay at church. I am who I am. I don't have to single one thing out.” Karen made a joke about being at church and greeting other parishioners, “'Oh hey. How you doing today? Nice to be in church today. Lesbian.' That's not necessary.” Indeed, it is not necessary. However, even if she does not greet other people with her "lesbian identity", she may fall into the space with countless other people who are complicit with the silences around same-sex sexuality in church (a sort of don't ask, don’t tell) because they have a vested interest in maintaining the type of community that church provides or she could be a member of an open and affirming congregation, which is a type of church that is gaining rapid popularity and commonality across the South and the United States more broadly. I 
cannot even correlate either of my theories to Black church discourse because I do not know if she attends a traditionally Black church. She could attend a traditionally white church or racially heterogeneous one. I would imagine that, based on Karen’s social justice and activist interests, that she does not attend a church that incorporates messages of abomination and promoting hatred in their sermons and proselytizing.

Karen also embodies a type of social gospel in her everyday life. In other words, it was evident throughout her interview that the language of the church is frequently accessed and used in everyday conversations, outside of church walls and church communities. It accompanies a type of literalism that is common in communities of faith, such as Black churches or Pentecostalism. During her interview, she made references that I immediately identified as common church discourse. In that sense, my positionality as one who was raised in a Christian church allowed me to access and understand the type of language she used with me. For example, when Karen described community, she stated that it is a "community of people who love each other like family. Socially related, like the body of Christ". She expanded by stating it meant, "People care about something other than themselves.” At another point in the interview, she made reference to "going home to Glory", a phrase that is commonly used to describe the time after death, with "Glory" signifying "Heaven" or "in the presence of God". Her use and ease of language helped me to understand that Karen needed her faith and her church to feel complete and that it is inextricable from her identity, which includes her sexuality. 


\section{Moving forward with/out religion}

In the current section, I talk a bit about where the women stand now in their faith practices, versus discussing their pasts directly. As I have argued throughout various points in the dissertation, the past never goes away. Rather it reshapes and manifests in other ways. In regards to religion, E.G. Ward asserts, "But what is also striking is the influence it wields indirectly in the lives of those that are not churchgoers. Even if as adults they no longer embrace the church or religious principles, many blacks have been profoundly influenced by the church ideology and imagery with which they were raised and continues to influences their later beliefs and practices” (Ward 2005, 494).

As stated earlier, Nicole considers herself to be a "non-practicing Christian". Her interaction with religion manifests through her personal struggles with supporting her friends who hold strongly to their church ties and maintain a stance outside of church that is contradictory to what is preached every week - possessing more liberal values and accepting Nicole's personhood. Nicole goes to church with her friends to support her "gay" and "straight” friends, who receive a variety of recognitions at church or who are themselves ministers, and she does her best to understand the balance of her friends' dualistic existence. In her interview she said,

Since we are in the Bible Belt, it is really interesting [here]. I have a [straight] friend who is in the position of becoming a minister. So I went to support her during her first sermon. And one thing I will say is that I've grown tough skin in the past few years, especially around my sexual identity. And it was really interesting to go to a church to support a friend and have to hear them talk about how homosexuality is bad. But yet, in previous days [they] support me and say there's nothing wrong with it. So I feel like there's this battle with the Black church that we have here. It's like, “OK. When I'm outside of church, I can think this way, but then when I'm in church, I have all this pressure on me to say 
'what's right' or what people deem is right.” I don't know. It was a little uncomfortable because I felt like I had I all eyes on me but in a very "Is she gonna go get saved today?" kind of way. Like "She's a great person, but if she was not a lesbian, she'd be perfect', you know?”

It is argued that double standards abound in common Christian practice, which might explain the reports of increased secularization in the United States. The example from Vern in the previous section and the one above from Nicole might provide clear evidence of the practice. It almost becomes an expectation of religion, especially situated in the Bible Belt as Nicole placed it. In reflecting on the ways that people practice hypocrisy, it is not surprising that Nicole would say she is non-practicing. She concluded the story above saying, "I grew up in the church, but I kind of stepped back from it. People will accept me as someone who is trying to help the Black community but they don't accept me as [a lesbian]."

What happens when a person finds herself outside of a religious community that had been a cornerstone of her life and is now unsure of how to move on? In her interview, Vern gave an indication of how she has traveled that road:

[I used to go to] church, and [I used to be a] chaplain, all that stuff. Earlier in my life, I would identify as a born-again Christian. Really active in church and raised kids in church and all of that. After I came out, I felt that my religious belief exploded. Just didn't make sense to me. I just didn't know what to do with it. Initially. Years later, I had lunch with a friend that's an Episcopal minster and he said to me, Maybe my faith didn't explode. Maybe it expanded. And that was really helpful to me. Because from that point forward, I just sought my relationship with God personally. And didn't need something organized necessarily to sustain that. Since then, my partner and I...she's kind of a new age-y person. Since then, we have become a part of a spiritual community that we both feel comfortable at. 
Now living in North Carolina, she has explored other options for maintaining her relationship with God and spirituality. In her interview she stated, "Here in Asheville...for instance, I've gone to Jubilee! I don't know if you've heard of that church. When my daughter came to visit, I took her there. And she said, 'it's a hippie church, mom'. Yeah, so it’s like a hippie church.”

Stephanie also mentioned Jubilee! in her interview. She states:

Trish and I and [our son] go to Jubilee!. Jubilee! is not a church to me. Jubilee is non-judgmental. They don't preach to you from the Bible. Trish and I can sit there and hold hands. We have our son sitting on our lap. And nobody looks twice.

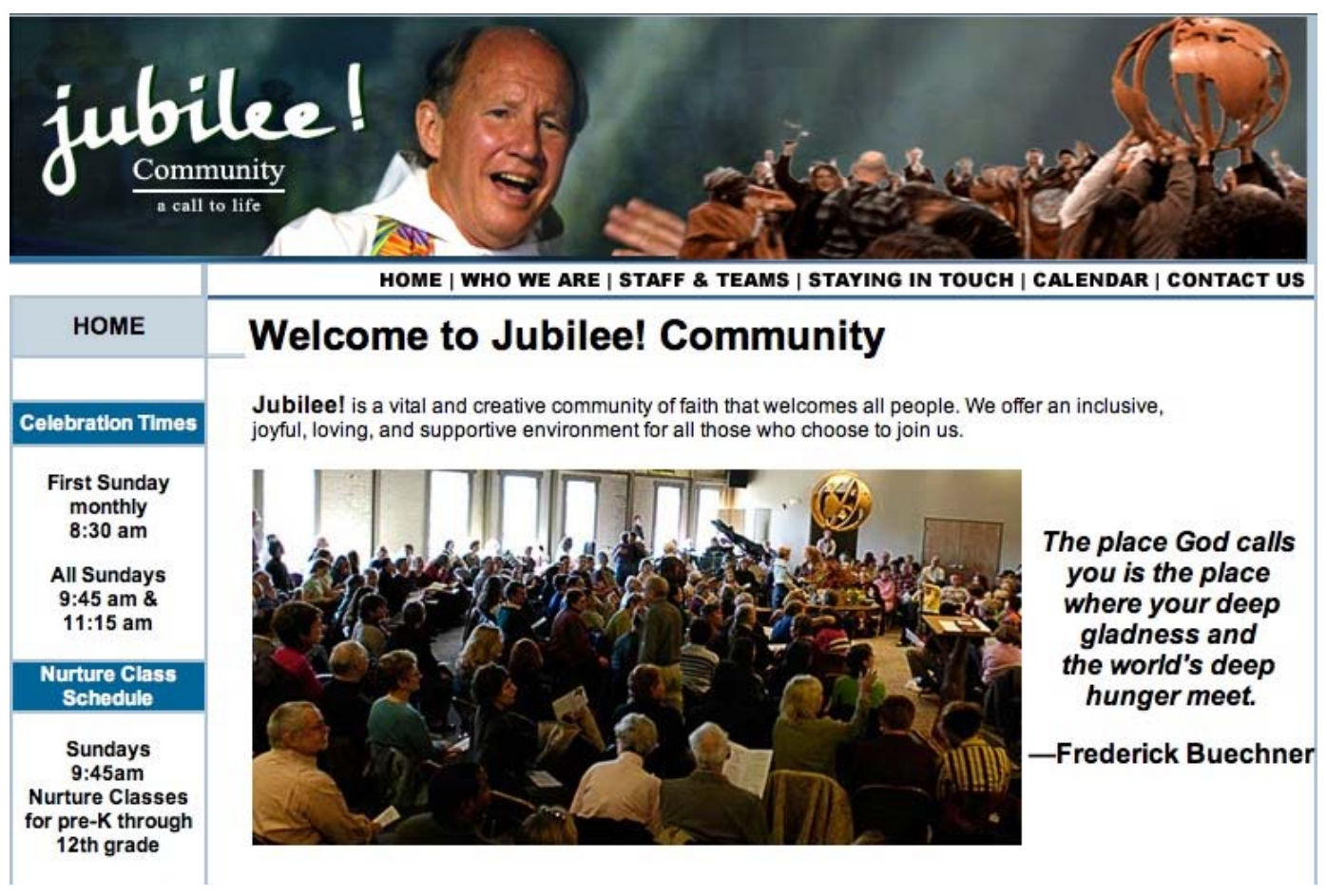

Figure 11. Screenshot of the homepage of Jubilee! 
Jubilee! is one of Asheville's unique religious fixtures, a multicultural, non-traditional community of faith. On their website, they describe themselves as "a vital and creative community of faith that welcomes all people. We offer an inclusive, joyful, loving, and supportive environment for all those who choose to join us”. They continue by saying, "At our Sunday Celebrations we express our faith through music, dance, poetry, evocative messages, and fellowship at our spiritual home on Wall Street in downtown Asheville, NC. And we also express it by sharing ourselves and our resources with other men, women, and children and with other organizations that serve our fellow humans, other living entities, and the Earth itself” (Jubilee! 2014). In the screenshot provided on their website, information is clearly presented about who they are, their mission, and how to join in their services. In a first encounter with the church's website, I was struck by the overwhelming whiteness that represents their inclusive ministry. Of course, a photo provides only one perspective of place and time. However, it makes me curious about their ability to attract a multicultural community. I was also intrigued by the use of a quote from Frederick Buechner, an author and theologian, rather than a passage of scripture, which I would expect from a Christian church website. However, I consider the use of Frederick Buechner as additional evidence of their interest in providing a fellowship and worship experience that allows for an expanded expression of faith. Perhaps it also provides a nod to Stephanie’s statement that Jubilee! does not preach from the Bible.

Vern and Stephanie are the only two participants who gave me a named present day place for their religious experiences (from the interviews, it was a bit difficult to 
discern how frequently either of them attend or how involved they are in that space). Stephanie stated she would only go into a church facility to attend funerals. She stated that her parents, who remain devout Christians, will be buried in the church. As such, that is when she will go to church. Vern has found a community of faith that is more intimate, with a smaller group of friends (I think it's safe to call them that). She did not specify the name, type, or other descriptors that characterize her current spiritual space.

Rebeca stated that she no longer identifies with mainstream religion. She got out of the Fundamentalist Christian faith and its residual effects have caused her to distance herself from the experience of organized religious institutions:

I wanted to be close to how I defined God at that time. I found that in my box of Fundamentalist Christian values, this emerging need for the love of another woman, I couldn't fit it all in. It's like a suitcase, where you know you've packed so much and you can sit on the damn thing and you still can't close it. I found that was just too much to contain.

When she thought through her over-packed "suitcase" she said, it had to be either sexuality or religion, and religion was the one to go. After having lived in Western North Carolina for a short period of time, she described herself as more spiritually free-minded, being open to the ways that spirituality affords her more flexibility and peace with herself.

As I have mentioned before, Karen's Christianity is active in her everyday practice. Karen centralizes her faith in very enunciated and explicit ways. She continues to be very active in her church. She defines her church experience as in alliance with 
social justice activities. In one instance she referenced the work of her church, of which she was clearly proud, saying, "Our church is real big on outreach, and one extension of the church is faith-based housing that helps people coming out of addiction and in and out of prison.” She also performs Christian comedy, and, after the interview, told me how to find her comedic ventures on YouTube. Because she told me after I had stopped recording on the interview, I took it as a signal that she wanted to maintain her privacy in some ways. Therefore, I will not include the name of her YouTube channel in the dissertation. In these videos, however, she embodies an exaggerated character of a Church lady who performs various acts, such as reading absurd and comical church announcements in a manner not unlike those done by one of comedian Rickey Smiley's alter-egos, Bernice Jenkins, who appears regularly on his morning show. Karen is probably the most satisfied with the role Christianity plays in her life than most women I have met on my various life journeys and especially among those who I have interviewed.

$* * * * *$

All of the women I interviewed described that their relationship with God was more personal and fluid than the parameters from which they had set out. In other words, they have, for the most part, separated a relationship with God from what it means to be a member of the church. As Stephanie argued, "As far as a church [is concerned], [I have] nothing to do with it. [It] doesn't mean [that] I don't have nothing to do with God. I have my relationship with God. But the church, nuh uh.” 
As Vern put it, their faith must have expanded. Certainly, the journey has not been an easy one. Perhaps "the norming constrictions of religion" are notably difficult for parishioners of the Black church. The Black Christian church (broadly construed and somewhat imagined) has served as a pillar of community and support since the time of slavery. As Brown describes, “After emancipation, African American men, women, and children, as part of black communities throughout the South, struggled to define on their own terms the meaning of freedom and in the process to construct communities of struggle. Central to African Americans' construction of a fully democratic notion of political discourse was the church as a foundation of the black public sphere...As a political space occupied by men, women, and children, literate and non-literate, ex-slave and formerly free, church members and nonmembers, the availability and use of [church spaces] for mass meetings enabled the construction of political concerns in democratic space” (Brown 2003, 436).

Brown continues by saying, “The church provided more than physical space, financial resources, and a communication network; it also provided a cultural base that validated emotion and experience as ways of knowing, and drew on a collective call and response, encouraging the active participation of all” (Brown 2003, 442). The Black Church has operated as not only a place to meet religious and spiritual needs but also as an impetus for change in discriminatory practices, particularly those regarding race. The Church also lends itself to support the temporal needs of its parishioners, through working towards the alleviation of economic despair (Barnes 2006). However, it is argued that many of the social problems stand unaddressed by religious leaders in the Black Church, leaving only the importance of "godly living, worship, religious programs, 
and [the provision of] survival skills" that are intended to assist in withstanding social ills (Barnes 2006, 371), including the strongholds of racism and sexism. These persist despite the Church's local civic and political involvement, as they take on projects that support a specific geography within the locus of community. These perspectives are inconsistent, yet they provide an accurate portrayal of the experiences of Black Church politics, which are significantly weighted in accordance to time, place, and space.

Moreover, the queer sexual subject in religious space is subject to a series of power relations. Power can be understood "as an amalgam of forces, practices, processes and relations. Power might be understood as a myriad of entanglements of resistance and domination that are mutually constitutive of one another. Power is not just something that happens to us; we are engaged in these entanglements. Power operates through how we interact with one another, how we regulate each other's behaviour and consequently make the spaces that we inhabit” (Brown, Browne, \& Lim 2009, 5).

The issue concerns the potential dissension between conservative bodies of faith, dominated by patriarchy and heterosexuality and enveloped in homophobia and a resistance to dialogue about non-heterosexuality, and the queer political agenda. Black queer women's interactions with a community of faith, though they have political rights and citizenship rights, could result in an interesting critique of private vs. public. It is not uncommon to hear a prayer that comes against "the spirit of homosexuality" in the traditional Christian church or phrases that are intended to demonize same-sex relationships. As such, it can be argued that "persons who identify, or are identified, as queer have varying relationships to 'legitimate,' ‘dominant’ power” (Brintnall 2013, 52). 
Understanding that Black churches and Black religion have been the focal point of the Black community for such a long period of United States history, including before the abolition of slavery, requires one to pay attention to its role in every day life. As Mignon Moore describes, “In African American communities, religious structures provide direction for the language, rituals, and behaviors individuals incorporate in their lives. People participate in churches and mosques not just for spiritual guidance but also to find a sense of community, and they use the teachings of these religious groups as a set of practices or blueprints by which to organize their lives, however loosely or stringently" (Moore 2010, 205). She continues by describing the role that church plays "across so many different community institutions and social groups, many researchers suggest that in Black communities, the philosophies and beliefs of religious organizations significantly impact the philosophies and views residents have on other issues” (Moore 2010, 205). Based on my own previous experience as a small town Black southerner, social circles heavily revolve around the church. Black queer women, myself included, tend to do a lot of soul-searching in attempting to reconcile the multi-scalar impacts of religion on their lives - with self, lovers, family, and community. The role of religion in the lives of black queer women will continue to influence they ways they think about themselves and how they choose to interact with the world.

As a Black queer woman myself, the fact that religion came up in my interviews was no surprise. When I first began having conversations with my mother about my sexuality and my partner at the time, one of the first questions she asked me was, "Well, LaToya, what about the Lord?” To which I responded, “Well, Ma, some days we have good days. And some days, we don't. But I still believe.” The strength by which 
religion manifested in these interviews was undeniably a call to pay attention to what was happening in these women's lives. As argued by Brace, Bailey, and Harvey in the introduction to the current chapter, "in order to understand the construction and meaning of society and space, it is vital to acknowledge that religious practices, in terms both of institutional organization and of personal experience, are central not only to the spiritual life of society but also the constitution and reconstitution of that society” (Brace, Bailey \& Harvey 2006, 29).

$* * * * *$

The discourses around never really reaching a righteous state or always in a state of sinning and falling "short of the glory of God" (Romans 3:23) are difficult ones to manage for someone interested in pursuing a spiritual relationship with God in the company of other Christians. It is the constant state of sin that positions the Virtuous Woman, discussed in the opening of the chapter, as an unattainable standard for women. It can be argued that a sense of righteousness seems much less attainable for women who engage in same-sex/same-gender relationships and partnerships. The queer body in religion is a seemingly paradoxical force that is always "lost" and never "saved". Queeridentified people often endure sociospatial violences in order to maintain a sense of community that is rarely recreated outside of church space. As bell hooks argues, some people "feel that patriarchal religion is the only place where anyone cares about their spiritual well-being” (hooks 2000, 109). Queer bodies reveal power relationships that exist in lived space and these power relationships, if they are not subsumed, have to be 
negotiated systematically. The women in the chapter have made a variety of choices, some more forcibly than others, towards reconciling a relationship with God. 


\section{CHAPTER VI}

\section{CONCLUSION}

"The invisibility of black women speaks of the separate narrative constructions of race, gender and class: in a racial discourse, where the subject is male; in a gendered discourse, where the subject is white; and a class discourse, where race has no place. It is because of these ideological blind spots that black women occupy a most critical place - a location whose very nature resists telling. In this critical space we can imagine questions that could not have been imagined before; we can ask questions that might have not been asked before.”

Heidi Safia Mirza (1997)

As part of my preliminary fieldwork in 2012, I worked to network with people affiliated with organizations in Western North Carolina whose objectives were lgbtq focused or otherwise interested in social justice issues in an effort to snowball connections to folks I was interested in interviewing. I emailed the leader of an lgbtq group and set up a meeting with her. During our conversation, we talked through her experiences living personally and professionally in Western North Carolina. She informed me that she and her partner had left and returned after some time, with an interest in pursuing the work towards same-sex equality throughout the South. Considering her long-standing relationship in the region, I inquired if she knew of any queer black women with who I could forge a partnership with for my research. She struggled to think of one black person, man or woman, in the area that she could introduce me to interview for my project. However, because she knew I had a specific interest in women and rurality, she quickly informed me that she could guide me to several exurban enclaves of “old white lesbians” (as she put it) around Western North Carolina. 
I assert one of my earliest research experiences in the concluding section of the dissertation to allow myself to return to where I began. The dissertation began out of an interest and investment in documenting the peripheral and subaltern experiences of Black lesbian and queer women. Heidi Safia Mirza asserts that the location of Black women is unique and obscure and that "it is because of these ideological blind spots that black women occupy a most critical place - a location whose very nature resists telling. In this critical space we can imagine questions that could not have been imagined before; we can ask questions that might have not been asked before” (Mirza 1997, 4). Moreover, Audre Lorde argues, "It is not easy for me to speak here with you as a Black Lesbian feminist, recognizing that some of the ways in which I identify myself make it difficult for you to hear me. But meeting across difference always requires mutual stretching, and until you can hear me as a Black Lesbian feminist, our strengths will not be truly available to each other as Black women." (Lorde 2010, 276). Standpoint theorizations, as developed through Anglin’s work among others (Hill Collins 2005, 2007; Engelhardt 2005; McKittrick 2006) argue for the importance of experience and point of view. These particular knowledges of self and the social world through personal perspective offer the opportunity to make more nuanced, transformative understandings of space and place. Standpoint theories offer a perspective on power that contextualizes experiences of oppression beyond the question of gender into different understandings of oppression, which is connected to the initiation of feminist theory. These types of feminist interventions of place and space also contribute to a broader understanding of scale. The limited perspective of the person who claimed to be working towards inclusivity and social justice but could not identify for me even one potential research subject solidifies 
the need for the current research project. To base the need in theoretical discussions, the latter assertions about Black women’s standpoints from Mirza, Lorde, and other Black feminist scholars and critical scholars of power structures offer crucial foundations for augmenting the narratives of space, place, and landscape.

\section{Dissertation summary}

The dissertation has attempted to complicate the monolithic, conservative symbolism of Southern and Appalachian space and identity. Through an analysis of the production of space and place demonstrated by qualitative research methods, the dissertation has focused on discourses of sexuality in place by discussing the simultaneous existence of Western North Carolina as a radical geography of progress and a geography of privileged whiteness as experienced through and informed by the interview participants. The dissertation also considers the ways race is articulated through Black women’s sociospatial interactions with a particular interest in relationships of power as mediated by symbolic structures of the South. In interrogating the sociospatial nuances of identity, the dissertation centralizes religion and religious identity as spatial concerns, particularly at the convergence of Bible Belt geographies, Black space, and sexualities. The dissertation also synthesizes the complexities of and relationships to experiences of home and regional identity, connections to community and to region as well as the conflicts and empowerment of same-sex/same-gender sexuality and politics among Black women. The research revealed the ways race and racism acted as barriers to full inclusion into the participants’ respective communities, largely in relationship to gay and lesbian-specific organizations and events. The research also 
supports Black sexualities as a crucial body of work that serves as a significant and necessary standpoint from which to augment and restructure narratives of place and geography. Moreover, the research revealed the ways rural and small town spaces supported a sense of agency and personal freedom that was less bounded by identity politics of urban areas. Finally, the dissertation functions to show how the world could be known differently if by centralizing lives that have been relegated to spaces of dismissal by examining a loosely bounded area of land known as Western North Carolina. The dissertation has taken the opportunity to dismantle assumptions about region and place and to center the multiple knowledges that interlink in the creation and maintaining of space through the connections of Black women's lives.

\section{Research contributions}

The research enters into conversation with the scholarly endeavors of Black geographies and feminist and queer geographies underscoring how raced and gendered attributes become spatially constructed and recognizing the transformations and disruptions made explicit when linking people and place. The research also furthers the goals of emerging empirical analyses of the South that destabilize the normativities of place and region. The current dissertation represents one of only two known geography projects that consider Black women's sexualities as necessarily constitutive to Southern regionalisms, and thus build upon studies of Southern Black sexualities (E. Patrick Johnson) and empirical Black lesbian/queer women’s scholarship (Mignon Moore). Moreover, the research adds to a long line of research centering Black women as necessary agents of social understanding. 


\section{Limitations}

The research process extended a number of limitations to the plans I had originally set during the dissertation proposal and in preliminary fieldwork. When I completed my dissertation proposal, I had anticipated a few limitations. First, because of the sensitive nature of "queer" identity and the society at large, participants may be hesistant to openly disclose information about their lives for fear of being discovered. Second, and in a related fashion, the ability to be freely mobile in the region without compromising the research project may be limited and must be strategic. Finally, because participation in the research is voluntary, the sample may or may not be differentiated from others who did not volunteer or be representative of Western North Carolina. I continue to be in agreement with what I had anticipated. I would like to elaborate on the latter and add one additional.

First, I had initially planned to conduct twenty interviews for the project. As my time in the field progressed, I change the goal from twenty interviews and reduced it to ten. As stated throughout the dissertation, I only ended up with six. I made contact with several women during the fieldwork; however, the opportunities to interview never coalesced, either because of a lack of response by potential interview participants after a certain number of exchanges over email (or in some cases a lack of response after to my initial contact) or because I met many women who did not live in Western North Carolina. While I could have decided to interview the latter set of women, who lived in other parts of North Carolina (particularly the piedmont cities Greensboro and Charlotte) or South Carolina (particularly the Upstate, which is Western North Carolina's neighbor 
to the south), I maintained my commitment to WNC. Western North Carolina's unique mountain South geography and reputation for inclusive and accepting spaces was important to grapple with through the project. Moreover, because non-urban and mountain spaces are often relegated as spaces of whiteness and therefore unsafe for habitation by people of color, the experiences of Black women in WNC were important to centralize in empirical work. In the future, I can (should I choose to) expand the project into urban North Carolina areas.

Another limitation of the study revolves around methodologies. Because of the lack of prior research on Black lesbian and queer women in non-urban spaces, the methodological aspects were and are much harder to work around, decipher, and apply in the current research.. While I recognize that there are non-urban sexualities studies, none of them focus specifically on people of color. Therefore, my approach to this study was to link pieces of previous empirical work and add in my judgment about what might be effective.

\section{Final notes}

The dissertation underscores the specific social locations that allow the women to invoke the ways they make meaning as they mediate sociospatial interactions and trouble a narrative of particular ways of geographic knowledge on identity formations. In the dissertation, I have used my subject position to create an opportunity for definition of self, space, and place and the ways that these mediate. In the research process, I encountered varying tensions and agreements with hegemonic discourses that relate to spatial productions by feminist, queer, and race scholarship as discussed in Chapter II. 
Moreover, I have articulated that multiple dimensions of identity provoked through queer, race, and feminist discourses requires a fundamental transgression of knowledge that highlights the interrelatedness of power and knowledge to discourse of race, gender, sexuality, and place. 


\section{LIST OF REFERENCES}

AAG. 2014. “About geography”. Accessed February 3, 2014.

http://www.aag.org/cs/about_aag/about_geography_2/overview.

Anglin, M. K. 2002. Women, power, and dissent in the hills of Carolina. Urbana: University of Illinois Press.

Bailey, M. M. and Shabazz, R. 2014. "Gender and sexual geographies of Blackness: new Black cartographies of resistance and survival (part 2)”. Gender, place \& culture: A journal of feminist geography 21(4): 449-452.

Barnes, S. L. 2006. "Whosoever will let her come: Social activism and gender inclusivity in the Black Church”. Journal for the Scientific Study of Religion, 45(3): 371-387.

Bell, David, and Jon Binnie. 2000. The Sexual Citizen. Cambridge, MA: Polity.

Bell, D. and Valentine, G. eds. 1995. Mapping desire: Geographies of sexualities. London: Routledge.

Billings, D., Norman, G., and Ledford, K., eds. 1999. Back talk from Appalachia: Confronting stereotypes. Lexington: University Press of Kentucky.

Blaut, J. M. 2009. “Geographic models of imperialism”. In Henderson, G. and Waterstone, M., eds., Geographic thought: A praxis perspective, 23-34. New York, New York: Routledge.

Brace, C., Bailey, A. R., and Harvey, D. C. 2006. "Religion, place and space: a framework for investigating historical geographies of religious identities and communities”. Progress in human geography, 30(1): 28-43.

Brown E. B. 2003. "Negotiating and transforming the public sphere: African American political life in the transition from slavery to freedom”. In West, C. and Glaude, E. S. African American religious thought: An anthology, 435-474. Louisville, Kentucky: Westminster John Knox Press.

Brown, G., Browne, K., and Lim, J. 2009. Geographies of sexualities: Theory, praxis, policies. Farnham, Surrey, England: Ashgate Publishing Limited.

Brintnall, K. L. 2013. “Queer studies and religion”. Critical research on religion 1(1): 51-61.

Bryant, L. and Pini, B. 2011. Gender and Rurality. New York: Routledge. 
Building Bridges Asheville. 2014. "Homepage”. Last accessed January 28, 2014. http://www.buildingbridges-ashevillenc.org/.

Burman, J. 2007. "Deportable or admissible? Black women and the space of 'removal'”. In Black geographies and the politics of place eds. K. McKittrick and C. Woods, 177192. Cambridge, MA: South End Press.

Campaign for Southern Equality. 2014. “Homepage”. Last accessed March 3, 2014. http://www.southernequality.org.

Cohen, C. J. 1997. "Punks, bulldaggers, and welfare queens: The radical potential of queer politics?” Gay and Lesbian Quarterly 3: 437-465.

Color ME Brown. 2014. “Homepage”. Last accessed March 3, 2014. http://thecolormebrownproject.org/.

Cooper, A. J. 1892/1988. A voice from the South. New York, New York: Oxford.

Crenshaw, K. 1991. "Mapping the margins: Intersectionality, identity politics, and violence against women of color”. Stanford Law Review 43(6): 1241-1299.

Davis T. 2011. Southscapes: Geographies of race, region, and literature. Chapel Hill, North Carolina: University of North Carolina Press.

Detamore, M. 2010. Queer Appalachia: Toward geographies of possibility. PhD dissertation, The University of Kentucky. Ann Arbor: ProQuest/UMI. (Publication No. 3491655.)

Dictionary.com. 2014. "Redemption”. Last accessed April 17, 2014. http://dictionary.reference.com/browse/redemption?s=t

Different Strokes Performing Arts Collective. 2014. “Homepage”. http://www.differentstrokesavl.com.

Domosh, M. 1999. “Sexing feminist geography”. Progress in Human Geography 23(3): 429-436.

Donaldson, F. 1969. "Geography and the Black American: The white papers and the invisible man”. Antipode: A radical journal of geography 1(1): 17-33.

Duggan, L. 1994. “Queering the state.” Social Text 39: 1-14.

Dwyer, O. J. 1997. “Geographical research about African Americans: A survey of journals, 1911-1995”. The professional geographer 49(4): 441-451. 
Engelhardt, E. S. D. 2005. “Creating Appalachian women’s studies: Dancing away from Granny and Elly May”. In Beyond hill and hollow: Original readings in Appalachian women's studies ed E. S. D. Engelhardt, 1-24. Athens, Ohio: Ohio University Press.

Ferguson, R. A. 2004. Aberrations in black: Toward a queer of color critique. Minneapolis: University of Minnesota Press.

Gamson, J. and Moon, D. 2004. “The sociology of sexualities: Queer and beyond.” Annual Review of Sociology 30: 47-64.

Gilmore, R. W. 2002. "Fatal couplings of power and difference: Notes on racism and geography”. The professional geographer 54(1): 15-24.

Graeber, D. 2011. Debt: The first 5,000 years. Brooklyn, New York: Melville House Publishers.

Gray, M. L. 2009. Out in the country: Youth, media, and queer visibility in rural America. New York: New York University Press.

Hay, I. 2010. Qualitative research methods in human geography. South Melbourne, Australia: Oxford University Press.

Higginbotham, E. B. 1992. “African-American women's history and the metalanguage of race”. Signs 17(2): 251-274.

Hill Collins, P. 2007. Black feminist thought: Knowledge, consciousness, and the politics of empowerment. New York: Routledge Publishers.

Hill Collins, P. 2005. Black sexual politics: African Americans, gender, and the new racism. New York: Taylor \& Francis Group.

Hollander G. M. 2008. Raising cane in the 'Glades: The global sugar trade and the transformation of Florida. Chicago, Illinois: University of Chicago Press.

hooks, b. 2000. Feminism is for everybody. Cambridge, Massachusetts: South End Press.

Howitt, R. and Stevens, S. 2005. "Cross-cultural research: Ethics, methods and relationships”. In Hay, I. ed., Qualitative research methods in human geography, 39-71. Melbourne, Australia: Oxford University Press.

Hsiung, D. C. 1997. Two worlds in the East Tennessee Mountains: Exploring the origins of Appalachian stereotypes. Lexington: University Press of Kentucky. 
Hudson, P. J. 2007. "The lost tribe of a lost tribe: Black British Columbia and the poetics of space”. In Black geographies and the politics of place eds. K. McKittrick and C. Woods, 154-176. Cambridge, MA: South End Press.

Human Rights Campaign. 2014. “A bold new chapter in the South”. Email message to listserv. April 27, 2014.

Inscoe, J. C. 2004. "Slavery and African Americans in the nineteenth century". In High mountains rising: Appalachia in time and place eds. R. A. Straw and H. T. Blethen, 30-45. Urbana, Illinois: University of Illinois Press.

Inwood, J. F. J. 2011. "Geographies of race in the American South: The continuing legacies of Jim Crow segregation”. Southeastern geographer 51(4): 564-577.

Johnson, E. P. 2008. Sweet tea: Black gay men of the south. Chapel Hill, NC: The University of North Carolina Press.

Johnson, E. P. 1998. "Feeling the Spirit in the dark: Expanding notions of the sacred in the African-American gay community”. Callaloo 21(2): 399-416.

Johnson, E. P. and Henderson, M. G., eds. 2000. Black queer politics: A critical anthology. Durham, North Carolina: Duke University Press.

Jubilee! 2014. “Homepage”. Last accessed February 19, 2014. http://www.jubileecommunity.org.

Kobayshi, A. and Peake, L. 2008. "Racism out of place: Thoughts on whiteness and antiracist geography in the new millennium”. In Moss, P. and Al-Hindi, K. F., eds., Feminisms in geography: Rethinking space, place, and knowledges, 155-170. Lanham, Maryland: Rowman and Littlefield Publishers.

Law, C. L. 2001. "Introduction.” In Dews, Carlos L. and Law, C. L., eds. Out in the South, 1-6. Philadelphia, PA: Temple University Press.

Lefebvre, H. 1992. The production of space. Oxford, United Kingdom: Wiley-Blackwell.

Lewis, R. L. 1999. "Beyond Isolation and Homogeneity: Diversity and the History of Appalachia”. In Billings, D., Norman, G., and Ledford, K., eds. Back talk from Appalachia: Confronting stereotypes, 47-66. Lexington: University Press of Kentucky.

Lorde, A. 2010. “I am your sister: Black women organizing across sexualities”. In McCann, C. and Kim, S. Feminist theory reader: Local and global perspectives, 276-280. 
Maggard, S. W. 1999. "Coalfield women making history. In Back talk from Appalachia: Confronting stereotypes eds. D. Billings, G. Norman, and K. Ledford, 228-250. Lexington: University Press of Kentucky.

McCutcheon, P. 2013. "Returning home to our rightful place: The Nation of Islam and Muhammad Farms”. Geoforum 49: 61-70.

McDowell, L. 1999. Gender, identity and place: Understanding feminist geographies. Minneapolis: University of Minnesota Press

--------. 1996. “Spatializing feminism: Geographic Perspectives”. In BodySpace:

Destablizing geographies of gender and sexuality ed. N. Duncan, 28-44. London: Routledge.

McDowell, L. and Sharp, J. P., eds. 1999. A feminist glossary of human geography. New York, New York: Oxford University Press.

McKittrick, K. 2011. "On plantations, prisons, and a black sense of place”. Social and cultural geography 12(8): 947-963.

McKittrick, K. 2006. Demonic grounds: Black women and the cartographies of struggle. Minneapolis, MN: University of Minnesota Press.

McKittrick, K. 2000. “Black and 'cause I'm black I’m blue': Transverse racial geographies in Toni Morrison's The bluest eye.” Gender, place and culture: journal of feminist geography, 7(2): 125-142.

McKittrick, K. and Woods, C. 2007. "No one knows the mysteries at the bottom of the ocean”. In McKittrick, K. and Woods, C. eds. Black geographies and the politics of place, 1-13. Cambridge, MA: South End Press.

McKittrick, K. and Woods, C., eds. 2007. Black geographies and the politics of place. Cambridge, MA: South End Press.

Mirza, H. S. 1997. "Introduction: Mapping a genealogy of Black British feminism”. In Mirza, H.S. Black British feminism: A reader, 1-29. London, England: Routledge.

Moore, M. 2011. Invisible families: Gay identity, relationships, and motherhood among black women. Berkeley, California: University of California Press.

--------. 2010. “Articulating a politics of (Multiple) Identities: LGBT Sexuality and Inclusion in Black Community Life". W. E. B. Du Bois Institute for African and African American Research 7 (2): 315-334. 
--------. 2006. "Lipstick or timberlands? Meanings of gender presentation in black lesbian communities.” Signs: Journal of Women in Culture and Society 32 (1): 113-139.

Morin, K. M. and Guelke, J. K. 2007. Women, religion and space: Global perspectives on gender and faith. Syracuse: Syracuse University Press.

Moss, P. and Al-Hindi, K. F. 2008. Feminisms in geography: Rethinking space, place, and knowledges. Lanham, Maryland: Rowman and Littlefield Publishers.

Muñoz, J. E. 1999. Disidentifications: Queers of color and the performance of politics. Minneapolis, Minnesota: University of Minnesota Press.

Muñoz, L. 2010. “Brown, queer and gendered: Queering the Latina/o 'street-scapes' in Los Angeles”. In Queer methods and methodologies: Intersecting queer theories and social science research eds. K. Browne and C. J. Nash, 55-68. Farnham, Surrey: Ashgate Publishing Ltd.

Myrdahl, T. M. 2014. "Sexuality, rurality, and geography”. Gender, place, and culture: A journal of feminist geography, 21(1): 134-135.

Nash, J. (2008). ‘Rethinking intersectionality’. Feminist Review 89: 1-15

Ndegeocello, M. 2002. "Dead nigga blvd., part 1" on the album Cookie: The anthropological mixtape. Maverick, MP3.

Paasi, A. 1999. "Boundaries as social practice and discourse: The Finnish-Russian border”. Regional Studies 33(7): 669-680.

Peake, L. and Kobayashi, A. 2002. "Policies and practices for an antiracist geography at the millennium”. The professional geographer 54(1): 50-61.

Peet, R. and Watts, M. 1996. "Liberation ecology: Development, sustainability, and environment in an age of market triumphalism". In Peet, R. and Watts, M., eds., Liberation ecologies: Environment, development, social Movements, 1-45, London: Routledge.

Puar, J. 2007. Terrorist assemblages: Homonationalism in queer times. Durham, North Carolina: Duke University Press.

Robbins, M. A. 2014. Journey to Liberation: The Legacy of Womanist Theology and Ethics at Union Theological Seminary. Directed by Robbins, A. Online digital stream.

Rose, G. 1993. Feminism and geography: The limits of geographical knowledge. Minneapolis, Minnesota: University of Minnesota Press. 
Said, E. 1979. Orientalism. New York, New York: Random House, Inc.

Schein, R. 2006. "Race and landscape in the United States". In Schein, R., ed. Landscape and race in the United States, 1-21. New York, New York: Routledge

Shabazz, R. 2014. "Masculinity and the mic: Confronting the uneven geography of hiphop”. Gender, place, and culture: A journal of feminist geography, 21(3): 370-386.

Shange, N. The love space demands: A continuing saga. New York, New York: St. Martin's Press.

Shapiro, H.D. 1978. Appalachia on our minds: The southern mountains and mountaineers in the American consciousness, 1870-1920. Chapel Hill, North Carolina: University of North Carolina Press.

Shelby, A. 1999. "The "R" word: What's so funny (and not so funny) about redneck jokes). In Back talk from Appalachia: Confronting stereotypes eds. D. Billings, G. Norman, and K. Ledford,153-160. Lexington: University Press of Kentucky.

--------- 1999. “'Beyond the mountains': The paradox of women's place in Appalachian history”. NWSA Journal 11 (3): 1-17.

Smith, B. E. 2004. "De-gradations of whiteness: Appalachia and the complexities of race”. Journal of Appalachian Studies 10 (1/2): 38-57.

Smith, N. 2008. Uneven development: Nature, capital, and the production of space. Athens, Georgia: University of Georgia Press.

Southerners on New Ground. 2013. “Why the South?”. Last accessed October 17, 2014. http://southernersonnewground.org/about/why-the-south/.

Southerners on New Ground 2014. "Life or Death”. Email message sent to listserv. April 29, 2014

Stephens, D. P. and Phillips, L. D. 2003. "Freaks, gold diggers, divas, and dykes: The sociohistorical development of adolescent African American women's sexual scripts". Sexuality and culture, 7(1): 3-49.

Swarr, A. L. and Nagar, R. 2004. "Dismantling assumptions: Interrogating "lesbian" struggles for identity and survival in India and South Africa”. Signs 29 (2): 491-516.

Tolia-Kelly, D. 2010. "The geographies of cultural geography I: Identities, bodies and race”. Progress in human geography, 34(3): 358-367. 
Tuhiwai Smith, L. 2012. Decolonizing methodologies: Research and Indigenous peoples. London, United Kingdom: Zed Books, Ltd.

United States Census Bureau. 2014. "Waynesville (town), North Carolina”. Last accessed May 3, 2014. http://quickfacts.census.gov/qfd/states/37/3771500.html.

Vaid, U. 1996. Virtual equality: The mainstreaming of gay and lesbian liberation. New York, New York: Anchor Books.

Valentine, G. 2007. Theorizing and researching intersectionality: A challenge for feminist geography. The Professional Geographer 59 (1): 10-21.

Walcott, R. 2007. "Homopoetics: Queer space and the black queer diaspora”. In Black geographies and the politics of place eds. K. McKittrick and C. Woods, 233-245. Cambridge, MA: South End Press.

Ward, E. G. 2005. "Homophobia, hypermasculinity, and the U.S. black church". Culture, Health, and Sexuality 7(5): 493-504.

Weiner, J. J. and Young, D. 2011. “Queer bonds”. GLQ: A Journal of Lesbian and Gay Studies 17 (2/3): 223-241.

Whittier, David Knapp. 2001. "Race and gay community in Southern Town.” In Out in the South, edited by Carlos L. Dews and Law, C. L., 72-94. Philadelphia, Pennsylvania: Temple University Press.

WildSeed Music. 2014. "Afro-digital migration: House music in post apartheid South Africa, vol. ii”. April 30, 2014. http://djlynneedenise.podomatic.com/entry/2014-04-30T07_58_05-07_00

Williams, J. A. 2002. Appalachia: A history. Chapel Hill, North Carolina: The University of North Carolina Press.

Wilson, B. M. 1992. "Structural imperatives behind racial change in Birmingham, Alabama”. Antipode: A radical journal of geography, 24(3): 171-202.

Women’s Wellness and Education Center. 2014. “Homepage”. Last accessed January 12, 2014. http://www.ashevillewomenswellness.com.

Woods, C. 2007. 'Sittin' on top of the world: The challenges of blues and hip hop geography". In McKittrick, K. and Woods, C. eds., Black geographies and the politics of place, 46-81. Cambridge, MA: South End Press.

Woods, C. 2002. “Life after death”. The professional geographer 54(1): 62-66. 
Woods, C. 1998. Development arrested: The blues and plantation power in the Mississippi Delta. New York, New York: Verso.

Woollacott, A. 2006. Gender and empire. New York, New York: Palgrave Macmillan. 


\section{APPENDIX A}

Interview Protocol

RESEARCH QUESTION BEHIND PROTOCOL: How are identities and sense of community expressed by black lesbian/gay/queer/SGL women living in Western North Carolina?

\section{Informed Consent (please read to respondent):}

"Thank you for participating in this interview. My name is LaToya, and I am working a graduate student at Florida International University in Miami, Florida. As you know, you have been invited to participate in a study about same-gender loving black women in Western North Carolina. We will proceed with the study in an interview format, and I will ask you questions regarding the terms 'identity' and 'community' and what it means to you. I will be taking notes about your responses; however, your identity will be kept confidential. I will only use your first name or a pseudonym you provide to me in order to guarantee your privacy. Your participation is voluntary and you may stop the interview at any time. I will use the information you provide for my dissertation. Is this your understanding of the procedure? [have informant say "yes"] And are you willing to be interviewed and to have this interview recorded? [have informant say "yes"]. Thank you. We will now begin the interview."

Record your name, the date, time and place of the interview. State the interviewee's first name, age, racial identity, gender identity, and sexual identity.

\section{Background Questions}

1. Could you take a moment to tell me a little bit about yourself and your background?

2. [If not already answered in Background question] How long have you lived in the Western North Carolina?

\section{Grand Tour Questions}

If you would, please answer the following questions for me.

1. What does the word 'identity' mean to you? [make notes of interviewee's responses to probe for more detail]

PROBE: Ask interviewee to explain each of her ideas about identity.

2. How would you define the word 'identity? 


\section{Questions on Topic (Factors)}

“Thank you. Now I'm going to ask you some more specific questions about the ways in which you have heard or seen the term 'identity'. You mentioned several things about the use of identity in answering the last question(s). I would like to think more precisely about how you have heard or seen the term used.

\section{GROUPS IN COMMON SOCIAL ENVIRONMENT}

1. How do common social environments affect one’s ideas about identity?

(Use the terms below to probe the interviewee. You do not need to cover all probes. Do not use a probe if interviewee has already mentioned it.)

POSSIBLE PROBES: Family; Educational institutions; Corporations (corporate culture), workplaces; Ethnic and racial groups; Nationality; Common age group/ generation; Sexual orientation; Gender Identity; Occupations/labor divisions; Political units (national identity); Religious/spiritual groups; Socioeconomic classes

\section{CONTACT WITH POLITICAL ACTIVISM}

2. What has been your connection with people or political groups that advocate an agenda on the basis of identity?

(Use the terms below to probe the interviewee. You do not need to cover all probes. Do not use a probe if interviewee has already mentioned it.)

POSSIBLE PROBES: National Organizations; Local Organizations; Conferences; Workplaces; Faith Groups; Formal or Informal

\section{CHARACTERISTICS/QUALITIES OF ISSUES}

3. How about specific characteristics? What do you think are characteristics of identity?

(Use the terms below to probe the interviewee. You do not need to cover all probes. Do not use a probe if interviewee has already mentioned it.)

POSSIBLE PROBES: Access to services; Ability to "come out"; Reconciliation with race/ethnicity; Respect for individual; Safety; Discrimination protection 


\section{Grand Tour Questions}

If you would, please answer the following questions for me.

1. What does the word 'community' mean to you? [make notes of interviewee's responses to probe for more detail]

PROBE: Ask interviewee to explain each of her ideas about community.

2. How would you define the word 'community'?

\section{Questions on Topic (Factors)}

"Thank you. Now I'm going to ask you some more specific questions about the ways in which you have heard or seen the term 'community'. You mentioned several things about the use of 'community' in answering the last question(s). I would like to think more precisely about how you have heard or seen the term used.

\section{GROUPS IN COMMON SOCIAL ENVIRONMENT}

1. How do common social environments affect one's ideas about community and belonging?

(Use the terms below to probe the interviewee. You do not need to cover all probes. Do not use a probe if interviewee has already mentioned it.)

POSSIBLE PROBES: Family; Educational institutions; Corporations (corporate culture), workplaces; Ethnic and racial groups; Nationality; Common age group/ generation; Sexuality; Gender Identity; Occupations/labor divisions; Political units (national identity); Religious/spiritual groups; Socioeconomic classes

\section{CONTACT WITH POLITICAL ACTIVISM}

2. What has been your connection with people or political groups that advocate a sense of community?

(Use the terms below to probe the interviewee. You do not need to cover all probes. Do not use a probe if interviewee has already mentioned it.)

POSSIBLE PROBES: National Organizations; Local Organizations; Conferences; Workplaces; Faith Groups; Formal or Informal

\section{CHARACTERISTICS/QUALITIES OF ISSUES}

3. How about specific characteristics? What do you think are characteristics of 'community'? 
(Use the terms below to probe the interviewee. You do not need to cover all probes. Do not use a probe if interviewee has already mentioned it.)

POSSIBLE PROBES: Access to services; Ability to "come out”; Reconciliation with race/ethnicity; Respect for individual; Safety; Discrimination protection

\section{Grand Tour Question}

1. What does the term "home" mean to you?

PROBE: Ask interviewee to explain each of her ideas about identity

2. What makes Western North Carolina/specific town "home”?

\section{Final Evaluation:}

Is there anything else that you wanted to add that you have thought of and have not mentioned?

\section{CONCLUSION:}

"Thank you for answering these questions and for participating in this study. Do you have any questions?” 


\section{APPENDIX B}

\section{Craigslist Advertisement}

\section{Making new connections - w4w - 32 (Asheville)}

I am PhD student working on a project about black women who experience same-gender love/desire/intimacy and live in Western North Carolina. I am looking for participants who identify as

age : 32

black, as woman, and who experience same-gender love to take part in interviews about living in

Western North Carolina. Participants must be $18+$ years of age and must currently reside in the region.

Women will be asked to participate in an individual interview. The interview will last approximately 1 hour. Participants' identities will be kept anonymous.

If you want to know more about the project or would like to be involved, please feel free to contact me over email.

- do NOT contact me with unsolicited services or offers

post id: 3776691190 posted: a year ago updated: 11 months ago email to friend 
VITA

\section{LATOYA ELISE EAVES}

Born, Shelby, North Carolina

1999-2004, 2008

B.A., Communication

B.A., English Language and Literature

North Carolina State University

Raleigh, North Carolina

2007

M.S., Higher Education Administration

The Florida State University

Tallahassee, Florida

2009-2014

Doctoral Candidate

Florida International University

Miami, Florida

Graduate Certificate, Women's and Gender Studies

Florida International University

Miami, Florida

2013-2014

Pre-Doctoral Fellow In Residence

University of Connecticut

Storrs, Connecticut

\section{PUBLICATIONS AND PRESENTATIONS}

Eaves, L. E. In Press. Review of A Place We Call Home: Gender, Race, and Justice in Syracuse, by K. Animashaun Ducre, Journal of Cultural Geography.

Eaves, L. E. 2015. "Spatialties of racialization in Asheville: Examining the lives of black lesbian women”. In Queering the Countryside: New Directions in Rural Queer Studies, edited by Mary L. Gray, Colin R. Thompson, and Brian Gilley. New York: NYU Press.

Eaves, L. E. 2014. Review of Sites of Slavery: Citizenship and Racial Democracy in the Post-Civil Rights Imagination, by Salamishah Tillet, Emotion, Space and Society, 11: 110-111.

Eaves, L. E. April 2014. "Black and Queer in Rural Appalachia: Exploring Identity in Western North Carolina”. Paper presented at the AAG meeting in Tampa, Florida.

Eaves, L. E. March 2014. "Call-and-response: The U.S. South, sexuality, and "progress"”. Paper presented at The University of Connecticut, Storrs, CT. 
Eaves, L. E. February 2014. “'Where are your other interviews?’: Doing Queer Black Geographic Research”. Paper presented at the Critical Geography Conference in Boulder, Colorado.

Eaves, L. E. February 2014. “'Maybe my faith didn’t explode. Maybe it expanded’: Religion and Black queer women”. Paper presented at the Rainbow Center Out to Lunch Lecture Series, University of Connecticut, Storrs, Connecticut.

Eaves, L. E. November 2013. “'Imagine a lesbian, a black lesbian’: Revisited”. Paper presented at the Rainbow Center Out to Lunch Lecture Series, University of Connecticut, Storrs, Connecticut.

Eaves, L. E. October 2013. “Fertile ground: Landscapes of race and desire”. Paper presented at University of Vermont, Burlington, Vermont.

Eaves, L. E. September 2013. “'I don’t need those qualifiers’: The nuances of race, region, and black lesbian women in Asheville, NC”. Paper presented at the Department of Geography Colloquium Series, University of Tennessee, Knoxville, Tennessee.

Eaves, L. E. April 2013. "Queering the body and place: Identity and community of Black women in Appalachia.” Paper presented at the AAG meeting in Los Angeles, California.

Eaves, L. E. 2013. "Space, place, and identity in conversation: Queer black women living in the rural U.S. South.” In Sexuality/Rurality/Geography, edited by Andrew GormanMurray, Barbara Pini, and Lia Bryant. Lanham, MD: Lexington Books.

Eaves, L. E. 2012. "Review of Queer methods and methodologies by Browne, K. and Nash, C., eds.” Gender, place and culture 19(2): 265-267.

Eaves, L. E. October 2012. “Black and queer in Appalachia: A case study.” Paper presented at the Race, Ethnicity, and Place Conference, San Juan, Puerto Rico.

Eaves, L. E. February 2012. "Cartographic inscriptions of the Black sexual subject: Women's politics of place and body.” Paper presented at the African and African Diaspora Studies Conference in Miami, Florida. 